\title{
Take a look through my eyes
}

Citation for published version (APA):

Haex, R. (2021). Take a look through my eyes: the development of an experienced quality measure with clients, informal, and formal caregivers in Dutch home care. [Doctoral Thesis, Maastricht University]. Maastricht University. https://doi.org/10.26481/dis.20211129rh

Document status and date:

Published: 01/01/2021

DOI:

10.26481/dis.20211129rh

Document Version:

Publisher's PDF, also known as Version of record

\section{Please check the document version of this publication:}

- A submitted manuscript is the version of the article upon submission and before peer-review. There can be important differences between the submitted version and the official published version of record.

People interested in the research are advised to contact the author for the final version of the publication, or visit the DOI to the publisher's website.

- The final author version and the galley proof are versions of the publication after peer review.

- The final published version features the final layout of the paper including the volume, issue and page numbers.

Link to publication

\footnotetext{
General rights rights.

- You may freely distribute the URL identifying the publication in the public portal. please follow below link for the End User Agreement:

www.umlib.nl/taverne-license

Take down policy

If you believe that this document breaches copyright please contact us at:

repository@maastrichtuniversity.nl

providing details and we will investigate your claim.
}

Copyright and moral rights for the publications made accessible in the public portal are retained by the authors and/or other copyright owners and it is a condition of accessing publications that users recognise and abide by the legal requirements associated with these

- Users may download and print one copy of any publication from the public portal for the purpose of private study or research.

- You may not further distribute the material or use it for any profit-making activity or commercial gain

If the publication is distributed under the terms of Article $25 \mathrm{fa}$ of the Dutch Copyright Act, indicated by the "Taverne" license above, 


\section{Take a look through my eyes}

The development of an experienced quality measure with

clients, informal, and formal caregivers in Dutch home care 
The research presented in this thesis was conducted at CAPHRI Care and Public Health Research Institute, Department Health Services Research of Maastricht University. CAPHRI participates in the Netherlands School of Public Health and Care Research CaRe.

The research in this dissertation was funded by the Brightlands Innovation Program LIME (Limburg Meet), a program that facilitates smarter measurement methods and more efficient data collection for better care and health, Province of Limburg, Zuyd University of applied sciences, Maastricht University.

Cover design: Danny Kusters

Layout: Roy Haex

Printing: Gildeprint

ISBN: 978-94-6419-336-7

(C) Roy Haex

All rights reserved. No part of this thesis may be reproduced or used in any manner whatsoever without prior written permission from the author. 


\section{Take a look through my eyes}

The development of an experienced quality measure with

clients, informal, and formal caregivers in Dutch home care

\section{PROEFSCHRIFT}

ter verkrijging van de graad van doctor aan de Universiteit Maastricht, op gezag van de Rector Magnificus, Prof. dr. Rianne M. Letschert volgens het besluit van het College van Decanen, in het openbaar te verdedigen

op 29 november 2021 om 16.00 uur

door

Roy Haex 


\section{Promotores}

Prof. dr. S.M.G. Zwakhalen

Prof. dr. A.J. Beurskens

\section{Copromotor}

Dr. T. Thoma-Lürken

\section{Beoordelingscommissie}

Prof. dr. G.D.E.M. van der Weijden (voorzitter)

Dr. N. Bleijenberg (UMC Utrecht \& Hogeschool Utrecht)

Prof. dr. S.M.A.A. Evers

Prof. dr. K.G. Luijkx (Tilburg University)

Dr. H.J.L. van Rossum 


\section{CONTENTS}

$\begin{array}{lll}\text { CHAPTER } 1 \text { General introduction } & 7\end{array}$

CHAPTER 2 Experienced quality of post-acute and long-term care from the care recipient's perspective: A conceptual framework

CHAPTER 3 How do clients and (in)formal caregivers experience quality of home care? A qualitative approach

CHAPTER 4 The needs of key-stakeholders for evaluation client's experienced quality of home care: A qualitative approach

CHAPTER 5 How to select adequate experienced quality measures in long-term care: An exemplary case study in Dutch home care

CHAPTER 6 Development of an experienced quality measure for clients, informal, and formal caregivers in home care: A participatory action research

$\begin{array}{lll}\text { CHAPTER } 7 & \text { General discussion } & 157\end{array}$

$\begin{array}{lr}\text { ADDENDUM Summary } & 180\end{array}$

$\begin{array}{ll}\text { Samenvatting } & 183\end{array}$

$\begin{array}{ll}\text { Impact } & 186\end{array}$

Living Lab in Ageing and Long-Term Care $\quad 192$

$\begin{array}{ll}\text { Dankwoord } & 194\end{array}$

$\begin{array}{ll}\text { About the author } & 198\end{array}$ 

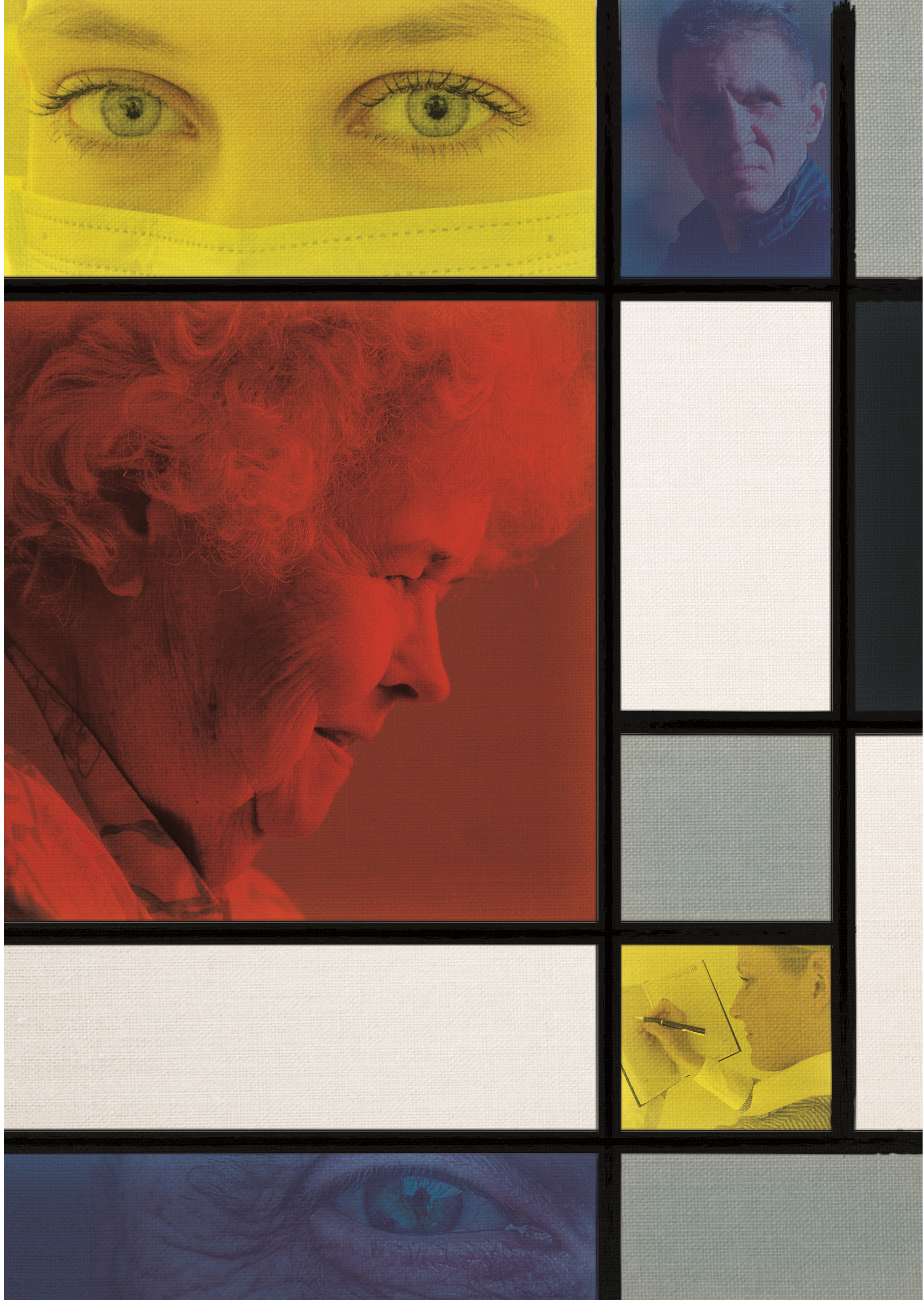
CHAPTER 1

General introduction 


\section{GENERAL INTRODUCTION}

Conversation with Carla, who is receiving formal home care:

Hello, my name is Carla and I am 82 years old. As you might notice, I tend to speak somewhat slowly. This is the result of a stroke I had last year. My husband Henk and I used to have a very active life. Although I do miss working in the garden at our previous house, we simply had to move to this bungalow because of all the stairs. Once I'm a bit more mobile again, I do hope we can go out some more. I look forward to going to the park with my husband, where we often went socializing with our jeu-de-boules association. I'm so grateful for the home care support we're receiving now, the nurses are all so kind. However, last week I had help from a male nurse that made me feel quite uncomfortable. I am not used to being showered by a male nurse, but I did not dare to tell him this. Although he did his best to make me feel at ease, I would prefer not to be showered again by a male nurse.

Conversation with Henk, informal caregiver and partner of Carla:

My name is Henk. We recently moved to this bungalow because of my wife's care situation. I used to be able to provide her all the care she needed, but now it's like she needs constant care. After the stroke, she stayed at the hospital for some days. During her hospital stay, we were not very satisfied with the caregivers there. They were so busy and had a hard time finding time for a short talk, in contrast to the home care nurses now. Some days ago, my wife received help from a male nurse. Although he was kind, my wife and I do not believe it is normal that you are being showered by the other gender! We did not know of this beforehand and we are from a generation that is just not used to that. Afterwards I said to my wife that the next time he shows up, I will shower her myself. Both I and my wife are proud members of the jeu-de-boules association, but because of the irregular home care visits we don't have time to go there together. I have been thinking of addressing this for some time now, but have not found the opportunity to do so. Isn't there a person in the care organisation with whom I can discuss this?

Conversation with Debby, formal caregiver of Carla:

Hey, I am Debby. I have been providing personal care for Carla for over a year now. In the morning and evening, she needs help getting dressed, with personal hygiene and taking her medication. They are such a sweet couple and are always so patient and thoughtful. Carla has been suffering with some difficulties since she had a stroke. Henk is a great help in providing her medication. I believe he used to be an engineer and is quite precise in his ways. He always sets multiple timers as reminders to take the medication throughout the day. They value the fact that we provide care at a specific time, for which we had to schedule a new male nurse the other day to provide care for Carla on time. As 
care providers we try to signal difficulties while providing care and we've received the impression that the current situation is becoming a bit too much for both Carla and Henk. We therefore started looking for possible daytime activities in which Carla could participate. However, it might be a good time for the district nurse to sit down with both Carla and Henk to evaluate formally how they are feeling about the current care situation.

The example above is based on a typical home care setting, with an older client, her partner and her formal caregiver. The different stories give a sense of how the provision of care and the corresponding experiences in a care network can differ, and they address the importance of making a structural assessment, with different key stakeholders, of the experienced quality from a client's perspective as part of maintaining a high standard of quality in the home care process. Looking through the lenses of the client as well as of the informal and formal caregivers can be beneficial for understanding the client's perspective, as each of these individuals can shed a different light on ongoing dilemmas and on the provision of the desired care. In the understanding of care experiences within long-term care and care in general, there is increasingly a focus on including both informal caregivers and formal caregivers in the care process. Therefore, one ought to strive for a true understanding of the different experiences, concerns and viewpoints from the client's perspective, as well as the ability to communicate these insights in a joined-up conversation. ${ }^{1}$ However, it might be necessary for a caregiver to put their own mental frame, beliefs, assumptions, knowledge and experiences temporarily on hold to obtain a true understanding of the client's perspective. ${ }^{2}$ Each individual in a care triad (consisting of the client, the informal caregiver and the formal caregiver) has their own care experiences that can shape or colour their new experiences; this may, as addressed in the fictional example, be a negative care experience in a former care situation. The general aim of this dissertation is to understand how to get insight into care experiences in the home care setting in order to provide the optimal care for individual clients, focusing on clients who are receiving long-term home care based on one or more chronic conditions. This chapter starts with an introduction to care provision in the home care setting, explains the concept of quality in home care and discusses current views on assessing the quality of care. The final paragraph will present the aim, the research questions and the outline of this dissertation.

\section{THE HOME CARE SETTING}

The statement 'There's no place like home' reflects a concept that is known in many cultures, and is a belief that is often shared in society as well as in movies like The Wizard of $\mathrm{Oz}$ and in sayings going back to the sixteenth and seventeenth centuries. ${ }^{3}$ Home care meets the needs and wishes of most clients because care is received within the familiar 
environment of home, and it is known that the majority of home care clients in the Netherlands are satisfied with the care they receive and the freedom they experience, in contrast to those receiving nursing home care. ${ }^{4,5}$. Across cultures, home has been defined in terms of three dimensions: home as a familiar place of comfort and ease because of routines and physical arrangements; home as the centre of everyday experiences in space, time, and social life; and home as the protector of one's privacy, identity and safety. ${ }^{6} \mathrm{~A}$ person's home is recognized as a place that can support them in maintaining their independence and autonomy. ${ }^{7,8}$ Home is seen as a place in which we meet with friends and family, sharing stories about past experiences, and it is a place where person-place transactions are constructed..$^{9,10}$ In addition, residing in a familiar neighbourhood can help maintain existing social networks, thereby providing social support, which can function as a buffer for the effects of stressful events and can even improve health and well-being. ${ }^{11-}$

${ }^{13}$ Being in one's own home when receiving care means that one maintains the right to be oneself and to stick to one's own daily routines. ${ }^{14}$

Across the world, the population of older people living in the community continues to increase. In the Netherlands, the proportion of people aged over 65 years is expected to rise from 3.4 million (19 per cent) in 2020 to 4.9 million (25 per cent) in $2050 .{ }^{15}$ In particular, the number of people aged 80 years and above is expected to increase rapidly, from 800,000 currently to 1.5 million in 2050 . As society ages, home care is perceived by western societies as a means of meeting individuals' needs to remain in the familiar environment of home, and of addressing rising costs. ${ }^{16}$ Since the proportion of older people who are living in Dutch nursing homes has decreased below $6 \%$, home care provision has become increasingly more important. ${ }^{4}$ Over $40 \%$ of people living in the community aged 75 and above are receiving some form of domestic support, personal care or nursing care. ${ }^{17}$ The provision of domestic support is regulated by the Social Support Act (Dutch acronym: Wmo), and domestic support is given by individual support workers who perform household activities (e.g. cleaning and preparing meals). ${ }^{18,19}$ Municipalities are responsible for both the funding and the assessment of domestic care services. Personal care (e.g. assistance with dressing, eating, drinking and personal hygiene), as well as nursing care (e.g. wound care and the administration of medication), are both regulated by the Healthcare Insurance Act (Dutch acronym: Zvw) or the Long-term Care Act (Dutch acronym: Wlz). Excluding domestic support, around 28\% of people aged 75 and above in the Netherlands, or 330,000 people, receive some form of personal or home care. ${ }^{17}$ This care is provided by (district) nurses, nursing assistants and nurse aides, working together in care teams, and therefore often cooperating with professionals from other disciplines like physiotherapists, dieticians and general practitioners. A district nurse (Dutch: wijkverpleegkundige) has the leading role in providing care for a client, liaising with the municipality and coordinating the client's care needs, while nursing assistants and nurse 
aides support the client by providing both medical and personal care. This dissertation focuses on both personal care and nursing care (referred to in combination as home care) for older people suffering from one or more chronic conditions (referred to as clients). Besides formal home caregivers, informal caregivers have a crucial role in supporting older people living at home to maintain their health, well-being, quality of life and functional status. $^{20}$ This informal care is most often given by a client's partner or their children. ${ }^{21}$ Moreover, reforms in the long-term care policies of many European countries have led to cutbacks in formal care, which will considerably increase the demand for informal care in the years to come. ${ }^{22}$ In addition to clients and formal caregivers, informal caregivers can shed a different light on a client's care experiences, and they are therefore considered important stakeholders for gaining insight into experienced quality in home care.

Although home care is generally perceived as clients' preferred type of care, there are some challenges for a person to receive the care they need in the home setting for an extended period of time. Although clients have the freedom to arrange their own home care, this can be perceived as daunting, since one out of every two people aged 65 and above lacks the skills to monitor their own physical or mental health status. ${ }^{23}$ Moreover, after realizing that care is needed, a certain psychological threshold has to be passed before people dare to ask for help. There are indications that almost half of all people aged 70 and above find it difficult to ask for help with their care needs. ${ }^{24,25}$ This procrastination in asking for care (informal as well as formal care), and a person's need to arrange their own care in the home environment, can result in a prolonged delay in receiving the necessary care, leading to self-neglect or even hospital admission. ${ }^{26,27}$ Even after formal home care is being provided, clients can experience an ambiguity in accepting formal care while simultaneously maintaining both their independence and their privacy at home. ${ }^{14}$ In addition, the physical environment of a home can pose challenges for the way in which its inhabitants cope with deteriorating physical or mental health and home care provision. ${ }^{28,29}$

\section{DEFINING THE QUALITY OF HOME CARE}

In line with the challenges previously described, there is an increasing need to maintain high-quality home care by gaining insight into clients' care experiences more continuously throughout the care process, which must be done by including the stakeholders in the care environment. ${ }^{30}$ In 2015, the National Health Care Institute (Zorginstituut Nederland) released a paper on how to improve quality in long-term care provision through striving for a more person-centred care approach and defining care standards. ${ }^{31}$ However, the National Health Care Institute also stated that care quality stands or falls with the quality of the care relationship between a client, their surroundings and their formal caregivers, and that there were no existing care standards addressing the need for sincere attention and dignity provided to individual clients. This culture change in long-term care, from task- 
oriented to both person-centred and relationship-centred care, is not unique to the Netherlands, and it challenges existing views on how care is provided, who is involved and consequently what is regarded as good quality home care. ${ }^{32,33}$

In relation to high-quality home care services, a common understanding should be found for the definition of quality of care. The concept of care quality in home care is broad, and encompasses more than the standards captured by normative quality indicators such as pain scores or unplanned hospitalizations. Traditionally, quality of care was defined by Donabedian as a reflection of the values and goals within the care system and society. ${ }^{34}$ This framework distinguishes between factors related to the structure, those related to the process and those related to the outcome when determining what quality is and how to assess it. ${ }^{35}$ The structure considers the attributes related to the setting, such as material resources (e.g. time available), human resources (e.g. number of care providers) and organizational structure (e.g. skill-mix in care teams). The process is defined as the activities taking place in both the receipt and the provision of care. The outcome is seen as the effects of care provision on a client's health care status and satisfaction. The Institute of Medicine (IOM) has elaborated on this by defining quality as 'the degree to which health care services for individuals and populations increase the likelihood of desired health outcomes and are consistent with current professional knowledge'. ${ }^{36}$ The IOM states that quality has the following domains: effectiveness; efficiency; equity; timeliness; safety; and patient-centredness. For the last of these, especially, insight into the client's perception of the quality is important, in addition to the generic quality domains and definitions, for objectively measuring the quality of care. ${ }^{37,38}$ In recent decades, there has been an ongoing culture change towards a more dynamic definition of quality and a holistic approach to the provision of care, incorporating the client's perspective as well as that of care providers. ${ }^{39-43}$ These approaches hold that quality exists in the interaction between people, and that clients should be included in the care process so that they can communicate their needs, wishes and experiences. ${ }^{42,44}$ Although the core of care provision can be seen as meeting the client's care needs, the dynamic relationship between clients and caregivers is increasingly taken into account in sharing and understanding individuals' experiences with home care services. ${ }^{45,46}$ This can be achieved by striving towards equality in care relationships between care recipients and care providers. ${ }^{47}$ Along these lines, the relationship-centred care (RCC) approach states that all care relationships between the different people involved in the care process should be considered, and that the focus should not be solely on the client. ${ }^{38}$ These different individuals, as we saw in the fictional example of Carla and her husband, all have unique views on the home care process and, consequently, can take a different perspective from that of the client as to which quality aspects are important. 
Previous studies have suggested that the relationship between care provider and client largely determines the quality of the care that is experienced and the subsequent outcomes. ${ }^{48}$ For clients it is, among other things, important to remain as autonomous as possible when facing the care needs of old age, and to maintain their existing way of living at home. ${ }^{14}$ For informal caregivers it might be important to maintain social contacts and to be able to combine care provision with other family responsibilities, to have access to adequate transportation and to find information on access to supportive services (e.g. home care services). ${ }^{49,50}$ From a formal caregiver's perspective it is important that home care is both dignified and satisfying, that positive relationships are established with home care clients while they strive for higher care quality and continuity of client care. ${ }^{51,52}$ Therefore the unique views from each perspective, as well as the dynamic interactions in the home care provision, should be captured both for defining and for measuring quality in home care. It is not known whether the existing definitions of quality in long-term care capture these multiple perspectives from a relationship-centred care approach, or how current practices and stakeholders' needs translate into a measurement of the experienced quality.

\section{MEASURING THE QUALITY OF HOME CARE}

The quality of home care can be measured for different goals and at various levels: providing external transparency and external accountability (macro-level); learning and improving in care teams and organizations (meso-level); and improving the provision of care to individual clients (micro-level). ${ }^{31}$ On the macro-level, aggregated quality data can aid future clients in selecting a care organization and for accountability purposes. In other words, how does one care organisation score in communicating and in meeting the client's personal care preferences, compared to other organisations? On the meso-level, quality information is used to learn about and improve general care provision or to improve organisational processes. For example, a care team might want to know how to address implicit personal hygiene preferences for clients who have difficulties communicating about this. On the micro-level, measuring quality can result in the improvement of direct care provision based on a client's needs, expectations or experiences. In the fictional example, measuring the client's care quality could help to gain insight into Carla's preferences and experiences in receiving help with her personal hygiene. Individual measures can have different goals, and in the same way key stakeholders can have different needs when measuring quality. ${ }^{53}$ Besides determining the purpose for which the experienced quality is to be measured, the measures have to fit the underlying quality domains and the stakeholders involved in the home care setting. ${ }^{53,54}$ If seemingly promising quality measures are, in practice, insufficiently accessible to specific stakeholders (for example, because of the use of difficult jargon or strict time constraints in applying them in practice), 
this could result in them not feeling involved in the process of improving care experiences and quality.

Internationally, there is increased attention on making health care more patient-centred, which requires patient-reported information on health and care provision to be collected in comprehensive ways. ${ }^{55}$ Patient-reported information refers to information collected from clients, but also information from proxies such as a client's family members if the client is unable to respond themselves (for example, in the case of dementia). In the past, numerous ways have emerged for collecting patient-reported information in health care, such as collecting patient ratings in surveys, gaining insight into problematic experiences through complaints and grievances mechanisms, and collecting patients' narratives based on their experiences with clinicians. ${ }^{56}$ The development of quality indicators based on patient-reported information can be divided into the following categories: patient-reported outcome measures (PROMs), satisfaction measures, and patient-reported experience measures (PREMs). PROMs are aimed at gaining insight into the perceived outcomes of a patient's health and functional status, measured on a quantified scale. Examples of this are the PROMs focused on measuring dimensions related to the patient-centred care domain that is endorsed by the IOM, such as questionnaires related to the provision of 'physical comfort'. ${ }^{57}$ In addition to PROMs are satisfaction measures (e.g. 'how did it make you feel?') considered to be important outcome for quality improvement activities such as total quality management, which emphasize the improvement of clients' satisfaction levels. ${ }^{58}$ PREMs are used to gain insight into patients' perceptions of their experiences of the care process, by collecting responses to closed and/or open-ended questions. ${ }^{59,60}$ By measuring care experiences, it is possible to know where improvements in the care process are required. ${ }^{37}$ Client experiences are recognized as a cornerstone in the improvement of care, distinct from other quality aspects or indicators. ${ }^{55}$ Examples of more closed (or more quantitative) PREMs applied in Dutch home care are Consumer-Quality (CQ) questionnaires, which focus primarily on quality indicators reflecting the process of care from a client's perspective. ${ }^{61,62}$

In recent years, there has been a growing trend towards including the client's voice in both measuring and improving the quality of care through the use of open-ended or more qualitative PREMs. ${ }^{56,63}$ Qualitative patient-reported information can help caregivers to gain more in-depth information, because elaborating on experiences can offer clues as to why a client has difficulties with, for example, interacting with a specific caregiver. In line with this, there are a growing number of methodologies being developed that include open dialogues for measuring care quality from a client's perspective, such as in the disability sector. ${ }^{64}$ Patient narratives are a means to facilitate the provision of space so that clients can share their experiences. In this way, a dialogue between caregivers and care receivers can be facilitated, to specify what needs to be improved and how. ${ }^{65-67}$ This 
approach can yield rich, detailed data that leave the participants' perspectives intact and provide contextual understanding for individual clients. Although client reports or narratives are often viewed as a group of measures that are distinct from quantitative measures, in practice these are often entwined. For example, a PREM can measure experiences by a number of closed questions but also provide room for written responses to open-ended questions like those that would be asked with more narrative measures.

If a measure is to be used in daily practice, then measures with true usefulness need to be developed. ${ }^{54,68}$ Usefulness is seen as the degree to which a system - in our case a measurement - is perceived by end-users as being capable of being used to their advantage (e.g. improve their job performance as a formal caregiver). ${ }^{69}$ To determine a measure's usefulness in daily practice, attention has to be paid to the goal, as well as to the feasibility of using the measure in the setting and its usability in the care process. The goal describes what the measure is intended to accomplish and what is needed, and is seen as the extent to which the measure's content and following outcomes can be used by the end-users. The feasibility of a system describes how well the users can use its functionality, and is seen as the extent to which the measure can be appropriately applied (e.g. as a result of its understandability or number of items) by those involved. The usability of the measure considers its fit with the ongoing care process, and provides insight into when the measure should be applied, who should carry out the evaluation, how the evaluation should be done, what motivates the evaluation and what to do with the outcomes. These constructs are often measured when evaluating products or services, when the ease of use and whether the product is a good fit for people using it are explored as the characteristics of the product. ${ }^{70,71}$ Previous studies have found that criteria relating to a measure's usefulness, such as whether it has good feasibility and usability, are accurate predicators of stakeholders' behavioural intention towards it (whether, for example, they would apply it in home care practice). ${ }^{72}$ If a measure is easy to use, stakeholders are more likely to continue using it in the future. However, questions remain as to which goals and dimensions to measure and what stakeholders need for a feasible and usable measure of experienced quality, from a client's perspective. The research reported on in this dissertation has been conducted to answer these questions. 


\section{AIM AND RESEARCH QUESTIONS}

This dissertation gives insight into the experienced quality in the home care setting, and presents the process of determining stakeholders' needs to enable the development of a novel qualitative experienced quality measure from a client's perspective. The research is done with clients, informal caregivers, and formal caregivers from a relationship-centred care approach and with the aim of improving clients' primary care processes in home care. To achieve this, the following research questions are addressed:

1. How can experienced quality in home care for older people, as perceived by the care recipients, be conceptualized?

2. What are the views of clients, formal caregivers and informal caregivers about the experienced quality of home care for older people?

3. What are the needs of clients, formal and informal caregivers, and managers/policy officers as regards the feasibility and usability aspects of measuring clients' experienced quality of home care?

4. How can potentially adequate measures be selected for measuring the experienced quality of home care?

5. How can a usable and feasible measure of experienced quality be developed to improve clients' primary care processes in home care? 


\section{DISSERTATION OUTLINE}

This dissertation describes six studies in three phases, as outlined in Figure 1.1. In the first phase an understanding of the concept of experienced quality is presented. Here we define experienced quality as a conceptual model, and operationalize it for the home care setting. In phase two, insight is gained into current practices and needs for measuring experienced quality, based on a needs assessment. In the last phase, the process of selecting existing measures and developing a qualitative experienced quality measure is presented.

Chapter two presents a conceptual model for experienced quality for long-term care, based on insights from both the literature and a discussion panel. Chapter three operationalizes experienced quality in home care based on the conceptual model, highlighting attributes from the perspectives of clients and informal and formal caregivers.

Chapter four determines the needs of clients, formal/informal caregivers, and managers/policy officers as key stakeholders, in order to discover the goals, pains and (desired) gains of measuring client's experienced quality of care. Chapter five describes the process of selecting potentially adequate measures for experienced quality. Chapter six illustrates the development of the qualitative experienced quality measure as a feasible and usable measure aimed at improving clients' primary care processes in home care. Chapter seven contains a general discussion that summarizes the main findings and is followed by the methodological considerations and implications for further research and practice. 


\section{Figure 1.1 Dissertation outline}

Phase 1 Understanding the concept of experienced quality of home care

Phase 2 Insight into current practices and needs of measuring experienced quality of home care

Phase 3 Development of qualitative experienced quality measure for home care
1. How can experienced quality in home care for older people, as perceived by the care recipients, be conceptualized?

2. What are the views of clients, formal caregivers and informal caregivers about the experienced quality of home care for older people?

3. What are the needs of clients, formal and informal caregivers, and managers/policy officers as regards the feasibility and usability aspects of measuring clients' experienced quality of home care?

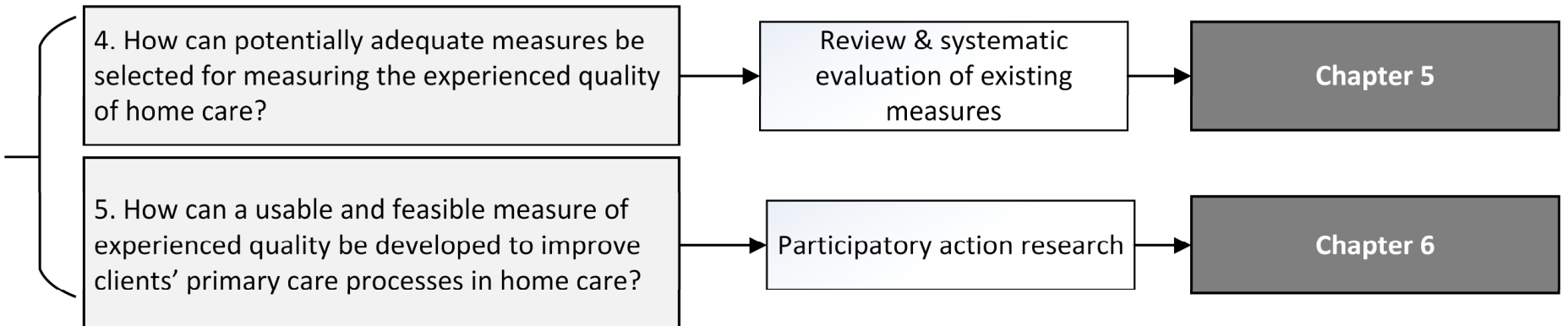




\section{REFERENCES}

1. Hojat M, Gonnella JS, Nasca TJ, Mangione S, Vergare M, Magee M. Physician empathy: definition, components, measurement, and relationship to gender and specialty. American Journal of Psychiatry. 2002;159(9):1563-1569.

2. Goossensen A. Schetsen van mismatch. Een zorgethische visie op Evaluatieonderzoek Utrecht. 2014.

3. There's no place like home. n.d.; https://idioms.thefreedictionary.com/there\%27s+no+place+like+home. Accessed April 22, 2021.

4. Kromhout M, Kornalijnslijper N, de Klerk M. Veranderde zorg en ondersteuning voor mensen met een beperking. Landelijke evaluatie van de Hervorming Langdurige Zorg. 2018.

5. Francke AL, Rijken PM, Groot Kd, de Veer A, Verkleij KA, Boeije HR. Evaluatie van de wijkverpleging: ervaringen van cliënten, mantelzorgers en zorgprofessionals. 2017.

6. Roush CV, Cox JE. The Meaning of Home: How It Shapes the Practice of Home and Hospice Care. Home Healthcare Now. 2000;18(6).

7. Sixsmith A, Bytheway B, Johnson J. Welfare and the ageing experience. 1990.

8. Moss P. Negotiating spaces in home environments: Older women living with arthritis. Social Science \& Medicine. 1997;45(1):23-33.

9. Sixsmith AJ, Sixsmith JA. Transitions in home experience in later life. Journal of Architectural and Planning Research. 1991:181-191.

10. Moore J. Placing home in context. Journal of environmental psychology. 2000;20(3):207-217.

11. Burt RS. A note on social capital and network content. Social networks. $1997 ; 19(4): 355-373$.

12. Krause N. Social support, stress, and well-being among older adults. Journal of gerontology. 1986;41(4):512-519.

13. Cornwell B, Laumann EO. The health benefits of network growth: New evidence from a national survey of older adults. Social Science \& Medicine. 2015;125:94106.

14. Holmberg M, Valmari G, Lundgren SM. Patients' experiences of homecare nursing: balancing the duality between obtaining care and to maintain dignity and selfdetermination. Scandinavian journal of caring sciences. 2012;26(4):705-712.

15. NIDI, CBS. Bevolking 2050 in beeld: drukker, diverser en dubbelgrijs. . Den Haag: NIDI; 2020.

16. de São José J, Barros R, Samitca S, Teixeira A. Older persons' experiences and perspectives of receiving social care: a systematic review of the qualitative literature. Health \& Social Care in the Community. 2016;24(1):1-11.

17. de Klerk M, Verbeek-Oudijk D, Plaisier I, den Draak M. Zorgen voor thuiswonende ouderen. 2019.

18. Kroneman M, Boerma W, van den Berg M, Groenewegen $\mathrm{P}$, de Jong J, vanGinneken E. The Netherlands: health system review. Health Systems in Transition. 18. 2016;2:1-239.

19. OECD/EU. Health at a Glance: Europe 2018: State of Health in the EU Cycle. 2018; https://doi.org/10.1787/health_glance_eur-2018-en.

20. Mello JdA, Macq J, Van Durme T, et al. The determinants of informal caregivers' burden in the care of frail older persons: a dynamic and role-related perspective. Aging \& mental health. 2017;21(8):838-843.

21. de Klerk M, de Boer A, Plaisier I, Schyns P. Voor elkaar?: stand van de informele hulp in 2016. Sociaal en Cultureel Planbureau; 2017.

22. van Groenou MIB, De Boer A. Providing informal care in a changing society. European Journal of Ageing. 2016;13(3):271-279.

23. Heijmans M, Brabers A, Rademakers J. Health literacy in Nederland. 2018. 
24. Janssen K. Belemmeringen voor informele hulp: Een onderzoek naar vraagverlegenheid onder ouderen in Leiden 2014.

25. Vermeij L. Small gestures. 2016.

26. Reesink F, Boelaarts L, Weinstein H. Zelfverwaarlozing bij ouderen, een complex probleem. Nederlands Tijdschrift voor Geneeskunde. 2009;153.

27. Verver $D$, Merten $H$, Wagner $C$. 'Toezicht op zorgnetwerken van thuiswonende kwetsbare ouderen'Fase I en II. EMGO Institute for Health and Care Research. 2015.

28. Tinker A. Housing for elderly people. Reviews in Clinical Gerontology. 1997;7(2):171-176.

29. Evans GW. The built environment and mental health. Journal of urban health. 2003;80(4):536-555.

30. Ruggiano N, Edvardsson D. Person-centeredness in home-and community-based long-term care: current challenges and new directions. Social work in health care. 2013;52(9):846-861.

31. Samen de kwaliteit van langdurige zorg verbeteren. 2015. https://www.zorginstituutnederland.nl/publicaties/publicatie/2015/02/10/samende-kwaliteit-van-langdurige-zorg-verbeteren. Accessed 25 February 2021.

32. McCormack B, van Dulmen S, Eide H, Skovdahl K, Eide T. Person-centred healthcare research. John Wiley \& Sons; 2017.

33. Soklaridis PhD S, Adler Nevo MD FRCPC G, PRCPC LM. Relationship-centred care in health: A 20-year scoping review. Patient Experience Journal. 2016;3(1):130-145.

34. Donabedian A. Evaluating the quality of medical care. The Milbank memorial fund quarterly. 1966;44(3):166-206.

35. Donabedian A. The quality of care: how can it be assessed? Jama. $1988 ; 260(12): 1743-1748$.

36. Institute of Medicine Committee on Quality of Health Care in America. In Crossing the Quality Chasm: A New Health System for the 21st Century. Washington (DC)2001.

37. LaVela SL, Gallan A. Evaluation and measurement of patient experience. Patient Experience Journal. 2014;1(1):28-36.

38. McCormack B, Roberts T, Meyer J, Morgan D, Boscart V. Appreciating the 'person' in long-term care. International Journal of Older People Nursing. 2012;7(4):284294.

39. Brownie S, Nancarrow S. Effects of person-centered care on residents and staff in aged-care facilities: a systematic review. Clinical interventions in Aging. 2013;8:1.

40. Snoeren MM, Janssen BM, Niessen TJ, Abma TA. Nurturing cultural change in care for older people: Seeing the cherry tree blossom. Health Care Analysis. 2016;24(4):349-373.

41. McColl-Kennedy JR, Snyder H, Lars Witell ME, Helkkula A, Hogan SJ, Anderson L. The changing role of the health care customer: review, synthesis and research agenda. Journal of Service Management. 2017;28(1):2-33.

42. Shura R, Siders RA, Dannefer D. Culture Change in Long-term Care: Participatory Action Research and the Role of the Resident. The Gerontologist. 2011;51(2):212225.

43. Baart AJ. Een theorie van de presentie. 2007.

44. McColl-Kennedy JR, Snyder H, Elg M, et al. The changing role of the health care customer: review, synthesis and research agenda. Journal of Service Management. 2017.

45. Fine MD. A caring society?: care and the dilemmas of human service in the twentyfirst century. Houndmills, Basingstoke; New York: Macmillan International Higher Education; 2006.

46. Tronto JC. Moral boundaries: A political argument for an ethic of care. Psychology Press; 1993.

47. Wilberforce M, Challis D, Davies L, Kelly MP, Roberts C, Loynes N. Personcentredness in the care of older adults: a systematic review of questionnaire-based scales and their measurement properties. BMC Geriatrics. 2016;16(1):63. 
48. Soklaridis S, Ravitz P, Nevo GA, Lieff S. Relationship-centred care in health: A 20year scoping review. Patient Experience Journal. 2016;3(1):130-145.

49. Criel B, Vanlerberghe V, De Koker B, Decraene B, Engels E, Waltens R. Informal home care for elderly in Belgium: a study on the features and challenges of informal care at local level. Community mental health journal. 2014;50(7):848-853.

50. Lamura G, Mnich E, Nolan M, et al. Family Carers' Experiences Using Support Services in Europe: Empirical Evidence From the EUROFAMCARE Study. The Gerontologist. 2008;48(6):752-771.

51. Delp L, Wallace SP, Geiger-Brown J, Muntaner C. Job stress and job satisfaction: Home Care Workers in a consumer-directed model of care. Health services research. 2010;45(4):922-940.

52. Tourangeau $A E$, Patterson $E$, Saari M, Thomson H, Cranley L. Work-related factors influencing home care nurse intent to remain employed. Health Care Management Review. 2017;42(1):87-97.

53. Foster A, Croot L, Brazier J, Harris J, O'Cathain A. The facilitators and barriers to implementing patient reported outcome measures in organisations delivering health related services: a systematic review of reviews. Journal of patient-reported outcomes. $2018 ; 2: 46$.

54. Lewis JR. Usability: Lessons Learned ... and Yet to Be Learned. International Journal of Human-Computer Interaction. 2014;30(9):663-684.

55. Berwick DM, Nolan TW, Whittington J. The triple aim: care, health, and cost. Health affairs. 2008;27(3):759-769.

56. Schlesinger $M$, Grob R, Shaller D. Using patient-reported information to improve clinical practice. Health services research. 2015;50:2116-2154.

57. Tzelepis F, Rose SK, Sanson-Fisher RW, Clinton-McHarg T, Carey ML, Paul CL. Are we missing the Institute of Medicine's mark? A systematic review of patientreported outcome measures assessing quality of patient-centred cancer care. BMC cancer. 2014;14(1):1-32.

58. Castle NG. A review of satisfaction instruments used in long-term care settings. Journal of aging \& social policy. 2007;19(2):9-41.

59. Devlin NJ, Appleby J. Getting the most out of PROMs. Putting health outcomes at the heart of NHS decision-making London: The King's Fund. 2010.

60. Anhang Price R, Elliott MN, Zaslavsky AM, et al. Examining the role of patient experience surveys in measuring health care quality. Medical Care Research and Review. 2014;71(5):522-554.

61. Triemstra M, Winters S, Kool RB, Wiegers TA. Measuring client experiences in longterm care in the Netherlands: a pilot study with the Consumer Quality Index Longterm Care. BMC health services research. 2010;10(1):95.

62. Delnoij DM, Rademakers JJ, Groenewegen PP. The Dutch consumer quality index: an example of stakeholder involvement in indicator development. BMC Health Services Research. 2010;10(1):88.

63. Berwick D, Black N, Cullen D, et al. Recommendations to OECD ministers of health from the high level reflection group on the future of health statistics: Strengthening the international comparison of health system performance through patientreported indicators. Statistics. 2017.

64. Triemstra M, Francke A. Kwaliteit van leven en zorg meten. Retrieved from https://www.waardigheidentrots.nl/wp-

content/uploads/2018/07/WT_Eindrapportage_thema_3_def.pdf. Accessed 21 February 2021

65. Martino SC, Shaller D, Schlesinger M, et al. CAHPS and comments: how closedended survey questions and narrative accounts interact in the assessment of patient experience. Journal of patient experience. 2017;4(1):37-45.

66. Schlesinger M, Grob R, Shaller D, et al. Taking patients' narratives about clinicians from anecdote to science. N Engl J Med. 2015;373(7):675-679.

67. Abma TA, Widdershoven GA. Sharing stories: Narrative and dialogue in responsive nursing evaluation. Evaluation \& the health professions. 2005;28(1):90-109. 
68. Stevens JA, Beurskens AJ. Implementation of measurement instruments in physical therapist practice: development of a tailored strategy. Physical therapy. 2010;90(6):953-961.

69. Davis FD. Perceived usefulness, perceived ease of use, and user acceptance of information technology. MIS quarterly. 1989:319-340.

70. Mayhew D. The Usability Engineering Lifecycle: A practitioner's Handbook for User. Interface Design Morgan Kaufmanm. 1999.

71. Wickens CD, Gordon SE, Liu Y. An introduction to human factors engineering. 1998.

72. Revythi A, Tselios N. Extension of Technology Acceptance Model by using System Usability Scale to assess behavioral intention to use e-learning. Education and Information technologies. 2019;24(4):2341-2355. 


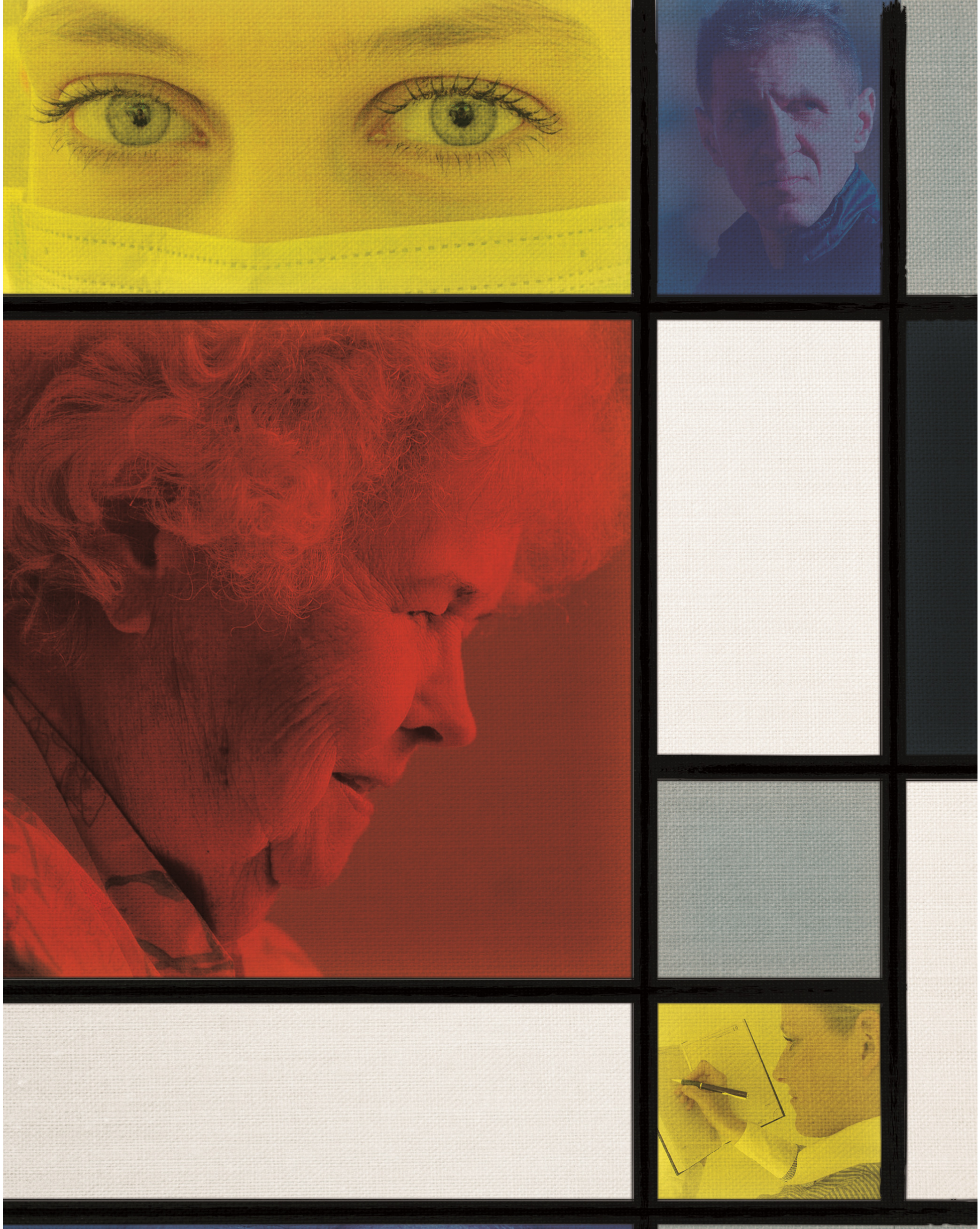


\section{CHAPTER 2}

\section{Experienced quality of post-acute and long-term care from the care recipient's perspective: A conceptual framework}

This chapter was published as: Sion KYJ, Haex R, Verbeek H, Zwakhalen SMG, Odekerken-Schröder G, Schols JMGA, \& Hamers JPH. Experienced Quality of Post-Acute and Long-Term Care From the Care Recipient's Perspective: A Conceptual Framework. Journal of the American Medical Directors Association, 2019;20(11), 1386-1390. Doi: https://doi.org/10.1016/j.jamda.2019.03.028 


\section{ABSTRACT}

This article aims to conceptualize experienced quality of post-acute and long-term care for older people (LTC) as perceived by care recipients. An iterative literature review and consultations with stakeholders led to the development of the INDividually Experienced QUAlity of Long-term care (INDEXQUAL) framework. INDEXQUAL presents the process of an individual care experience consisting of a pre (expectations), during (experiences), and post (assessment) phase. Expectations are formed prior to an experience by personal needs, past experiences and word-of-mouth. An experience follows, which consists of interactions between the actors in the caring relationships. Lastly, this experience is assessed by addressing what happened and how it happened (perceived care services), how this influenced the care recipient's health status (perceived care outcomes) and how this made the care recipient feel (satisfaction). INDEXQUAL can serve as a framework to select or develop methods to assess experienced quality of LTC. It can provide a framework for quality monitoring, improvement and transparency. 
LTC comprises a range of services to maintain or improve the functional and health outcomes of frail, chronically ill and physically or cognitively disabled older people. ${ }^{1}$ LTC has been defined as 'the activities undertaken by others to ensure that people with or at risk of a significant ongoing loss of intrinsic capacity can maintain a level of functional ability consistent with their basic rights, fundamental freedoms and human dignity', portraying the importance of relationships within this type of care delivery. ${ }^{2}$ LTC provision used to be considered a task-oriented, profession-driven service focused on safety and efficiency. ${ }^{3}$ Over the past decades, there has been an ongoing culture change striving towards a more holistic approach to care provision, incorporating not only the professional, but also the care recipient's perspective. Thus, allowing more focus on the care recipients' preferences, autonomy, and self-determination. ${ }^{4-7}$ This has resulted in the emerging need to define and assess quality of LTC as experienced by the care recipient.

In the mid-60s, Donabedian already touched upon the complexity of defining and assessing quality of care. ${ }^{8}$ He portrayed quality as a reflection of values and goals within the care system and society. Building on this, the Institute of Medicine ${ }^{9}$ defined quality of care as "the degree to which health services for individuals and populations increase the likelihood of desired health outcomes and are consistent with current professional knowledge". As quality of care consists of many aspects, it is challenging to assess, and therefore indicators are often used to operationalize quality of care with Donabedian's structure-process-outcomes mode ${ }^{10}{ }$, such as the prevalence of fall incidents, malnutrition or pressure ulcers. ${ }^{11}$ Indicators however often focus on the physical aspects of care (i.e. pressure ulcers), underrepresenting the social (i.e. engagement in daily life) and emotional aspects (i.e. satisfaction), and ignoring others in the caring environment. ${ }^{11-13}$ This is more in line with the professional or regulatory agency perspective, instead of representing the values and needs of what care recipient and their families find most important. ${ }^{1,14}$ This increasing focus on the care recipient's perspective, has led to the development of quality indicators that can be assessed by the care recipients themselves by means of patient reported outcome measures (PROMs), such as severity of pain and patient-reported experience measures (PREMs), such as the Consumer-Quality Index. ${ }^{15,16}$ PROMS and PREMS do not capture the care recipient's journey that is important for establishing the experienced quality of care for an older person. ${ }^{17}$

Furthermore, from a service science perspective, care service delivery has certain characteristics that complicate the assessment of the experienced quality of care from the recipient's perspective. Care service delivery is characterized as being intangible, heterogeneous, perishable, interactive, and multifaceted. ${ }^{18,19}$ This means that the experience of care provision is built on interactions between people involved in a value creating process, and therefore, its quality cannot be judged in advance (intangible), it 
cannot be provided with uniformity (heterogeneous) and it cannot be stored, thus the location and timing influence the experiences as well (perishability). Care provision is usually achieved during interactions between the care recipient and the care provider (interactive), and it is considered a complex service (multifaceted quality). The complexity of care services in combination with the more holistic view on (health) care and the increasing importance of the care recipient's perspective, have resulted in the need for a clear understanding of the meaning of experienced quality of LTC.

\section{Conceptualization of experienced quality of long-term care}

In order to conceptualize experienced quality of care, we performed multiple actions. The literature within the service sciences and health sciences was reviewed to identify models and frameworks defining the process of service quality from the user's perspective and care quality from the care recipient's perspective. Iterative searches were performed in PubMed, PsycInfo and EBSCO Business Source Complete, and by means of snowballing. We used search terms, including: "quality of care", "experienced quality" and "service quality". Based on identified relevant articles, we added search terms including: "expectations", "perceived quality", "patient reported" and "satisfaction". We considered articles relevant if they presented a model, framework, concept or theory related to experienced quality of LTC from the care recipient's perspective. Studies focused on the evaluation of an intervention or validation of an instrument were considered out of scope. Additionally, the grey literature was searched to assure key publications were identified. Appendix 2.1 presents additional information on the article selection.

The identified models and frameworks were reviewed, compared to each other, and combined into a conceptual framework; because, existing models and frameworks did not fully fulfill the research aim to conceptualize experienced quality of LTC from the care recipient's perspective. This was an iterative process, during which results were reviewed, discussed and adjusted in the research team. The research team consisted of a Professor in Care of Older Persons, a Professor in Old Age Medicine, a Professor in Nursing Science, a Professor in Customer Centric Service Science, an Associate Professor in Long-Term Care Design, and two researchers with a background in Psychology and Health Sciences. Additionally, a panel of experts was assembled and gathered three times to reflect on the framework. This panel consisted of representatives from multiple national stakeholders in the Netherlands specialized in long-term care policy, including the Ministry of Health $(n=2)$, the National Health Care Institute $(n=2)$, the National Client Council $(n=1)$, the Professional Association of Nurses $(n=2)$, the Health and Youth Care Inspectorate $(n=2)$ and Nursing Home Organisations $(n=4)$. When consensus could not be reached within the research team, the topic of discussion was presented to the panel of experts. Eventually, 
these iterative steps have resulted in the development of the INDividually EXperienced QUAlity of Long-term care (INDEXQUAL) framework (Figure 2.1, Table 2.1).

Figure 2.1 A framework of individually experienced quality of long-term care (INDEXQUAL)

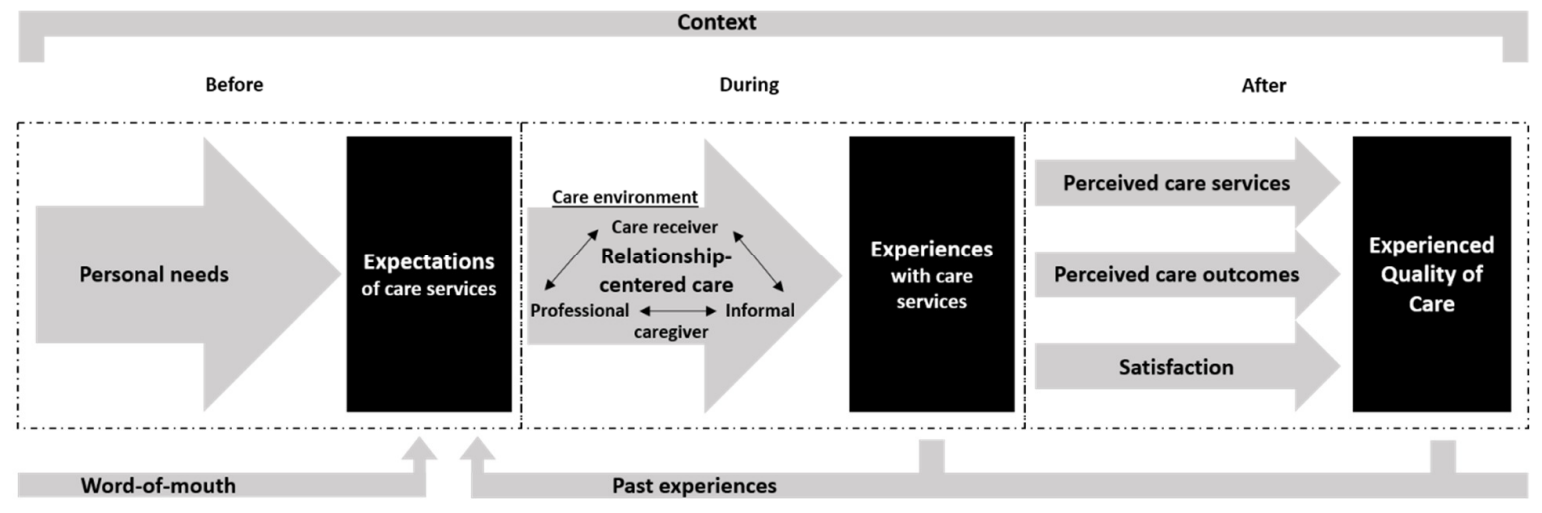

INDEXQUAL aims to provide a framework describing the process of experienced quality of LTC, by focusing on the care recipient's experiences with care services and factors occurring prior to, during and after this experience, within a certain context. The framework presents a process that starts with a personal need and ends after an experience. In the after experience, a differentiation could be made between a variety of care recipient groups, including moving out of one particular long-term care setting (e.g. nursing home) to another type of care setting (for example home care), remaining in the long-term care setting or passing away. The framework is a global representation that allows for adaptation to a specific long-term care setting, timing and population.

Two principles underlie the development of INDEXQUAL. First, INDEXQUAL assumes that care provision is a form of service delivery, and therefore a process that consists of a before, during and after phase. ${ }^{17}$ Secondly, INDEXQUAL places relationshipcentered care (RCC) at the core of care experiences, emphasizing that all relationships within the caring process need to be considered and not solely the care recipient's. ${ }^{20,21}$ It assumes that care experiences are mainly influenced by the interactions throughout the caring process; especially within long-term care provision, which is more often focused on care, and less on cure. ${ }^{22}$ 
Table 2.1. Overview and definitions of individual components from the INDEXQUAL framework

\begin{tabular}{|c|c|c|}
\hline Concept & Description & Examples of themes, indicators and/or tools to assess \\
\hline Context & $\begin{array}{l}\text { Care receiver characteristics and the } \\
\text { setting in which care is delivered. }{ }^{30,39}\end{array}$ & $\begin{array}{l}\text { - Interpersonal environment: description of care } \\
\text { recipient i.e. age, sex, ethnicity, health status } \\
\text { Organisational environment i.e. type of care } \\
\text { organisation (nursing home, home care, } \\
\text { rehabilitation care); size; skill mix; available facilities } \\
\text { and supportive organisational systems }\end{array}$ \\
\hline \multicolumn{3}{|c|}{ Expected care services } \\
\hline $\begin{array}{l}\text { Personal } \\
\text { care needs }\end{array}$ & $\begin{array}{l}\text { In the long-term care setting, care } \\
\text { needs can be placed into Nolan's } \\
\text { senses framework: security, } \\
\text { continuity, belonging, significance, } \\
\text { purpose and fulfilment. }^{25}\end{array}$ & $\begin{array}{l}\text { - Security - to feel safe physically, psychologically, } \\
\text { existentially } \\
\text { - } \text { Belonging - to feel part of a valued group, to } \\
\text { maintain or form important relationships } \\
\text { - Continuity - to be able to make links between the } \\
\text { past, present and future } \\
\text { - Purpose - to enjoy meaningful activity, to have } \\
\text { valued goals } \\
\text { - Achievement - to reach valued goals to satisfaction } \\
\text { of self and/or others } \\
\text { Significance - to feel that you 'matter' and are } \\
\text { accorded value and status }\end{array}$ \\
\hline
\end{tabular}

The client's previous exposure to a Past care service that is relevant to the experience current service, and can shape predictions and desires. ${ }^{23}$
Factors related to the experience of care transition between different care services, such as experiencing changes of significant relationships, moving from familiar to unknown environments and cultures, being prepared for transfer and achieving responsibility. ${ }^{44}$

\begin{tabular}{|c|c|c|}
\hline $\begin{array}{l}\text { Word } \\
\text { mouth }\end{array}$ & $\begin{array}{l}\text { Personal and sometimes non- } \\
\text { personal statements made by parties } \\
\text { other than the care organisation or } \\
\text { care receivers themselves. They } \\
\text { convey to care receivers what the } \\
\text { service will be like (i.e. what they can } \\
\text { expect). It is perceived as unbiased } \\
\text { and tends to be quite important in } \\
\text { care services, because services are } \\
\text { difficult for care receivers to evaluate } \\
\text { prior to purchasing and directly } \\
\text { experiencing them. }{ }^{26}\end{array}$ & $\begin{array}{l}\text { All information received from experts about the type of } \\
\text { care delivery, including reviews from other care } \\
\text { receivers, friends and family, such as reviews on Yelp. }{ }^{23,} \\
45\end{array}$ \\
\hline \multicolumn{3}{|c|}{ Experienced care services } \\
\hline $\begin{array}{l}\text { Care } \\
\text { environmen } \\
\mathrm{t}\end{array}$ & $\begin{array}{l}\text { The direct environment influencing } \\
\text { the care experience. }{ }^{20}\end{array}$ & $\begin{array}{l}\text { Shared decision-making; effective staff relationships, } \\
\text { power sharing, potential for innovation and risk taking } \\
\text { and the physical (home-like) environment. }{ }^{20}\end{array}$ \\
\hline $\begin{array}{l}\text { Relationship } \\
\text {-centered } \\
\text { care }\end{array}$ & $\begin{array}{l}\text { A framework that conceptualizes } \\
\text { care. It focusses on the influence of } \\
\text { the nature and quality of } \\
\text { relationships in the process and } \\
\text { outcomes of care services. }{ }^{22}\end{array}$ & $\begin{array}{l}\text { Observations with for example the Maastricht } \\
\text { Observation in Daily Living tool (MEDLO) assessing } \\
\text { activities, physical environment, social interaction and } \\
\text { emotional well-being }{ }^{41} \text { or Dementia Care Mapping. }{ }^{40}\end{array}$ \\
\hline
\end{tabular}




\section{Experienced quality of care}

The care receiver's assessment of what happened and how it happened. ${ }^{35}$ It is the impact of the process of the care on the care Perceived receiver's experience. This can care include relational aspects, assessing services the experience of the relationships during treatment (i.e. feeling heard) and functional aspects, assessing more practical issues (i.e. available facilities). ${ }^{36}$

\begin{tabular}{ll}
\hline Perceived & The care receiver's view on his or her \\
care & health status. $^{36}$ \\
outcomes &
\end{tabular}

The gap between expectations and experiences, seen as an evaluative, Satisfaction affective, or emotional response. ${ }^{37}$ It expresses how a care service encounter made the care receiver feel. $^{36}$
Consumer Assessment of Healthcare Providers and Systems (CAHPS) survey, includes indicators on i.e. food quality, environment, safety, pain management, staff skills and choice. ${ }^{46}$

Picker Patient Experience Questionnaire, includes indicators on i.e. information and education, coordination of care, physical comfort, emotional support, respect for patient preferences, involvement of family and friends, and continuity and transition. ${ }^{47}$

Health status outcomes, such as health-related quality of life and improvement in health status measured by disease-specific instruments.

Net Promotor Score measures customer experience on a $0-10$ scale. $^{48}$

\section{Expectations (before)}

There are two types of expectations: adequate and desired. Adequate expectations are what is likely to happen and what a care recipient considers to be acceptable. Desired expectations are the services a care recipient hopes and desires to receive, thus what they feel a service should offer. ${ }^{23}$ The range between an adequate and desired expectation of LTC services is formed by three influences: personal needs, past experiences and word of mouth, as adopted from the SERVQUAL model. ${ }^{18}$ This is the most widely known model in the field of service sciences, describing experienced service quality from the customer's perspective. ${ }^{18}$ It recognizes the difference between expected services and perceived services, known as the gap representing customer satisfaction. ${ }^{23,24}$

Experienced quality of care starts with the occurrence of a personal need. Everyone has basic personal needs, and within relationship-centered care these are defined as the six basic senses: a sense of security, continuity, belonging, significance, purpose and fulfilment. ${ }^{25}$ Underlying any care service, there is a need related to one or multiple of these senses. For example, the need to receive competent care can be placed in the sense of security; or the need to form meaningful and interactive relationships can be placed in the sense of belonging. Past experiences are the care recipient's previous exposures to a care service that are relevant to the current service, and can shape predictions and desires. ${ }^{23}$ They can have a direct impact on what someone expects from a care service. Other 
people's past experiences can influence a care recipient's expectations by word of mouth. ${ }^{18}$ These are personal and sometimes non-personal statements made by parties other than the organisation, such as care recipient reviews, friends and family. ${ }^{26}$ They express what the service will be like to care recipients (i.e. what they can expect). Word of mouth is perceived as unbiased and has shown to be quite important in care services, because services are difficult for consumers to evaluate prior to purchasing and directly experiencing them. ${ }^{26}$

\section{Experiences (during)}

Experiences with care services are defined as the sum of interactions across the care process, influencing the care recipient's perception within the organisational culture. ${ }^{27}$ The care environment influences the care experience for example by means of the level of shared decision-making and the physical aspects of the environment such as a home-like atmosphere, privacy, noise and cleanliness. ${ }^{20,28,29}$ During the actual experience with a care service in the care environment, interactions within the caring relationships can influence the experience. Caring relationships are defined as 'human interactions grounded in caring processes, incorporating physical work (doing), interactions (being with), and relationships (knowing each other)'.$^{30}$ They are deemed necessary in order to provide high quality of care. ${ }^{30}$ How care is delivered and received, is dependent on how we define ourselves and others within a network of relationships and social circumstances. ${ }^{22}$ In service sciences, this is portrayed as balanced centricity implying that value is co-created by all involved stakeholders, who each deserve satisfaction of their needs and wants. ${ }^{31}$ Relationships are the medium of care that should be based upon mutual respect, equity and shared understanding. ${ }^{32}$ Family is considered an important actor in long-term care, as their involvement can influence the care recipient's experiences by means of for example choice, community connection and quality of life. ${ }^{33}$ Figure 2.1 presents the relationships in a triangle consisting of the care recipient, professional caregivers and informal caregivers. This network of relationships can differ for each individual care recipient; however, the simplified visualization in the framework portrays the emphasis on the relationships between the involved actors. Actors in the caring relationships can each have a view on the experienced QoC process from the care recipient's perspective, because they are part of the experience. For example, a family member also has certain expectations and experiences with the care provided to their loved one, and this can influence the experienced QoC results.

Experienced quality of long-term care (after)

After the experience, the care recipient makes a conscious or unconscious assessment by comparing his or her expectations with the actual experience, taking into consideration 
the gap between the experience and the reported experience. ${ }^{34}$ This leads to an evaluation of three aspects: perceived care services, perceived care outcomes and satisfaction. ${ }^{35,36}$ Within perceived care services, the process of the experience is evaluated, answering questions such as what happened and how it happened. ${ }^{35}$ This can include relational aspects, assessing the experience of the care relationships (i.e. feeling heard) and functional aspects, assessing more practical issues (i.e. allocated caregiving time). ${ }^{36}$ Within perceived care outcomes, the care recipient's health status is assessed, such as (health-related) quality of life, levels of pain and other changes in the care recipient's health outcomes. ${ }^{36}$ Within satisfaction, the care recipient attaches an emotional response to the experience, expressing how the experience made him or her feel. ${ }^{35}$ It is considered to be the gap between expectations and experiences, seen as an evaluative, affective, or emotional response. ${ }^{37}$ Eventually the sum of these evaluations contributes to the assessment of the overall experienced quality of LTC.

Context

Considering the framework presents the process of experiences from an individual care recipient's perspective, it needs to be taken into account that each individual within the care process has his or her own personal characteristics such as age, sex, education, ethnicity and social class. ${ }^{34,38}$ The framework has been developed within the LTC setting for older people. ${ }^{1}$ The individual characteristics and the LTC setting for older people in which care is delivered (i.e. at home or in a nursing home) shape the context of an experience. ${ }^{30,39}$

Example

INDEXQUAL can be adapted to different settings, timings and populations. For example, the framework can be adapted to people with dementia living in nursing homes for the remainder of their lives. In this case, the framework can focus on assessing the entire experience of living in the nursing home for a longer period of time. The method to assess the experience might be by means of observations as the care recipients cannot always express themselves anymore. ${ }^{40,41}$ Additionally, the position of the family in the triangle may gain more importance in this setting to support and voice the needs of the care recipient.

\section{IMPLICATIONS FOR PRACTICE, POLICY AND/OR RESEARCH}

INDEXQUAL presents a framework of a care recipient's journey including the expectations, experiences and assessment of quality of LTC in terms of perceived care services, care 
outcomes and satisfaction. INDEXQUAL has been based on theory and the next step is to validate it in practice. The framework was developed for the LTC setting for older people, however it may be applicable for other LTC settings as well. Currently, there is an occurring trend focused on the importance of relationships within care delivery. ${ }^{42}$ INDEXQUAL can provide insight into the care process as experienced within these relationships (care recipient, professional caregiver and informal caregiver). It can be used as a framework to select existing methods or develop a new method to assess how LTC provision is experienced.

The INDEXQUAL framework differs from existing frameworks and models, because it incorporates knowledge from health care literature and service sciences literature, from the care recipient's perspective. It is a dynamic model presenting the process of experienced quality of care, highlighting the importance of relationships within this experience. The framework presents an overarching representation allowing flexibility to adapt to specific LTC settings, timing and population. Additionally, INDEXQUAL addresses quality of LTC not only from the physical, but also from the social and emotional aspects of care. This is in line with the growing focus on assessing more than standardized quality indicators, and assessing the care recipient's experiences as well. Perceived care processes assess what happened and how it happened, perceived care outcomes assess the care recipient's self-reported health status, and satisfaction assesses how the experience made the care recipient feel. ${ }^{23,35,43}$ The sum of these results provide a more holistic view on how care provision is experienced. INDEXQUAL can serve as a framework for quality monitoring, improvement and transparency. 


\section{REFERENCES}

1. OECD/EU. A Good Life in Old Age? Paris: OECD Publishing, 2013.

2. World Health Organisation. World report on ageing and health. Luxembourgh; 2015.

3. Rosher RB, Robinson S. Impact of the Eden Alternative on family satisfaction. Journal of the American Medical Directors Association 2005;6(3):189-193.

4. Brownie S, Nancarrow S. Effects of person-centered care on residents and staff in aged-care facilities: a systematic review. Clinical Interventions in Aging 2013;8:110.

5. Snoeren MM, Janssen BM, Niessen TJ, et al. Nurturing cultural change in care for older people: Seeing the cherry tree blossom. Health Care Analysis 2016;24(4):349-373.

6. McColl-Kennedy JR, Snyder H, Lars Witell ME, et al. The changing role of the health care customer: review, synthesis and research agenda. Journal of Service Management 2017;28(1):2-33.

7. Shura R, Siders RA, Dannefer D. Culture Change in Long-term Care: Participatory Action Research and the Role of the Resident. The Gerontologist 2011;51(2):212225.

8. Donabedian A. Evaluating the quality of medical care. The Milbank memorial fund quarterly 1966;44(3):166-206.

9. Institute of Medicine. Chapter 1. Health, Health Care, and Quality of Care. In: Lohr, KN, ed. Medicare: A Strategy for Quality Assurance: Volume 1. Washington (DC): National Academies Press (US) 1990.

10. Donabedian A. The quality of care. How can it be assessed? Jama 1988;260(12):1743-1748.

11. Castle NG, Ferguson JC. What Is Nursing Home Quality and How Is It Measured? The Gerontologist 2010;50(4):426-442.

12. Huber $M$, Knottnerus JA, Green $L$, et al. How should we define health? BMJ $2011 ; 343$.

13. Huber $M$, van Vliet $M$, Giezenberg $M$, et al. Towards a 'patient-centred' operationalisation of the new dynamic concept of health: a mixed methods study. BMJ open 2016;6(1):e010091.

14. Berwick DM. Medical associations: guilds or leaders? Either play the role of victim or actively work to improve healthcare systems 1997;314(7094):1564.

15. Triemstra M, Winters S, Kool RB, et al. Measuring client experiences in long-term care in the Netherlands: a pilot study with the Consumer Quality Index Long-term Care. BMC health services research 2010;10:95.

16. Weldring T, Smith SM. Article Commentary: Patient-Reported Outcomes (PROs) and Patient-Reported Outcome Measures (PROMs). Health services insights 2013;6:HSI. S11093.

17. Voorhees CM, Fombelle PW, Gregoire Y, et al. Service encounters, experiences and the customer journey: Defining the field and a call to expand our lens. Journal of Business Research 2017;79:269-280.

18. Parasuraman A, Zeithaml VA, Berry LL. A Conceptual Model of Service Quality and Its Implications for Future Research. Journal of Marketing 1985;49(4):41-50.

19. Goffin K, Mitchell R. Innovation Management: Effective strategy and implementation. Macmillan Education UK, 2016.

20. McCormack B, Roberts T, Meyer J, et al. Appreciating the 'person' in long-term care. International journal of older people nursing 2012;7(4):284-294.

21. Pew-Fetzer Task Force \& Tresolini CP. Health professions education and relationship-centered care : report. Pew Health Professions Commission, UCSF Center for the Health Professions, 1994.

22. Soklaridis S, Ravitz P, Nevo GA, et al. Relationship-centred care in health: A 20year scoping review. Patient Experience Journal 2016;3(1):130-145. 
23. Parasuraman A, Zeithaml VA, Berry LL. SERVQUAL: A multiple-item scale for measuring customer perceptions of service quality. Journal of Retailing $1988 ; 6(41): 12-40$.

24. Kulašin D, Fortuny-Santos J. Review of the SERVQUAL concept. Paper presented at: The 4th Research/expert Conference with International Participation, In Macau.

25. Nolan M, Brown J, Davies S, et al. The Senses Framework: improving care for older people through a relationship-centred approach. Getting Research into Practice (GRiP) Report No 2.: University of Sheffield., 2006.

26. Zeithaml VA, Berry LL, Parasuraman A. The nature and determinants of customer expectations of service. Journal of the academy of Marketing Science $1993 ; 21(1): 1-12$.

27. Wolf JA, Niederhauser V, Marshburn D, et al. Defining Patient Experience. Patient Experience Journal 2014;1(1):7.

28. Chan J, Beard RL, Lyons W, et al. Factors That Influence End-of-Life Care in Nursing Homes: The Physical Environment, Inadequate Staffing, and Lack of Supervision. The Gerontologist 2003;43(suppl_2):76-84.

29. Mahmood A, Chaudhury $H$, Valente M. Nurses' perceptions of how physical environment affects medication errors in acute care settings. Applied Nursing Research 2011;24(4):229-237.

30. Duffy JR, Hoskins LM. The Quality-Caring Model: blending dual paradigms. ANS Advances in nursing science 2003;26(1):77-88.

31. Gummesson E. Extending the service-dominant logic: from customer centricity to balanced centricity. Journal of the Academy of Marketing Science 2008;36(1):1517.

32. Adams T, Clarke CL. Dementia care: Developing partnerships in practice. Bailliere Tindall Limited, 1999.

33. Gaugler JE. Family involvement in residential long-term care: A synthesis and critical review. Aging \& Mental Health 2005;9(2):105-118.

34. Sandager M, Freil M, Knudsen JL. Please tick the appropriate box: Perspectives on patient reported experience. Patient Experience Journal 2016;3(1):63-79.

35. LaVela SL, Gallan AS. Evaluation and measurement of patient experience. Patient Experience Journal 2014;1(28):36.

36. Kingsley C, Patel S. Patient-reported outcome measures and patient-reported experience measures. BJA Education 2017;17(4):137-144.

37. Oliver RL, DeSARBO WS. Processing of the satisfaction response in consumption: a suggested framework and research propositions. Journal of Consumer Satisfaction, Dissatisfaction and Complaining Behavior 1989;2(1):1-16.

38. Chow A, Mayer EK, Darzi AW, et al. Patient-reported outcome measures: The importance of patient satisfaction in surgery. Surgery 2009;146(3):435-443.

39. McCormack B, McCance TV. Development of a framework for person-centred nursing. Journal of Advanced Nursing 2006;56(5):472-479.

40. Brooker DJ, Surr C. Dementia Care Mapping (DCM): initial validation of DCM 8 in UK field trials. International journal of geriatric psychiatry 2006;21(11):10181025.

41. de Boer B, Beerens HC, Zwakhalen SM, et al. Daily lives of residents with dementia in nursing homes: development of the Maastricht electronic daily life observation tool. International psychogeriatrics 2016;28(8):1333-1343.

42. McCormack B, van Dulmen S, Eide H, et al. Person-Centred Healthcare Research. Wiley, 2017.

43. Cronin JJ, Taylor SA. Measuring Service Quality: A Reexamination and Extension. Journal of Marketing 1992;56(3):55-68.

44. Fegran $L$, Hall EO, Uhrenfeldt $L$, et al. Adolescents' and young adults' transition experiences when transferring from paediatric to adult care: a qualitative metasynthesis. International Journal of Nursing Studies 2014;51(1):123-135.

45. Johari K, Kellogg C, Vazquez K, et al. What Consumers Say About Nursing Homes in Online Reviews. The Gerontologist 2018;58(4):e273-e280. 
46. Agency for Healthcare Research and Quality. CAHPS: Consumer Assessment of Healthcare Providers and Systems.; http://www.cahps.ahrq.gov. Accessed.

47. Jenkinson C, Coulter A, Bruster S. The Picker Patient Experience Questionnaire: development and validation using data from in-patient surveys in five countries. International Journal for Quality in Health Care 2002;14(5):353-358.

48. Reichheld FF. The one number you need to grow. Harvard business review 2003;81(12):46-54, 124. 


\section{APPENDIX}

\section{Appendix 2.1. Additional Literature Used in Model Development but Not Cited}

The special article presents the final selection of core publications that were used to compose the INDEXQUAL framework. Behind the development of this framework lies a broad literature review of experienced quality of care from the care recipient's perspective. There is a secondary list of articles that contributed to the insights in this special article, but were not the primary contributors to the final framework. Reasons for exclusion were that these articles a) did not focus on the care receiver's perspective; b) focused on quality of life instead of quality of care; c) presented specific outcomes or themes related to a specific setting or construct; d) presented an adaptation of an existing model; or e) did not present a model, framework or theory of quality of care or care experiences.

1. Alonazi WB, Thomas SA. Quality of care and quality of life: convergence or divergence? Health services insights 2014;7:1-12.

2. Babakus E, Mangold WG. Adapting the SERVQUAL scale to hospital services: an empirical investigation. Health Services Research 1992;26(6):767-786.

3. Beach MC, Inui T. Relationship-centered care. A constructive reframing. Journal of general internal medicine 2006;21 Suppl 1:S3-8.

4. Beattie M, Murphy DJ, Atherton I, et al. Instruments to measure patient experience of healthcare quality in hospitals: a systematic review. Systematic reviews 2015;4(1):97.

5. Beerens HC. Adding life to years : quality of life of people with dementia receiving long-term care. Maastricht: Hanneke Beerens, 2016.

6. Bird M, Anderson K, MacPherson S, et al. Do interventions with staff in long-term residential facilities improve quality of care or quality for life people with dementia? A systematic review of the evidence. International psychogeriatrics 2016;28(12): 1937-1963.

7. Bjerregaard K, Haslam SA, Mewse A, et al. The shared experience of caring: a study of care-workers' motivations and identifications at work. Ageing \& Society 2017;37(1):113-138.

8. Bjertnaes OA, Sjetne IS, Iversen $\mathrm{HH}$. Overall patient satisfaction with hospitals: effects of patient-reported experiences and fulfilment of expectations. BMJ Qual Saf 2012;21(1):39-46.

9. Bradshaw SA, Playford ED, Riazi A. Living well in care homes: a systematic review of qualitative studies. Age and ageing 2012;41(4):429-440.

10. Brod M, Stewart AL, Sands L, et al. Conceptualization and measurement of quality of life in dementia: the dementia quality of life instrument (DQoL). The Gerontologist 1999;39(1):25-35.

11. Brooker D. Person-Centred Dementia Care: Making Services Better. Jessica Kingsley Publishers, 2006.

12. Brownie S, Nancarrow S. Effects of person-centered care on residents and staff in aged-care facilities: a systematic review. Clinical Interventions in Aging 2013;8:110.

13. Campbell SM, Roland MO, Buetow SA. Defining quality of care. Social science \& medicine (1982) 2000;51(11):1611-1625.

14. Care Alliance Ireland. Literature review on the relationship between family carers and home care support workers. 2014. 
15. Carr AJ, Gibson B, Robinson PG. Measuring quality of life: Is quality of life determined by expectations or experience? BMJ (Clinical research ed) 2001;322(7296):1240-1243.

16. Carr AJ, Higginson IJ. Are quality of life measures patient centred? BMJ (Clinical research ed) 2001;322(7298):1357-1360.

17. Chow A, Mayer EK, Darzi AW, et al. Patient-reported outcome measures: The importance of patient satisfaction in surgery. Surgery 2009;146(3):435-443.

18. Cooney A, Murphy K, O'Shea E. Resident perspectives of the determinants of quality of life in residential care in Ireland. Journal of advanced nursing 2009;65(5):10291038.

19. Cossette S, Cara C, Ricard N, et al. Assessing nurse-patient interactions from a caring perspective: report of the development and preliminary psychometric testing of the Caring Nurse--Patient Interactions Scale. International journal of nursing studies 2005;42(6):673-686.

20. Cronin JJ, Taylor SA. Measuring Service Quality: A Reexamination and Extension. Journal of Marketing 1992;56(3):55-68.

21. D'Astous V, Abrams R, Vandrevala T, et al. Gaps in understanding the experiences of homecare workers providing care for people with dementia up to the end of life: A systematic review. Dementia 0(0):1471301217699354.

22. Dewar B, Nolan M. Caring about caring: developing a model to implement compassionate relationship centred care in an older people care setting. International journal of nursing studies 2013;50(9):1247-1258.

23. Garvin DA. What Does "Product Quality" Really Mean? Sloan Management Review $1984 ; 26(1): 25-43$.

24. Gerteis M. Through the patient's eyes: understanding and promoting patientcentered care. 1993.

25. Glass AP. Nursing home quality: a framework for analysis. Journal of applied gerontology : the official journal of the Southern Gerontological Society $1991 ; 10(1): 5-18$.

26. Griffiths P. State of the art metrics for nursing: a rapid appraisal. London: National Nursing Research Unit, King's College London, 2008.

27. Gronroos C. Service quality: The six criteria of good perceived service. Review of business 1988;9(3):10.

28. Gummesson E. Extending the service-dominant logic: from customer centricity to balanced centricity. Journal of the Academy of Marketing Science 2008;36(1):1517.

29. Hudon C, Fortin M, Haggerty JL, et al. Measuring patients' perceptions of patientcentered care: a systematic review of tools for family medicine. Annals of family medicine $2011 ; 9(2): 155-164$.

30. Jenkinson C, Coulter A, Bruster S, et al. Patients' experiences and satisfaction with health care: results of a questionnaire study of specific aspects of care. Quality \& safety in health care 2002;11(4):335-339.

31. Kane RA. Long-term care and a good quality of life: bringing them closer together. The Gerontologist 2001;41(3):293-304.

32. Kane RA, Kling KC, Bershadsky B, et al. Quality of life measures for nursing home residents. The journals of gerontology Series A, Biological sciences and medical sciences 2003;58(3):240-248.

33. Kobayashi H, Takemura Y, Kanda K. Patient perception of nursing service quality; an applied model of Donabedian's structure-process-outcome approach theory. Scandinavian journal of caring sciences 2011;25(3):419-425.

34. Kuis EE, Hesselink G, Goossensen A. Can quality from a care ethical perspective be assessed? A review. Nursing ethics 2014;21(7):774-793.

35. Kulašin D, Fortuny-Santos J. Review of the SERVQUAL concept. The 4th Research/expert Conference with International Participation, In Macau. 2005:133137. 
36. Lee D. HEALTHQUAL: a multi-item scale for assessing healthcare service quality. Service Business 2017;11(3):491-516.

37. Marcoen A. Filial maturity of middle-aged adult children in the context of parent care: Model and measures. Journal of Adult Development 1995;2(2):125-136.

38. McColl-Kennedy JR, Snyder H, Lars Witell ME, et al. The changing role of the health care customer: review, synthesis and research agenda. Journal of Service Management 2017;28(1):2-33.

39. Mead N, Bower P. Patient-centredness: a conceptual framework and review of the empirical literature. Social science \& medicine (1982) 2000;51(7):1087-1110.

40. Miller D, Gray CS, Kuluski K, et al. Patient-centered care and patient-reported measures: let's look before we leap. The Patient-Patient-Centered Outcomes Research 2015;8(4):293-299.

41. Morgan S, Yoder LH. A concept analysis of person-centered care. Journal of holistic nursing : official journal of the American Holistic Nurses' Association 2012;30(1):615.

42. Oliver RL, Swan JE. Consumer Perceptions of Interpersonal Equity and Satisfaction in Transactions: A Field Survey Approach. Journal of Marketing 1989;53(2):21-35.

43. Oliver RL. Cognitive, affective, and attribute bases of the satisfaction response. Journal of consumer research 1993;20(3):418-430.

44. Oliver RL. Customer Satisfaction. In: Wiley International Encyclopedia of Marketing. John Wiley \& Sons, Ltd, 2010.

45. Pascoe GC. Patient satisfaction in primary health care: a literature review and analysis. Evaluation and program planning 1983;6(3-4):185-210.

46. Rantz MJ, Mehr DR, Popejoy L, et al. Nursing home care quality: a multidimensional theoretical model. Journal of nursing care quality 1998;12(3):30-46; quiz 69-70.

47. de Rooij AH, Luijkx KG, Spruytte N, et al. Family caregiver perspectives on social relations of elderly residents with dementia in small-scale versus traditional longterm care settings in the Netherlands and Belgium. Journal of clinical nursing 2012;21(21-22):3106-3116.

48. Rosher RB, Robinson S. Impact of the Eden Alternative on family satisfaction. Journal of the American Medical Directors Association 2005;6(3):189-193.

49. Shah DR, Roland T. ; Parasuraman, Ananthanarayanan ; Staelin, Richard ; Day, George S. The Path to Customer Centricity. Journal of Service Research 2006;9(2):113-124.

50. Shippee TP, Henning-Smith C, Kane RL, et al. Resident- and Facility-Level Predictors of Quality of Life in Long-Term Care. The Gerontologist 2015;55(4):643655.

51. Spreng RA, Mackoy RD. An empirical examination of a model of perceived service quality and satisfaction. Journal of retailing 1996;72(2):201-214.

52. Tronto JC. Moral Boundaries: A Political Argument for an Ethic of Care. Routledge, 1993.

53. Uman GC, Urman HN. Measuring consumer satisfaction in nursing home residents. Nutrition (Burbank, Los Angeles County, Calif) 1997;13(7-8):705-707.

54. De Waele I, Van Loon J, Van Hove G, et al. Quality of Life Versus Quality of Care: Implications for People and Programs. Journal of Policy and Practice in Intellectual Disabilities 2005;2(3-4):229-239.

55. Zubritsky $C$, Abbott $\mathrm{KM}$, Hirschman $\mathrm{KB}$, et al. Health-related quality of life: expanding a conceptual framework to include older adults who receive long-term services and supports. The Gerontologist 2013;53(2):205-210. 


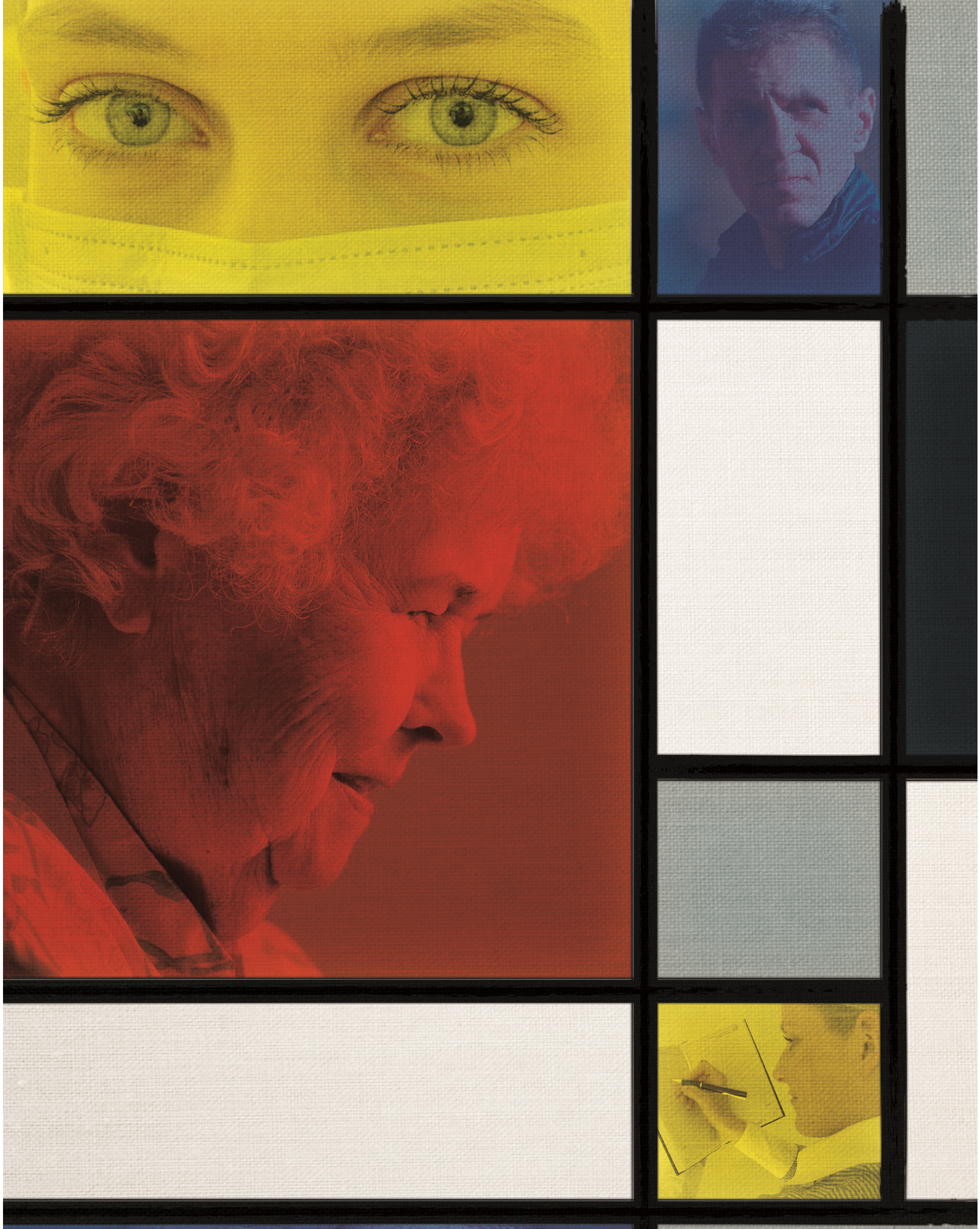


\section{CHAPTER 3}

\section{How do clients and (in)formal caregivers experience quality of home care? A qualitative approach}

This chapter was published as: Haex R, Thoma-Lürken T, Beurskens AJHM, \& Zwakhalen SMG. How do clients and (In) formal caregivers experience quality of home care? A qualitative approach. Journal of advanced nursing, 2020; 76(1), 264-274. Doi: https://doi.org/10.1111/jan.14234 


\section{ABSTRACT}

Aim: To explore and understand the views of clients, and formal and informal caregivers about the experienced quality of home care for older people.

Design: A descriptive qualitative study was conducted using individual interviews. Methods: Six home care clients, four formal and six informal caregivers were recruited from two Dutch home care organisations. Individual, semi-structured interviews took place between April and November 2018. The INDividually EXperienced QUAlity of Long-term care framework was used to guide data collection and content analyses.

Results: The analyses revealed several important attributes contributing to experienced quality of home care such as a preferred small number of caregivers, perceived sufficient time for care provision, and a caring atmosphere facilitating open communication and humour. Participants indicated that care routines fitting with the care receiver's former way of living were important. A more 'close' personal care relationship related to trust, openness, and empathy was preferred over a more 'detached' professional care relationship.

Conclusion: This study identified a wide range of attributes related to experienced quality of care from the perspectives of clients, and formal and informal caregivers in home care.

Impact: Care providers are being challenged to structurally assess individual experienced quality of home care. This study underlines the importance of incorporating care preferences and experiences throughout the care process from a relationship-centred care approach. Relevant care measures and outcomes should be determined in order to gain insight and further improve individual care provision. 


\section{INTRODUCTION}

Ageing in place is a common policy in Western societies to address rising costs and meet the needs of older people to remain in the familiar environment of the home.1,2 Consequently, there is an increasing need for high-quality home care services and quality measures. ${ }^{3-5}$ In the Netherlands, two types of formal home care services are provided in addition to domestic support: personal care and nursing care. Personal care and nursing care (referred to as 'home care') are both regulated by the Dutch health care insurance act ( $\mathrm{V} v \mathrm{w})$ and provided by teams comprising a district nurse, registered nurses, and nurse assistants/aides. This care is provided to community-dwelling older people who receive long-term care based on one or multiple chronic conditions and who are referred to in this article as 'clients'. The district nurse leads the care process by liaising with municipalities and coordinating the client's care, while registered nurses and nurse assistants/aides provide medical and personal care. Health insurers fund personal as well as nursing care in the Netherlands. ${ }^{6-8}$

In addition to formal care, informal caregivers play an increasingly important and active role in supporting care-dependent clients. Informal caregivers are unpaid family members, friends, or neighbours who provide assistance. ${ }^{9}$ They are seen as active care partners in providing home care in the Netherlands. 6,9 Both formal and informal caregivers exert enormous effort in providing the necessary home care. ${ }^{10}$ The Dutch national quality framework for home care recognises these efforts, stating the need to use patient-reported experience measures to improve the primary care process and home care team functioning by understanding what clients and their family members experience as 'good care'.11 Therefore, it is important to understand how quality of care (Q०C) is individually experienced, thereby enabling clients and caregivers to reflect on their care experiences to improve care.

\section{Background}

In defining experienced $\mathrm{QoC}$, it is important to include the perspective of care receivers and providers in addition to frequently used normative quality indicators, such as safety, efficiency, or prevalence rates.6,12 Acknowledging the care receiver in the caregiving process, thereby understanding the needs and expectations of individual clients in home care, has attracted widespread support from both international institutions and organisations. ${ }^{13-15}$ However, existing patient-reported experience measures, such as the Consumer-Quality Index, do not capture the client's journey through the process, which is important for establishing the experienced QoC. ${ }^{16}$ It was primarily developed to provide external accountability, public reporting, and general quality improvements and it failed to address the needs of individual clients and caregivers to improve the primary care 
process. ${ }^{17}$ In addition to the clients' perspective, there is ongoing movement to include the experiences of both formal and informal caregivers within the caring process. ${ }^{18}$ Care provision and experiences with care depend on how we define ourselves and how we relate to others within a social network, as suggested by the relationship-centred care (RCC) approach. ${ }^{18,19}$ RCC places personhood and the importance of care relationships at its core, described as 'human interactions grounded in clinical caring processes'. ${ }^{20}$ Although the essence of home care provision can be viewed as meeting clients' needs, the dynamic relationship between clients and caregivers should be accounted for to understand the individual experiences with home care services. ${ }^{21,22}$

In a previous study on conceptualising quality in long-term care the INDividually EXperienced QUAlity of Long-term care (INDEXQUAL) framework was developed, describing the care process and general concepts related to the experienced quality of long-term care (both home and nursing home care) from a RCC perspective (see Figure 3.1). ${ }^{23}$ The framework was developed based on an iterative literature review of existing frameworks and consultation with stakeholders from different long-term care settings. The development of INDEXQUAL was informed by frameworks such as the Senses Framework, SERVQUAL, and the Quality-Caring Model. ${ }^{20,24,25}$ For instance, the Senses Framework's six senses (security, continuity, belonging, significance, purpose and achievement) are seen as the basis of personal needs, shaping individual care experiences from RCC. ${ }^{26}$ By integrating insights from this and other frameworks, the importance of care relationships throughout the care process for experienced QoC was emphasized. INDEXQUAL describes experienced quality in terms of expectations before care is provided, experiences during the actual care provision taking place in care relationships, and an evaluation of this experience afterwards. Each individual is unique in terms of personal characteristics, influencing their quality experience with the caring context. ${ }^{27,28}$ Clients and formal and informal caregivers can hold converging or diverging views about key features of home care provision, such as determining when care needs are met. ${ }^{29}$ It is therefore expected that both clients and caregivers in the home care environment have unique representations of the care process. However, it is unknown what these representations from different perspectives entail relating to the experienced quality in home care. 
Figure 3.1 INDEXQUAL - conceptual model of experienced quality of long-term care. ${ }^{15}$

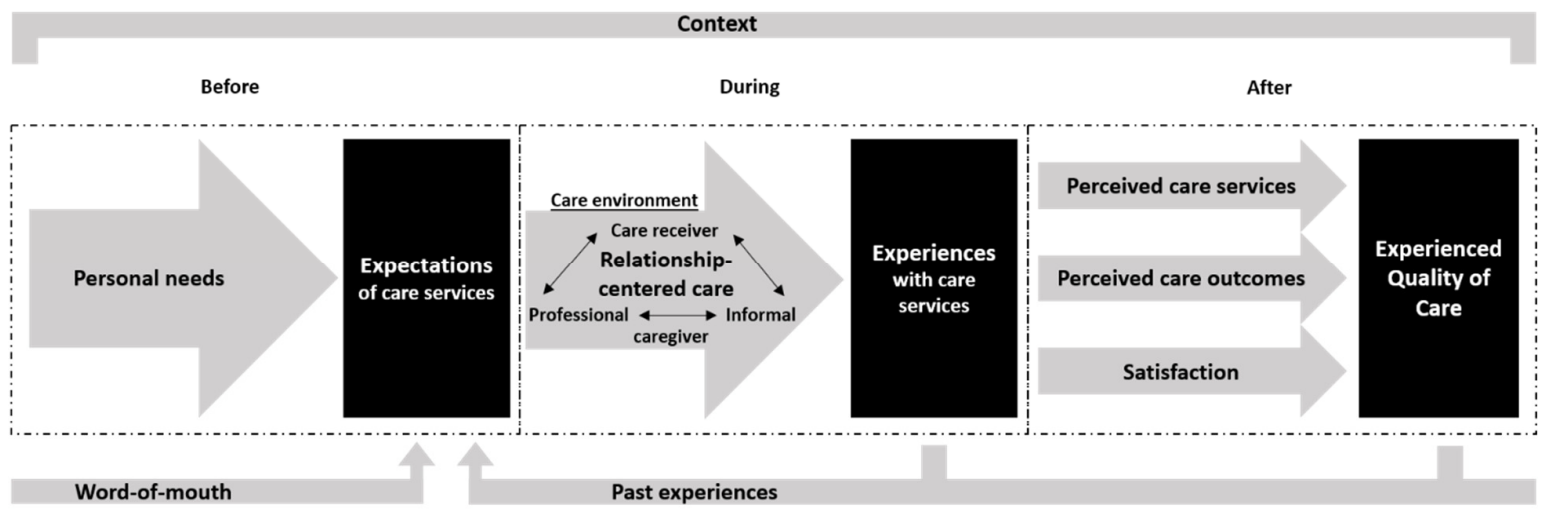

Although the INDEXQUAL framework describes the care process related to experienced QoC services in general, it requires further operationalisation for the home care setting when measuring experienced $\mathrm{QoC}$. Thus, evaluating experienced $\mathrm{QoC}$ is dependent on the process of care, its context, and the perspectives of the people who are involved. ${ }^{15}$ It is therefore essential to investigate the attributes determining experienced quality from the perspective of the client and from formal and informal caregivers. This is necessary to operationalise, evaluate, and ultimately improve the experienced QoC in home care.

\section{THE STUDY}

\section{Aim}

This study sought to explore and understand the views of clients, and formal and informal caregivers about the experienced quality of home care for older people.

\section{Design}

A descriptive, qualitative study was conducted using individual, semi-structured interviews with clients, their informal and formal caregivers. Insight from a pre-study into existing experienced quality frameworks and the INDEXQUAL provided guidance for data collection and analyses. ${ }^{30}$

\section{Setting and sample}

The research took place within two publicly funded, team-based home care organisations of the Living Lab in Ageing and Long-Term Care South Limburg. ${ }^{30}$ Three perspectives in existing home care triads were included in this study, consisting of one client, one informal caregiver, and one home care nurse/assistant. Purposive sampling was executed based on the client's experienced care relationship perceived by the formal caregiver, where a balance was strived for regarding less complex vs more complex relationships or 
situations, presence of an informal caregiver (spouse or other), and the client's residence (living in the community or sheltered housing estate). All informal caregivers were eligible, and formal caregivers were eligible if they currently worked in Dutch home care as a district nurse, registered nurse, or nurse assistant and were recruited to vary in function. Participants were recruited via the district nurses from the participating organisations. Home care clients living at home and their direct (most active/involved) formal caregiver were identified and contacted by the district nurse. Participating clients were (in the district nurses' opinion) both mentally and physically able, and received care from both informal and formal caregivers. District nurses first consulted their clients, formal and informal caregivers before providing contact information. Those willing to be approached received a letter informing them of the purpose of the study. They were contacted by telephone by the research team and asked to participate in a face-to-face interview. Participants were recruited until data saturation was reached.

\section{Data collection}

Individual semi-structured interviews were scheduled at a location preferred by the participant. The interviews were preferably conducted separately with participants. If necessary, the informal caregiver could support the client in the interview but was asked to not actively engage in the conversation (e.g. in case a client had trouble speaking clearly). The planned duration of the interviews was one hour. A topic list, guided by the INDEXQUAL framework for the client and formal and informal caregiver, was used (Appendix, Table A3.4). The researcher took notes during the interviews, later fleshed out these notes with details, and used them as data along with the interviews.

For participants needing help in elaborating on some of the abstract topics (three clients, one informal and three formal caregivers), questions were facilitated using photo elicitation during the interviews. ${ }^{31}$. Using photos in combination with asking questions may elicit information in a different manner than using words alone. ${ }^{32} \mathrm{~A}$ collection of generic photos (e.g. people, animals, objects, landscapes, and scenery) from the MyHomeLife visual inquiry tool was used. ${ }^{33}$ Participants selected a photo best representing their feelings about a certain topic (e.g. for the relationship with the caregiver) and were asked to

explain their choice. Afterwards, participants were asked to fill in a number of demographics.

Ethical considerations

The study protocol was approved by the medical ethics committee (METCZ20180003), which concluded that the study did not fall under the scope of the Medical Research Involving Human Subjects Act. Participants were informed about the aim and expected burden of the study verbally and in writing, and gave their written informed consent to voluntarily participate and have the conversation audiotaped. 


\section{Data analysis}

All interviews were audiotaped and transcribed verbatim. Field notes were taken by the interviewer to log the context of the interviews and provide meaning to the reported experiences. Paraphrasing was used during and after individual interviews to determine accuracy and correct interpretation with the participant. All interviews were analysed by means of directed content analysis using MAXQDA Standard 2018. ${ }^{34}$ The themes of INDEXQUAL were used as a priori coding themes (Table 3.1). Using condensation, each previously coded meaning unit was shortened while preserving the core meaning. ${ }^{35} \mathrm{Next}$, the condensed text was interpreted using a higher logical level, also known as abstraction. This was followed by sorting, labelling, and categorising the abstracted text, for which categories and subcategories were constructed deductively. Two researchers (RH \& TTL) individually coded six transcripts (first and fourth triad) to assess and increase confirmability between researchers. A third independent rater (SZ) assessed the coding process by random sampling. Throughout the analysis, both researchers (RH \& $T L L)$ reflected on the data and discussed the discovery of possible new (sub)categories. All research steps and argumentation processes were logged and reported in a detailed codebook throughout the data analysis. Afterwards, all participants were invited for a group meeting. During this meeting, participants received a presentation of the findings and were asked to reflect on any omissions.

Table 3.1. A priori themes and operational definitions, based on the INDEXQUAL framework

\begin{tabular}{ll}
\hline Theme & Operational definition \\
\hline $\begin{array}{l}\text { Personal needs } \\
\text { Word-of-mouth }\end{array}$ & $\begin{array}{l}\text { Individual needs related to home care services. } \\
\text { Personal and non-personal statements made by } \\
\text { parties other than care organisation or care receiver, } \\
\text { conveying expectations of home care services. } \\
\text { Emotional judgements on previous care experiences } \\
\text { beyond the home care services. }\end{array}$ \\
Expectations of care services & $\begin{array}{l}\text { Desired and/or adequate expectations of home care } \\
\text { service quality. } \\
\text { Interpersonal attributes of relationships influencing } \\
\text { belationship-centred care attributes }\end{array}$ \\
both expected and experienced care quality. \\
Emotional judgement about the sum of all care \\
interactions related to home care services. \\
Care receiver characteristics and the setting in which \\
care is delivered.
\end{tabular}




\section{Rigour}

Several strategies recommended by Korstjens, Moser ${ }^{36}$ were used to meet the criteria of credibility, transferability, dependability, confirmability, and reflexivity, thereby strengthening the trustworthiness of this study. ${ }^{37}$ To increase credibility, the results were presented during two group meetings with nine participants to verify correct interpretation and completeness of the results. To enhance transferability, a detailed description was made on the context of the research, setting, sample, demographics, and exemplary quotes. Furthermore, a detailed codebook was made to keep track of all theory-driven (themes) and data-driven codes (categories and subcategories) during the analysis.

\section{FINDINGS}

\section{Participants}

Between April 2018 and November 2018, a total of 18 semi-structured interviews with 16 participants were conducted and lasted 54 minutes on average. One formal caregiver (district nurse) participated in three different care triads as the formal caregiver. Interviews took place in six existing home care triads, each consisting of a client and an informal and formal caregiver. Table 3.2 provides information about the context of each triad and demographics of the participants. 
Table 3.2. Demographics of individual triads $(N=16)$.

\begin{tabular}{|c|c|c|c|c|}
\hline Triad & Care needs & Client & Informal caregiver & Formal caregiver \\
\hline 1 & $\begin{array}{l}\text { Activities of daily living (ADL) } \\
\text { support (personal hygiene, } \\
\text { compression stockings, eye } \\
\text { drops) ostomy care, medication } \\
\text { assistance, wound treatment }\end{array}$ & $\begin{array}{l}\text { M, 77y, married, } 7 \mathrm{~h} \\
\text { home care } \quad \text { (since } \\
\begin{array}{l}5.5 \mathrm{y}), \\
\text { domestic, }\end{array}\end{array}$ & $\begin{array}{l}\text { F, 77y, wife, Iwc, 30h } \\
\text { inf. care }\end{array}$ & $\begin{array}{lr}\text { F, 25y, district } \\
\text { nurse, } \\
\text { contract, } 36 \mathrm{y} \text { exp }\end{array}$ \\
\hline 2 & $\begin{array}{l}\text { ADL support (personal hygiene, } \\
\text { meal preparation) }\end{array}$ & $\begin{array}{l}\mathrm{F}, 96 \mathrm{y}, \text { widow, } 3.5 \mathrm{~h} \\
\text { home care (since } \\
5 \mathrm{y}), 3.3 \mathrm{~h} \text {. domestic }\end{array}$ & $\begin{array}{l}\text { F, 67y, daughter, not } \\
\text { Iwc, 46h Inf. care }\end{array}$ & $\begin{array}{l}\text { F, 25y, district } \\
\text { nurse, } \quad 36 \mathrm{~h} \\
\text { contract, } 3 y \text { exp }\end{array}$ \\
\hline 3 & $\begin{array}{l}\text { ADL support (personal hygiene, } \\
\text { dressing), } \\
\text { assistance }\end{array}$ & $\begin{array}{l}\text { F, 84y, married, } \\
3.5 \mathrm{~h} \text { home care } \\
\text { (since } 3 y \text { ), } 4 \mathrm{~h} \\
\text { domestic }\end{array}$ & $\begin{array}{l}\text { M, 83y, husband, } \\
\text { Iwc, } 42 \mathrm{~h} \text { Inf. care }\end{array}$ & $\begin{array}{l}\mathrm{F}, \quad 25 \mathrm{y}, \quad \text { district } \\
\text { nurse, } \quad 36 \mathrm{~h} \\
\text { contract, } 3 y \text { exp }\end{array}$ \\
\hline 4 & $\begin{array}{l}\text { ADL support (personal hygiene, } \\
\text { compression stockings, meal } \\
\text { preparation), } \\
\text { assistance }\end{array}$ & $\begin{array}{l}\mathrm{F}, 86 \mathrm{y}, \text { married, } 7 \mathrm{~h} \\
\text { home care } \text { (since } \\
\begin{array}{l}1.5 \mathrm{y}), \\
\text { domestic }\end{array}\end{array}$ & $\begin{array}{l}\text { M, 86y, husband, } \\
\text { Iwc, 24h Inf. care }\end{array}$ & $\begin{array}{l}\mathrm{F}, \quad 31 \mathrm{y}, \quad \text { nurse } \\
\text { assistant, } 24 \mathrm{~h} \\
\text { contract, } 4 \mathrm{y} \text { exp }\end{array}$ \\
\hline 5 & ADL support (personal hygiene) & $\begin{array}{l}\mathrm{M}, 86 \mathrm{y}, \text { married, } 7 \mathrm{~h} \\
\text { home care (since } \\
1.5 \mathrm{y}), 2 \mathrm{~h} \text { domestic }\end{array}$ & $\begin{array}{l}\text { F, 67y, wife, Iwc, } \\
67.2 \mathrm{~h} \text { Inf. care, pjob }\end{array}$ & $\begin{array}{lr}\text { F, 63y, registered } \\
\text { nurse, } & 24 \mathrm{~h} \\
\text { contract, } & 15 y \text { exp }\end{array}$ \\
\hline 6 & $\begin{array}{l}\text { ADL support (personal hygiene, } \\
\text { compression stockings, eye } \\
\text { drops) }\end{array}$ & $\begin{array}{l}\mathrm{F}, 85 \mathrm{y}, \text { married, } 3 \mathrm{~h} \\
\text { home care } \text { (since } \\
\begin{array}{l}5.5 \mathrm{y}), \\
\text { domestic }\end{array}\end{array}$ & $\begin{array}{l}\text { M, 59y, cousin, Iwc, } \\
4 \mathrm{~h} \text { Inf. care }\end{array}$ & $\begin{array}{l}\text { F, 61y, nurse } \\
\text { assistant, } 30 \mathrm{~h} \\
\text { contract, } 30 y \text { exp }\end{array}$ \\
\hline
\end{tabular}

Identified categories per experienced quality theme

An overview of the findings based on the a priori themes is listed in Table 3.3. Next, we will discuss the discovered attributes (both categories and subcategories) following the order of the individual themes of the INDEXQUAL framework. Following that, the findings per theme are presented by combining the perspectives of the client and the informal and formal caregiver. 
Table 3.3. Categories and subcategories based on the a priori main themes

\begin{tabular}{|c|c|c|}
\hline Themes & Categories & Subcategories \\
\hline Personal needs & $\begin{array}{l}\text { Type of personal need } \\
\text { Dealing with personal needs }\end{array}$ & $\begin{array}{l}\text { Care needs, social needs, emotional needs } \\
\text { Communicating needs, fulfilling needs, } \\
\text { professional standard conflicting with needs }\end{array}$ \\
\hline Word-of-mouth & Compare care provision with others & \\
\hline Past experience & $\begin{array}{l}\text { Past experience former care services } \\
\text { at home (e.g. other home care team, } \\
\text { organisation, or domestic care) } \\
\text { Past experience institutionalised care } \\
\underline{\text { services (e.g. hospital admission) }}\end{array}$ & \\
\hline $\begin{array}{l}\text { Expectations of care } \\
\text { service }\end{array}$ & $\begin{array}{l}\text { Based on previous experience } \\
\text { current home care services } \\
\text { Based on familiarity formal caregiver } \\
\text { Based on available information and } \\
\underline{\text { communication }}\end{array}$ & \\
\hline \multirow[t]{3}{*}{$\begin{array}{l}\text { Relationship-centred } \\
\text { care }\end{array}$} & Type of care relationship & $\begin{array}{l}\text { Personal care and/or professional care } \\
\text { relationship }\end{array}$ \\
\hline & Aspects of care relationships & $\begin{array}{l}\text { Knowing and understanding the other, } \\
\text { opening up to the other, thinking along with } \\
\text { the other, trusting the other, motivating the } \\
\text { other }\end{array}$ \\
\hline & $\underline{\text { Balance between care relationships }}$ & Polarisation/form subgroup, equality \\
\hline \multirow[t]{4}{*}{$\begin{array}{l}\text { Experiences with care } \\
\text { services }\end{array}$} & $\begin{array}{l}\text { Aspects influencing the care } \\
\text { experience }\end{array}$ & $\begin{array}{l}\text { Small regular care team, perceived availability } \\
\text { of time, following up care appointments, } \\
\text { personal factors }\end{array}$ \\
\hline & $\underline{\text { Integrating care with daily life }}$ & $\begin{array}{l}\text { Discovering (former) way of living, care } \\
\text { routines, fit care planning with way of life }\end{array}$ \\
\hline & Working together with each other & Sharing common goal \\
\hline & Open communication & Humour, addressing sensitive topics \\
\hline Context & $\begin{array}{l}\text { Organisational and occupational } \\
\underline{\text { aspects }}\end{array}$ & Role conflict, working conditions \\
\hline
\end{tabular}

Personal needs. Based on the responses of participants relating to the type of personal needs, most participants mentioned current care needs for which home care was needed (e.g. help with personal hygiene). In addition, some also mentioned emotional needs (e.g. dealing with grief) and social needs (e.g. need for a conversation).

With respect to dealing with personal needs, participants often mentioned ways in which they communicated about personal needs (e.g. discovery of personal needs by formal caregivers). Also discussed were the topics of describing the care process and activities to fulfil the client's needs. Formal caregivers mostly focused on how to discover (hidden) personal needs of their clients. In some instances, the formal caregiver was aware of a client's unfulfilled personal need. The type of care need was, however, seen as conflicting with professional care standards and thus, falling outside that person's role as 
professional caregiver (e.g. clipping of nails). In two cases, care needs were determined based on professional standards (e.g. what would be best for the client), as opposed to accepting the personal client's needs (e.g. what does the client want).

Word-of-mouth. Regarding word-of-mouth information, some clients compared their care provision with others, for instance based on information received from relatives and neighbours. Participants mentioned this when the care was seen as out of line compared to the word-of-mouth information. For instance, one client heard that her friend receives home care from two formal caregivers and was therefore dissatisfied with the large number of different formal caregivers from whom she receives care:

[I would like] a more fixed team of formal caregivers. . . My friend in Maastricht, she has the same formal caregivers. Only those two. (client 6)

Past experiences. Past experiences with former home care services were described by both clients and informal caregivers. This was mostly a result of moving to a different house and changing the home care organisation. Although the quality of medical care was often seen as similar between different services, a comparison was made between previous and current formal caregivers. From a caregiver's perspective, one nurse assistant mentioned that her past experience working in a different team resulted in trying to motivate her client to become more self-reliant:

I already came from another team, well they valued self-management highly. So, if you can wash yourself . . . then we will not do it. (formal caregiver 1)

Past experiences in an institutionalised care setting (e.g. hospital admission) in some cases led to a comparison between formal caregivers in the two different care settings. One client was very dissatisfied about care received during hospital intake, especially when he compared the formal caregivers in the two settings:

I receive very warm-hearted (home) care, warm-hearted care and that actually differs completely compared to the general hospital, it differs completely! They [in the hospital] are not sensitive, they are more business-like. (client 5)

Expectations of care service. With regards to expectations in home care, most expected a continuity of care based on previous care experiences with current home care services. However, both clients and informal caregivers mentioned that knowing which familiar formal caregiver to expect helped to create more realistic expectations about the care. For instance, one informal caregiver clearly indicated that her mother does not like to be showered, and only one specific caregiver would succeed in this task: 
If you say [specific caregiver] is coming in the morning, then you already almost certainly know she will get her into the shower. Because my mother never really wants to be showered. (informal caregiver 6)

The availability of information obtained from patient files or speaking with colleagues about the client helped the formal caregivers to create a clear picture of both the clients' care expectations and their own expectations as caregivers. Some formal caregivers, however, preferred to provide care with as little pre-obtained information, other that medical information, of the client as possible:

If you're blank [no information beforehand], of course you look with a much broader view . . . except for the medical aspects, those things I would indeed like to know. (formal caregiver 6)

Relationship-centred care attributes. Care relationships were seen as important in home care, and two types of care relationships can be distinguished based on the responses: a professional and a personal care relationship. A professional care relationship was often seen as being the result of providing appropriate medical care. On the other hand, a personal care relationship (e.g. having a 'connection') was strived for by most. Participants noted aspects of care relationships as knowing and understanding others in the home care environment. Opening up and thinking along with others, in addition to trusting and motivating each other during care provision, were seen as important aspects for personal care relationships. Some formal caregivers indicated that a more complicated medical condition made it easier to build a personal care relationship with their client. One formal caregiver reflected on how 'being liked' by others helped her to form personal care relationships and be trusted:

If people like you, they are more inclined to trust you. With others . . you will really need to prove that you are capable of things. And if you are only there to administer eye drops ... then of course you cannot prove yourself. (formal caregiver 6 )

In addition, discovering similarities with clients (e.g. hobby) or just the amount of time spent together were also seen as fundamental in building a personal care relationship:

If you do have a 'connection' with people or a similar background, it is of course easier to build a relationship than when you don't. (formal caregiver 6)

Informal caregivers regarded care provision as something that is naturally done for a spouse or relative, and as gradually increasing when a relative is in need of more (intense) care. Clients focused mostly on reasons why they did or did not prefer specific caregivers. However, some clients pointed out that they do not look for a 'connection' with their formal 
caregiver at all and prefer to have a more professional care relationship. Often, a more pleasant formal caregiver was linked to having the right personal 'characteristics', providing 'warm cooperative care' or just being 'nice'. The picture of holding hands and embracing people was often used by participants to describe their feeling of a care relationship with their formal caregiver, as the following quote shows:

The card with the two holding hands. . . Yes, this already illustrates it. The warmth, it is probably a child's hand holding an adult, but the fact that it goes hand-in-hand. Yes, that is how it feels, hand-in-hand. (client 5)

In terms of the balance between care relationships, clients and their spousal informal caregivers in our sample expressed feelings of a strong unity. This sometimes led to forming a subgroup within the care context, thereby increasing the personal distance with the formal caregiver. This was especially the case when clients and informal caregivers indicated a large number of differing formal caregivers, without a clear preference for one specific caregiver. However, in one occurrence, the spousal informal caregiver expressed a strong connection with the formal caregiver. In this case, the informal caregiver mentioned that her husband tried to polarise against the formal caregiver, to undermine the authority of the formal caregiver.

Experiences with care services. With regard to how care is experienced, some aspects influencing care experiences were important for participants to have a positive outcome. Most of the clients and informal caregivers valued a small number of formal caregivers, despite recognising that this might not always be possible. Some clients and informal caregivers (mostly spouses) communicated a clear preference for certain personal factors related to positive care experiences (e.g. do not like to be showered by a male caregiver), and they stressed the importance of the right care being provided at the right time. Although formal caregivers indicated that the availability of time per client is limited, they stressed that clients should not experience time pressure:

It's the most pleasant if you always get the same caregivers, but that does not happen. It changes quite often. (client 5)

Integrating care with daily life by discovering the former way of living before care was needed was mentioned by a number of formal caregivers. This varied from applying makeup to finding subjects to talk about and adjusting care planning in order to fit care with personal life. These 'discovered extras' were personally valued from all perspectives and important in care routines fitting with clients' previous and current ways of living: 
I think it's very important to pay attention to the period in their lives where they lived independently. What did you do back then? Did you apply make-up or not? (formal caregiver 5)

Clients and formal and informal caregivers considered working together with each other, thereby sharing a common goal in the care process, as vital in establishing proper care. Some formal caregivers found it important that the type of care should be tailored to the client's experiences, thereby potentially ignoring their own experiences as a caregiver. However, some formal caregivers struggled in coping with negative experiences of a client as a result of their professional care (e.g. first-time provision of incontinence pants). Others, however, had to provide care using medical aides (compression garments) because of their own medical condition as a caregiver. In two cases, this had resulted in conflicts and resistance to care by the client. One client elaborated on an occasion when she was initially not pleased about the introduction of a new care aide, although now being satisfied about the outcome and knowing the reason why this care aide was needed:

Of course they have quarrelled a lot with me about putting on the stockings . . but now I think it's ok. And also for the girl [formal caregiver], she had a hand condition. (client 1)

Finally, establishing open communication was seen as important for the care experience. Formal caregivers indicated that they strived for a caring environment where both clients and informal caregivers openly communicate and reflect on care experiences. Informal caregivers and clients, despite being aware of the limited time available, shared this view. Furthermore, humour was seen as important from all perspectives to create a more relaxing atmosphere. This was especially true when specific care tasks were seen as potentially discomforting for the client. Different ways to address sensitive topics during care provision (e.g. loss of a partner) were discussed and were seen as important for the QoC.

Context. The context of the participants involved information about team, organisational, and occupational aspects. Most formal caregivers described their role and how it conflicted with performing certain informal and care tasks. One example noted especially was the inability to drink a cup of coffee with a client or perform specific medical tasks without consulting a GP first. Some perceived this as influencing their autonomy as formal caregivers:

[Relating to a specific medical procedure] yes, we did that before, we just did that! And now that is not allowed. . . . While you do it on your own professional insight and competence. Hey, I know how it should be done, because it was taught to me a long time ago. And now you must ask a physician for permission. (formal caregiver 2) 
Discontent about working conditions such as the terms of employment of formal caregivers was mentioned by all perspectives. A shortage of staff in their team was mentioned by some formal caregivers and was related to feelings of work pressure, a lack of energy, and the effect it might have on the QoC provided. Some informal caregivers were also aware of these working conditions within the care organisation. They indicated that they were understanding towards individual formal caregivers and the negative consequences for their lives and the life of the client (e.g. scheduling issues). Relating to the work atmosphere in the organisation or team, some mentioned that there currently is no structure or safe environment to discuss or evaluate individual care situations:

I am full of admiration, also for the pressure they have at the moment with actually far too few staff. . . . I do worry for them because I'm afraid they cannot cope with the pressure at a given moment. (informal caregiver 2)

\section{DISCUSSION}

This study found a variety of attributes throughout the caregiving process. Before care was provided, some personal needs conflicted with professional care standards and thus, fell outside the caregiver's professional standards. Anticipating a familiar formal caregiver helped clients form realistic expectations of fulfilling these needs. During care provision, care routines fitting with the care receiver's former way of living were seen as important contributors to experienced $\mathrm{QoC}$ in home care. For the relationship between client and formal caregiver, a more 'close' personal care relationship was preferred over a more 'detached' professional care relationship. Other attributes that were seen as beneficial for positive care experiences were a small number of caregivers, perceived sufficient time for care provision, and a caring atmosphere facilitating open communication and humour. Aspects on an organisational, team, or occupational level such as staff shortages and work pressure influenced QoC from a contextual level in home care.

This study contributes to understanding the individual attributes shaping the experienced QoC from multiple perspectives and underlines the importance of simultaneously applying aspects of both individualised and RCC in providing home care. Although most attributes were described by at least two perspectives (Appendix, Table A3.5), some attributes were not mentioned by the other perspectives as related to experienced quality. These differences in perspectives show that obtaining insight into the perspective of the other as well as sharing one's own perspective in home care are of great importance for providing the desired care and determining the experienced QoC. Therefore, a true understanding of the experiences, concerns, and viewpoints from the participating perspectives should be strived for, as well as the ability to communicate these 
insights insights. ${ }^{38}$ To truly understand the perspective of the other, putting one's own mental frame, beliefs, assumptions, knowledge, and experience temporarily on hold may be necessary. ${ }^{39}$ This notion is supported by RCC, in which all relationships between the perspectives are considered and are deemed necessary to provide high QoC. ${ }^{18,20,40}$ Care relationships, based on trust between people of old age and general nursing staff, are a key element in determining QoC. ${ }^{41}$ Our results show that feelings of trust and opening up to each other were seen as important attributes in personal care relationships and QoC in home care from all perspectives. This is also recognised by the new Dutch quality framework for home care, stating that formal home care is inextricably linked to building trustful and equal care relationships. ${ }^{11}$

This study and others demonstrate that experienced QoC is a great deal more than meeting perceived care outcomes, and more focus is needed to gain insight into attributes of experienced QoC and the relationships in the care environment. ${ }^{42,43}$ To obtain the most valid view of QoC, the importance of implementing self-reported measures from several perspectives in the home care environment should be acknowledged. ${ }^{44}$ The INDEXQUAL framework proved a robust guide in our quest to chart the care process in which no additional data emerged that could not be mapped onto the initial themes. It, however, was not developed to operationalise experienced quality for a specific long-term care setting. In this study, we aimed, as a first step, towards investigating relevant attributes of experienced QoC in home care. Further work should go towards understanding the needs and requirements for developing a measurement for experienced $\mathrm{Q} O \mathrm{C}$ in this setting.

\section{Limitations}

Several limitations require consideration. First, participants were asked about experiences and attributes with the caring process at one point in time. Consequently, a possible recall bias is present that could have resulted in a misclassification of care expectations, previous care interactions, and possible outcomes by the participants. To control for this, participants were encouraged to provide concrete examples of care interactions during the interviews. Second, one district nurse participated in three care triads, which could have resulted in over-representation of her perspective. During the analyses, this was taken into consideration by combining and mitigating the results of all caregivers before interpreting the findings. Third, the interviewers and interviewees did not have an existing relationship prior to the interviews. This might have inhibited participants from talking openly. Participants were therefore interviewed in the environment of their preference, efforts were made to make participants feel at ease beforehand, and some interviews were held in dialect when preferred. Fourth, the components of the framework used in this study were used both as general topics in the interview guide as well as coding themes in analysing the findings. To account for possible confirmation bias, participants were 
encouraged to elaborate on other relevant topics related to their experienced care quality beyond the interview guide questions, for example by using photo elicitation.

\section{Conclusion}

Older people living at home receive more prolonged home care as a result of ageing in place policies; thus, more attention should go to long-term care relationships between clients and (in)formal caregivers. Since receiving care is generally regarded as a discontinuity of one's past life, our results show that care routines should fit with the client's former way of living to improve the experienced QoC. Care relationships based on trust and openness to each other should be strived for in general, while providing space to account for individual differences. Clients as well as caregivers should be aware of the perspective of the other when evaluating care experiences. Attention should be paid to gaining insight into individual preferences relating to the home care process. The findings have implications for how to operationalise experienced QoC by a variety of care attributes from multiple perspectives. The attributes found in this study can help home care organisations and professionals in understanding experienced quality from a RCC approach. However, more research is needed to develop instruments to structurally assess experienced QoC in home care. It is furthermore a necessity to determine which attributes are most relevant for each care context to account for individual preferences. 


\section{REFERENCES}

1. de São José J, Barros R, Samitca S, Teixeira A. Older persons' experiences and perspectives of receiving social care: a systematic review of the qualitative literature. Health \& Social Care in the Community. 2016;24(1):1-11.

2. Wiles JL, Leibing A, Guberman N, Reeve J, Allen RES. The Meaning of "Aging in Place" to Older People. The Gerontologist. 2012;52(3):357-366.

3. Wilberforce $M$, Challis $D$, Davies L, Kelly MP, Roberts C. The preliminary measurement properties of the person-centred community care inventory (PERCCI). Quality of Life Research. 2018;27(10):2745-2756.

4. O'Connor M, Davitt JK. The Outcome and Assessment Information Set (OASIS): A review of validity and reliability. Home health care services quarterly. 2012;31(4):267-301.

5. Carpenter I, Hirdes JP. Using interRAI assessment systems to measure and maintain quality of long-term care. A good life in old age. 2013:93-139.

6. Kroneman $M$, Boerma W, van den Berg $M$, Groenewegen $P$, de Jong J, vanGinneken E. The Netherlands: health system review. Health Systems in Transition. 18. 2016;2:1-239.

7. OECD/EU. Health at a Glance: Europe 2018: State of Health in the EU Cycle. 2018; https://doi.org/10.1787/health_glance_eur-2018-en.

8. Ministry of Health Welfare and Sport. Care and support at home. 2018; https://www.government.nl/topics/care-and-support-at-home/livingindependently-for-longer.

9. Galiatsatos P, Nelson K, Hale WD. Caring for the Caregiver: Identifying the Needs of Those Called to Care Through Partnerships with Congregations. Journal of religion and health. 2017;56(3):946-950.

10. Anker-Hansen C, Skovdahl K, McCormack B, Tønnessen S. The third person in the room: The needs of care partners of older people in home care services-A systematic review from a person-centred perspective. Journal of Clinical Nursing. 2018;27(7-8):e1309-e1326.

11. Stuurgroep Kwaliteitskader Wijkverpleging. Kwaliteitskader Wijkverpleging. 2018; https://www.zorginzicht.nl/kwaliteitsinstrumenten/wijkverpleging-kwaliteitskader. Accessed 15th Oktober, 2019.

12. Wolfe A. Institute of Medicine Report: Crossing the Quality Chasm: A New Health Care System for the 21st Century. Policy, Politics, \& Nursing Practice. 2001;2(3):233-235.

13. Luxford K, Safran DG, Delbanco T. Promoting patient-centered care: a qualitative study of facilitators and barriers in healthcare organizations with a reputation for improving the patient experience. International Journal for Quality in Health Care. $2011 ; 23(5): 510-515$.

14. Ritchie CS, Leff B, Garrigues SK, Perissinotto C, Sheehan OC, Harrison KL. A Quality of Care Framework for Home-Based Medical Care. Journal of the American Medical Directors Association. 2018;19(10):818-823.

15. Koksma J-J, Kremer JA. Beyond the Quality Illusion: The Learning Era. Academic medicine: journal of the Association of American Medical Colleges. 2018;94(2):166-169.

16. Triemstra M, Winters S, Kool RB, Wiegers TA. Measuring client experiences in longterm care in the Netherlands: a pilot study with the Consumer Quality Index Longterm Care. BMC health services research. 2010;10(1):95.

17. Voorhees CM, Fombelle PW, Gregoire Y, et al. Service encounters, experiences and the customer journey: Defining the field and a call to expand our lens. Journal of Business Research. 2017;79:269-280.

18. McCormack B, Roberts T, Meyer J, Morgan D, Boscart V. Appreciating the 'person' in long-term care. International Journal of Older People Nursing. 2012;7(4):284294. 
19. Soklaridis S, Ravitz P, Nevo GA, Lieff S. Relationship-centred care in health: A 20year scoping review. Patient Experience Journal. 2016;3(1):130-145.

20. Duffy JR, Hoskins LM. The quality-caring model@): Blending dual paradigms. Advances in Nursing Science. 2003;26(1):77-88.

21. Tronto JC. Moral boundaries: A political argument for an ethic of care. Psychology Press; 1993.

22. Fine MD. A caring society?: care and the dilemmas of human service in the twentyfirst century. Houndmills, Basingstoke; New York: Macmillan International Higher Education; 2006.

23. Sion KYJ, Haex R, Verbeek $\mathrm{H}$, et al. Experienced Quality of Post-Acute and LongTerm Care From the Care Recipient's Perspective-A Conceptual Framework. Journal of the American Medical Directors Association. 2019.

24. Parasuraman A, Zeithaml VA, Berry LL. Servqual: A multiple-item scale for measuring consumer perc. Journal of retailing. 1988;64(1):12.

25. Nolan M, Brown J, Davies S, Nolan J, Keady J. The Senses Framework: improving care for older people through a relationship-centred approach. Getting Research into Practice (GRiP) Report No 2. 2006.

26. Nolan MR, Davies S, Brown J, Keady J, Nolan J. Beyond 'person-centred'care: a new vision for gerontological nursing. Journal of clinical nursing. 2004;13:45-53.

27. Chow A, Mayer EK, Darzi AW, Athanasiou T. Patient-reported outcome measures: the importance of patient satisfaction in surgery. Surgery. 2009;146(3):435-443.

28. Sandager M, Freil M, Knudsen JL. Please tick the appropriate box: Perspectives on patient reported experience. Patient Experience Journal. 2016;3(1):63-79.

29. Han SJ, Kim HK, Storfjell J, Kim MJ. Clinical Outcomes and Quality of Life of Home Health Care Patients. Asian Nursing Research. 2013;7(2):53-60.

30. Verbeek H, Zwakhalen SM, Schols JM, Hamers JP. Keys to successfully embedding scientific research in nursing homes: a win-win perspective. Journal of the American Medical Directors Association. 2013;14(12):855-857.

31. Dewar B. Using creative methods in practice development to understand and develop compassionate care. International Practice Development Journal. 2012;2(1).

32. Harper D. Talking about pictures: A case for photo elicitation. Visual studies. $2002 ; 17(1): 13-26$.

33. University of the West of Scotland. My Home Life visual inquiry cards. Scotland2017.

34. Hsieh $\mathrm{H}-\mathrm{F}$, Shannon SE. Three approaches to qualitative content analysis. Qualitative health research. 2005;15(9):1277-1288.

35. Graneheim UH, Lundman B. Qualitative content analysis in nursing research: concepts, procedures and measures to achieve trustworthiness. Nurse education today. 2004;24(2):105-112.

36. Korstjens I, Moser A. Series: Practical guidance to qualitative research. Part 4: Trustworthiness and publishing. European Journal of General Practice. 2018;24(1):120-124.

37. Lincoln YS, Guba EG. Naturalistic inquiry. London: Sage; 1985.

38. Hojat M, Gonnella JS, Nasca TJ, Mangione S, Vergare M, Magee M. Physician empathy: definition, components, measurement, and relationship to gender and specialty. American Journal of Psychiatry. 2002;159(9):1563-1569.

39. Goossensen A. Schetsen van mismatch. Een zorgethische visie op Evaluatieonderzoek Utrecht. 2014.

40. Pew-Fetzer Task Force, Tresolini CP. Health professions education and relationshipcentered care: report of the Pew-Fetzer task force on advancing psychosocial health education. Pew Health Professions Commission; 1994.

41. Fosbmder D. Patient perceptions of nursing care: an emerging theory of interpersonal competence. Journal of Advanced Nursing. 1994;20(6):1085-1093. 
42. Bjerregaard K, Haslam SA, Mewse A, Morton T. The shared experience of caring: a study of care-workers' motivations and identifications at work. Ageing \& Society. 2017;37(1):113-138.

43. Lyons KS, Zarit SH, Sayer AG, Whitlatch CJ. Caregiving as a dyadic process: Perspectives from caregiver and receiver. The Journals of Gerontology Series B: Psychological Sciences and Social Sciences. 2002;57(3):P195-P204.

44. Curyto KJ, Van Haitsma K, Vriesman DK. Direct observation of behavior: A review of current measures for use with older adults with dementia. Research in Gerontological Nursing. 2008;1(1):52-76. 


\section{APPENDIX}

Table A3.4 Topic list and exemplary questions

\begin{tabular}{|c|c|}
\hline Topic (theme) & Exemplary questions \\
\hline Home care needs (personal needs) & $\begin{array}{l}\text { Which home care services do you receive/provide } \\
\text { and does this fit with the care needs? }\end{array}$ \\
\hline \multirow[t]{2}{*}{$\begin{array}{l}\text { Expectations home care services (expectations of } \\
\text { care services }\end{array}$} & $\begin{array}{l}\text { What do you expect in the following home care } \\
\text { provision? }\end{array}$ \\
\hline & $\begin{array}{l}\text { What were the expectations when you/your next of } \\
\text { kin/your client received home care for the first time? }\end{array}$ \\
\hline \multirow[t]{2}{*}{$\begin{array}{l}\text { Care relationships } \\
\text { attributes) }\end{array}$} & $\begin{array}{l}\text { What is important in the interaction with your formal } \\
\text { caregiver/next of kin/client in home care provision? }\end{array}$ \\
\hline & $\begin{array}{l}\text { How would you describe your care relationship with } \\
\text { your formal caregiver/next of kin/client? }\end{array}$ \\
\hline \multirow{2}{*}{$\begin{array}{l}\text { Experiences with home care (past experiences/ } \\
\text { experiences with care services) }\end{array}$} & How do you experience home care (provision)? \\
\hline & $\begin{array}{l}\text { Could you think of an experience when you were very } \\
\text { satisfied or unsatisfied with the home care } \\
\text { (provision)? }\end{array}$ \\
\hline Context & $\begin{array}{l}\text { What would you like to see different in the home care } \\
\text { provision/organisation? }\end{array}$ \\
\hline
\end{tabular}


Table A3.5 Mentioned categories and subcategories per perspective

\begin{tabular}{|c|c|c|c|c|}
\hline (Theme) Category & Subcategory & Clients & $\begin{array}{c}\text { Informal } \\
\text { caregivers }\end{array}$ & $\begin{array}{c}\text { Formal } \\
\text { caregivers }\end{array}$ \\
\hline \multirow[t]{3}{*}{ - (PN) Type of personal need } & - Care needs & $\mathrm{x}$ & $x$ & $\mathrm{x}$ \\
\hline & - Social needs & $x$ & & \\
\hline & - Emotional needs & & & $x$ \\
\hline \multirow[t]{3}{*}{$\begin{array}{l}\text { - (PN) Dealing with personal } \\
\text { needs }\end{array}$} & $\begin{array}{l}\text { - Communicating } \\
\text { needs }\end{array}$ & $x$ & $\mathrm{x}$ & $\mathrm{x}$ \\
\hline & - Fulfilling needs & $x$ & $x$ & $x$ \\
\hline & $\begin{array}{l}\text { - Professional } \\
\text { standard conflicting } \\
\text { with needs }\end{array}$ & & $x$ & $\mathrm{x}$ \\
\hline $\begin{array}{l}\text { - (WoM) Compare care } \\
\text { provision with others }\end{array}$ & & $\mathrm{x}$ & $\mathrm{x}$ & \\
\hline $\begin{array}{l}\text { - (PEXP) Past experience } \\
\text { former care services at home }\end{array}$ & & $x$ & $\mathrm{x}$ & $x$ \\
\hline $\begin{array}{l}\text { - (PEXP) Past experience } \\
\text { institutionalized care services }\end{array}$ & & $\mathrm{x}$ & $\mathrm{x}$ & $\mathrm{x}$ \\
\hline $\begin{array}{l}\text { - (ECS) Based on previous } \\
\text { experience current home care } \\
\text { services }\end{array}$ & & & $\mathrm{x}$ & $\mathrm{x}$ \\
\hline $\begin{array}{l}\text { - (ECS) Based on familiarity } \\
\text { formal caregiver }\end{array}$ & & $x$ & $x$ & \\
\hline $\begin{array}{l}\text { - (ECS) Based on available } \\
\text { information and } \\
\text { communication }\end{array}$ & & & $\mathrm{x}$ & $\mathrm{x}$ \\
\hline $\begin{array}{l}\text { - }(\mathrm{RCC}) \text { Type of care } \\
\text { relationship }\end{array}$ & $\begin{array}{l}\text { - Personal care } \\
\text { and/or professional } \\
\text { care relationship }\end{array}$ & $x$ & $x$ & $x$ \\
\hline \multirow[t]{5}{*}{$\begin{array}{l}\text { - }(\mathrm{RCC}) \text { Aspects of care } \\
\text { relationships }\end{array}$} & $\begin{array}{l}\text { - Knowing and } \\
\text { understanding the } \\
\text { other }\end{array}$ & $x$ & $x$ & $x$ \\
\hline & $\begin{array}{l}\text { - Opening up to the } \\
\text { other }\end{array}$ & $x$ & & \\
\hline & $\begin{array}{l}\text { - Thinking along with } \\
\text { the other }\end{array}$ & $x$ & $\mathrm{x}$ & $x$ \\
\hline & - Trusting the other & & & $x$ \\
\hline & $\begin{array}{l}\text { - Motivating the } \\
\text { other }\end{array}$ & $\mathrm{x}$ & & $\mathrm{x}$ \\
\hline
\end{tabular}


- (RCC) Balance between care relationship

- (EXPCS) Aspect influencing the care experience

- (EXPCS) Integrating care with daily life

- (EXPCS) Working together with each other

- (EXPCS) Open communication

- (CON) Organisational and occupational aspects
- Polarisation/form subgroup

- Equality

- Small regular care team

- Perceived availability of time

- Following up care appointments

- Personal factors

- Discovering (former) way of living

- Care routines

- Fit care planning with way of life

- Sharing common goal

- Humour

- Addressing sensitive topics

- Role conflict

- Working conditions
X

$\mathrm{x}$

X

X

$\mathrm{x}$

$\mathrm{x}$

X

X

$\mathrm{x}$

$\mathrm{x}$

X

X $x$

$P N=$ personal needs, $W O M=$ worth-of-mouth, $P E X P=$ past experience, ECS = expectations of care services, $R C C=$ relationship-centred care, EXPCS = experiences with care services, $C O N=$ context . 

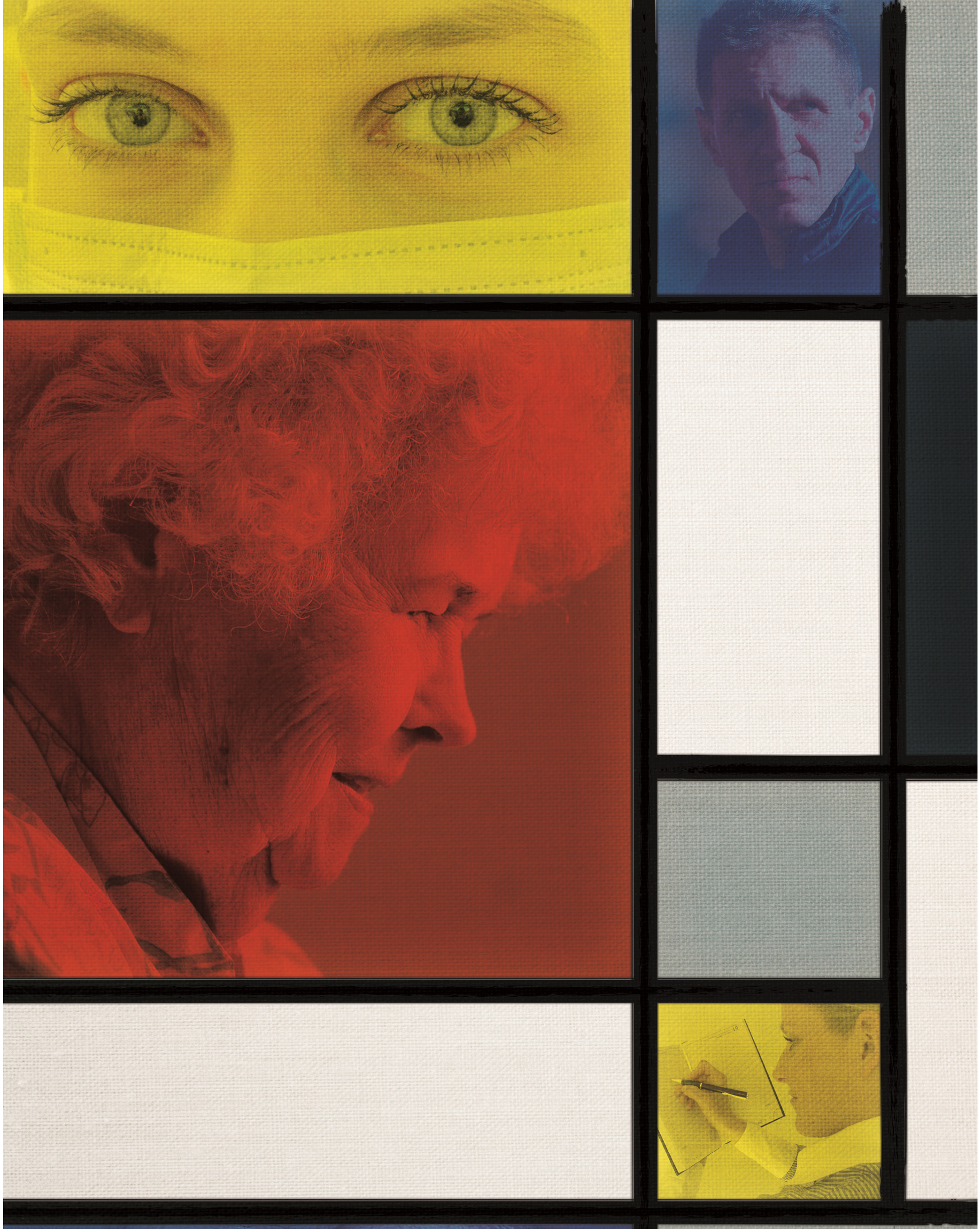


\section{CHAPTER 4}

The needs of key-stakeholders for evaluation client's experienced quality of home care: A qualitative approach

This chapter was published as: Haex R, Thoma-Lürken T, Zwakhalen SMG, \& Beurskens AJHM. The needs of key-stakeholders for evaluating client's experienced quality of home care: a qualitative approach. Journal of patient-reported outcomes, 2020; 4(1), 1-12. Doi: https://doi.org/10.1186/s41687-020-00260-3 


\section{ABSTRACT}

Background To optimize home care, it is essential to determine how care recipients experience quality of care. Traditionally, quality of care is measured with normative quality indicators such as safety, efficiency, or prevalence rates such as falls. The growing interest for qualitative patient-reported experience measures in home care requires insight into the needs of care receivers, providers, and organisations as key-stakeholders. Each stakeholder has their own needs that are important to communicate and use to conduct thorough comparisons before implementing new experience measures. This study aims to understand the needs of clients, formal/informal caregivers, and managers/policy officers in measuring client's experienced quality of care in home care.

Methods Four focus group interviews and 25 semi-structured interviews with keystakeholders were conducted and analyzed by means of content analysis. The value-proposition canvas was used as a thematic framework to explore the purpose of experience quality of care measures and related pains and gains.

Results There were two main purposes for measuring experienced quality of care: first improving the primary care process of individual clients and second for learning and improving in home care team. Using experienced quality of care measures for external accountability and transparency on an organisational or national level were considered less relevant. Among others, participants described not having time and no clear procedure for conducting an evaluation as a pain of the current methods used to evaluate perceived quality of home care. As gains they put forward the ability to informally evaluate experiences during care delivery and to openly discuss complaints with a familiar caregiver.

Conclusions This study advocates that home care organisations should be aware of the goal of quality of care measures. They should consider selecting experienced quality of care measures mainly for improving primary care processes of individual clients. The results also underline the relevance of adopting next to quantitative evaluations, more narrative evaluation methods which support communicating openly on care experiences, leading to concrete points of improvement. The findings of this study can serve as guide for both the development or selection of adequate methods, from the perspectives of key-stakeholders, in assessing experienced quality in home care. 


\section{Background}

In the European Union, the percentage of people aged 80 and older is expected to increase from $5.4 \%$ in 2016 to $12.5 \%$ in $2070 .{ }^{1}$. With an aging population, there is an increasing need for home care services to facilitate aging in place 2,3. In the Netherlands, the percentage of people receiving long-term care at home has increased by $23 \%$ in 2018 compared to $2015 .{ }^{4}$ To optimize home care, it is essential to determine how clients experience quality of care (QoC). Traditionally, QoC has been defined using criteria such as safety, efficiency, or effectivity or prevalence rates of care problems, such as falls and the use of physical restraints. 5,6 These criteria can be measured in home care using existing quantitative instruments such as the National Prevalence Measurement of Quality of Care. ${ }^{7}$ Besides measuring criteria from a quantitative point of view, it is essential to understand the individual needs of clients and their experiences with home care services to assess the experienced QoC. ${ }^{8-10}$ Although long-term home care is traditionally provided to clients aged 65 and above, there is a proportion of clients under 65 who, for instance, receive short-term home care while recovering from hospital care and may have differing preferences communicating care needs. ${ }^{11,12}$ Furthermore, it is increasingly important to include informal and formal caregivers to understand and interpret the experienced QoC in the home care context since quality is achieved during interactions between caregiver and receiver. ${ }^{13-15}$ Existing measures for experienced QoC in home care, such as the Net Promotor Score (NPS) or rating caregivers online (e.g. via a website named ZorgKaart Nederland), focus mainly on satisfaction which is defined as a subjective evaluation of the gap between a client's care expectations and experiences. ${ }^{16-18}$ Furthermore, in the Netherlands QoC in home care is often evaluated yearly or half-yearly by formal conversations between district nurses and clients, in addition to more informal evaluations by direct caregivers during care provision. ${ }^{19}$ However, no obligatory or clearly defined format and structure have been established for these evaluations.

In 2018, a new national quality framework was released in the Netherlands stating the importance of utilizing patient-reported experience measures (PREMs) to gain insight into the experienced QoC in home care. ${ }^{19}$ However, before deciding how experienced QoC should be measured it is important to define why it should be measured (e.g. the goal), who will use it (e.g. the key-stakeholders) and determine the context surrounding the method that is being applied (e.g. when, where, and by whom). ${ }^{20}$ For example, a nurse may choose a tool to find specific points of improvement in the daily care routine using different requirements regarding eligible instruments compared to a policy officer's goal to publicly report the organisation's care quality. It is therefore important to distinguish three different goals in evaluating experienced QoC. The first goal is to provide insight into 
clients' experiences so the primary care process can improve. The second goal is to assist care teams in creating an environment that facilitates learning from and improving the experienced QoC. The final goal is to use the evaluations on an organisational or national level for external accountability and transparency. ${ }^{20}$

Involving key-stakeholders such as clients, (in)formal caregivers, and managers/policy officers as active partners is crucial to gain insights in the needs for measuring experienced QoC in home care. Doing so ensures that the chosen methods have greater value for stakeholders in both the direct care process and organization. ${ }^{21,22}$ It is expected that each stakeholder has their own needs, which can either facilitate or hinder the implementation of a new method. ${ }^{23}$ As a consequence, by incorporating these needs in determining a method for experienced QoC, a better connection can be made to the organisational current workflow and individual home care processes. ${ }^{24}$ In addition to stakeholders in the primary care process (clients, informal, and formal caregivers), care organisations can play a facilitating role in implementing interventions such as measures for experienced QoC. ${ }^{23}$ Managers and policy officers of care organisations make decisions regarding allocating resources for QoC measures to be incorporated in all layers of the organization. ${ }^{21,25}$ The needs of clients, informal caregivers, formal caregivers, and managers/policy officers as key-stakeholders to evaluate experienced quality in home care are currently unknown. Therefore, the aim of this study is to gain insight into the needs of clients, formal and informal caregivers, and managers/policy officers in measuring client's experienced QoC in home care.

\section{Methods}

\section{Design}

This qualitative study followed a descriptive design in which a needs assessment was conducted using principles of the Value Proposition Canvas (VPC) for structuring and analyzing the needs of clients, formal and informal caregivers, and managers/policy officers. ${ }^{26}$ The VPC has been applied in healthcare to involve stakeholders in improving the value of new instruments, services, and products. ${ }^{24}$ The VPC is developed to match the needs of key-stakeholders with the value proposition of the method, and thus achieve a problem-solution fit. ${ }^{27}$ The VPC differentiates between determining the customer-profile (who are they) and value map (which features are of value). This study adopted principles of VPC and an underlying human-centered design approach helps to understand keystakeholders' current situation in measuring QoC and allows for identifying a method fitting their needs best. 


\section{Setting}

The research took place between July 2017 and May 2019 as part of a larger study, within three publicly funded, team-based home care organisations in the southern part of the Netherlands.

\section{Participants and data collection}

Individual and focus group interviews were used for data collection. Convenience sampling was used to recruit participants for each group of key-stakeholders, while striving for a balance in distribution between the different groups of stakeholders. A total of 25 semistructured interviews and four focus groups with 15 participants were conducted. Focus group interviews were used, in addition to individual interviews, since it helps participants to identify, share, and clarify their views. ${ }^{28}$ It is expected that experiences and opinions are shared that might not emerge during individual interviews. ${ }^{29} \mathrm{~A}$ topic list with exemplary questions from both the individual and focus group interviews is included in the Appendix.

\section{Individual interviews}

For the individual interviews, clients, informal caregivers, formal caregivers, and managers/policy officers were recruited from three home care organisations in the Living Lab in Aging and Long-Term Care South Limburg. ${ }^{30}$ Home care clients were eligible to participate if they were receiving long-term home care based on at least one chronic condition and were both mentally and physically able to participate according to their district nurse. Informal caregivers were eligible if they provided care for home care clients. Both clients and their informal caregivers were informed by their formal caregiver first and asked for permission to be contacted by the research team. Formal caregivers were eligible if they currently worked in home care as a district nurse, nurse assistant, nursing aide, or dementia case manager. Dementia case managers are professionals supporting and advising people with dementia and their family in the diagnostic phase and coordination of care. ${ }^{31}$ In addition, the organisation's district-managers and policy officers were eligible if they were working in long-term home care. Both formal caregivers and managers/policy officers were contacted by either mail or telephone and invited to participate. Individual semi-structured interviews were scheduled at a preferred location of the participant (either at home, the care organisation, or at the university). If necessary, the informal caregiver could support the client in the interview (e.g. if a client had trouble speaking clearly) but was asked to not actively engage in the conversation. The planned duration for the individual interviews was one hour. 


\section{Focus group interviews}

Four focus group interviews were conducted to gain insight into the current methods and needs of measuring experienced QoC in home care. For two focus group interviews, clients and informal and formal caregivers employed in a home care organisation were eligible and invited. However, two informal caregivers and one client could not attend this focus group because of personal circumstances for which one additional focus group was organised. In addition, one focus group interview was conducted with managers/policy officers in order to include the perspectives from the participating organisations. This was done to prevent any communicating difficulties as a result of status differences between participants (caregivers - managers/policy officers) or by discussing technical terms beyond the scope of the direct caregiving process (e.g. legislative, regulatory or organisational requirements). ${ }^{32}$ The discussion leader (RH) took field notes to log the context of the focus group interviews and to provide meaning to the reported needs. Focus group interviews were scheduled to last around one hour.

\section{Data analysis}

Both the individual and focus group interviews were audiotaped and transcribed verbatim. The data from both the individual and focus group interviews were merged and analyzed using MAXQDA Standard 2018, following principles of directed content analysis. ${ }^{33}$ In the deductive analysis, the VPC was used as a thematic framework to categorize keystakeholders' needs into goals, pains, or drawbacks of current evaluation methods and (desired) gains or benefits as a priori themes (see Table 4.1 for operational definitions). ${ }^{20,26}$

Table 4.1. A priori themes and operational definitions, based on the VPC 27

\begin{tabular}{ll}
\hline A priori themes & Operational definition \\
\hline Goals & Purposes or tasks that key-stakeholders strive to satisfy by measuring experienced \\
QoC. These were categorized in the following three categories: \\
1) understand and improve the primary care process for individual clients; \\
2) learn and improve the performance of home care teams based on the outcomes of \\
quality measurements; \\
3) use outcomes for external accountability, transparency, and generally improve \\
organisational service provision ${ }^{20}$. \\
Prawbacks of current methods to measure QoC, negative emotions, undesired \\
situations, or risks key-stakeholders have experienced before, during, or after \\
fulfilling the goals. \\
Benefits of current methods and desires in measuring QoC. \\
Gains
\end{tabular}


New categories and sub-categories were identified from both the pains and gains by means of inductive analysis. Using condensation, the categorized data was shortened while preserving the core meaning. ${ }^{34}$ Next, the condensed data was interpreted using a higher logical level, also known as abstraction. This was followed by axial coding in which the individual pains and gains were categorized, and sub-categories emerged through careful examination and constant comparison by two researchers independently (RH and TTL). In case of disagreements, the researchers discussed the (sub)categories to reach a consensus.

\section{Rigour}

Several strategies recommended by Korstjens and Moser ${ }^{35}$ were used to meet the criteria of credibility, transferability, dependability, confirmability, and reflexivity, thereby strengthening the trustworthiness of this study. ${ }^{36}$ To increase credibility, the results were presented during two group meetings with six participants to verify correct interpretation and completeness of the results. To enhance transferability, a detailed description was made on the context of the research, setting, sample, demographics, and exemplary quotes. Furthermore, a detailed codebook was made to keep track of all data-driven codes (categories and sub-categories) during the analysis.

\section{RESULTS}

A total of 25 participants took part in the individual interviews and 15 participants took part in four focus group interviews. The mean duration for individual interviews and focus group interviews were 55 minutes and 63 minutes respectively. Table 4.2 provides information about the demographics of the participants and composition of the focus group interviews. Outcomes of the individual and focus group interviews displayed different goals, pains, and gains for measuring experienced quality in home care. 
Table 4.2. Demographics

\begin{tabular}{|c|c|c|c|c|}
\hline \multicolumn{2}{|c|}{ (2) } & $\mathbf{N}$ & Sex (male, female) & Mean age \\
\hline \multicolumn{5}{|c|}{ Individual interviews $(\mathrm{N}=25)$} \\
\hline \multirow[t]{7}{*}{ Role } & Client & 6 & 2 male, 4 female & 85.5 (19) \\
\hline & Informal caregiver & 6 & 3 male, 3 female & $72(27)$ \\
\hline & Nurse aide/assistant & 2 & 2 female & $46(30)$ \\
\hline & Dementia case manager & 1 & 1 male & 53 \\
\hline & Registered nurse & 1 & 1 female & 63 \\
\hline & District nurse & 6 & 1 male, 5 female & $25.5(30)$ \\
\hline & Manager/Policy officer & 3 & 3 female & $54(27)$ \\
\hline \multicolumn{5}{|c|}{ Focus group 1 (N=7) } \\
\hline \multirow[t]{3}{*}{ Role } & Client & 2 & 1 male, 1 female & $80.5(8)$ \\
\hline & Informal caregiver & 3 & 1 male, 2 female & $77(16)$ \\
\hline & District nurse & 2 & 2 female & $33(14)$ \\
\hline \multicolumn{5}{|c|}{$\begin{array}{l}\text { Focus group interview } 2 \\
(\mathrm{~N}=2)\end{array}$} \\
\hline \multirow[t]{2}{*}{ Role } & Nurse aid/assistant & 1 & 1 female & 61 \\
\hline & Registered nurse & 1 & 1 female & 64 \\
\hline \multicolumn{5}{|c|}{$\begin{array}{l}\text { Focus group interview } 3 \\
(\mathrm{~N}=3)\end{array}$} \\
\hline \multirow[t]{2}{*}{ Role } & Client & 1 & 1 female & 86 \\
\hline & Informal caregiver & 2 & 1 male, 1 female & $76.5(17)$ \\
\hline \multicolumn{5}{|c|}{$\begin{array}{l}\text { Focus group interview } 4 \\
(\mathrm{~N}=3)\end{array}$} \\
\hline Role & Manager/Policy officer & 3 & 1 male, 2 female & $54(21)$ \\
\hline
\end{tabular}

\section{Goals in measuring experienced quality (why)}

All stakeholders mentioned goals related to at least one of the three main goals for evaluating experienced QoC. The first goal of "understanding and improving the primary care process for individual clients" was mentioned by all key-stakeholders. Clients focused mostly on problem-solving when being dissatisfied to improve care provision. One client mentioned that "if I receive care from a specific caregiver and I am dissatisfied about the care, I would make this clear." Informal caregivers tried to provide direct feedback to the formal caregiver when possible in order to improve the primary care process. Formal caregivers indicated that they strove to remain critical and wanted to have a clear/genuine picture of the client's and informal caregiver's experienced QoC. Managers/policy officers preferred obtaining structural feedback of the client's fulfilled and unfulfilled needs and experienced QoC for each area of interest so care provision could be improved.

The second goal of "learning from and improving the performance of home care teams based on the outcomes of quality measurements" was mentioned by formal caregivers, managers/policy officers and informal caregivers. The importance to create awareness for evaluating experienced quality in care teams from an organisational 
perspective was mentioned by both informal and formal caregivers. This awareness would enable caregivers to work toward concrete care improvements as a team. For instance, one formal caregiver mentioned, regarding evaluating experienced quality, that " $I$ think you can use it [experienced quality of care assessments] to steer the care process and also with your team or with employees or with the entire organisation you can look at which points scored less and how and when will we tackle them". Managers/policy officers aimed to generally improve care quality by discovering concrete points of improvement for care teams. This resulted in formulating appropriate actions to learn and improve for both individual teams and the organisation as a whole.

The last goal of "using outcomes for external accountability, transparency, and generally improving organisational service provision" was only noted by managers/policy officers. Use of a yearly mandatory measure for experienced quality was mentioned to meet the requirements of external accountability, as well as providing information on the organisation's website for transparency toward current and possible new clients.

Pains and gains in measuring experienced quality

The described pains and gains were categorized in the following categories: when to evaluate, who should evaluate, how to evaluate, what motivates one to evaluate, what to do with outcomes, and prerequisites for evaluating. Next, the results for each of the categories are presented.

\section{When to evaluate}

In deciding when to evaluate QoC (see Table 4.3 for an overview), participants in general would like to have more evaluations compared to the current yearly or half-yearly evaluations. Additionally, more flexibility in evaluation frequency was desired, based on the client's condition. Both clients and informal caregivers preferred to have more opportunities to initiate an evaluation more proactively, thus preventing the escalation of an unsatisfactory experienced QoC. Moreover, formal caregivers needed clarification to plan mandatory evaluations with a set interval, given the goal of evaluating (e.g. once every six months).

Current pains regarding when to evaluate QoC were the few evaluation moments, specifically for clients who receive more complex home care. Moreover, pains included not knowing when to formally evaluate the experienced QoC and when it is most effective to evaluate the care process. Furthermore, informal caregivers often had difficulties finding an appropriate moment during the care provision to evaluate QoC. For instance, one informal caregiver mentioned that there was "No room to evaluate the client, this comes in last place." However, some participants mentioned as a gain that the initiative to 
evaluate QoC is taken whenever it seems required (e.g. when an informal caregiver is dissatisfied about the care provision for the client). Furthermore, formal caregivers preferred to either initiate an evaluation based on signals from other caregivers or based on their own experiences with the client. Moreover, a formal caregiver indicated that it would be desirable to clarify the frequency of evaluations.

Table 4.3. Identified pains and (desired) gains for 'when to evaluate'.

\begin{tabular}{|c|c|c|c|}
\hline Category & & Pains & Gains \\
\hline \multirow[t]{7}{*}{$\begin{array}{l}\text { When } \\
\text { evaluate }\end{array}$} & to & $\begin{array}{l}\text { - Too few evaluation moments, } \\
\text { especially during complex care }(I, P)\end{array}$ & $\begin{array}{l}\text { - Taking opportunity for evaluating when } \\
\text { required }(C, I, F)\end{array}$ \\
\hline & & $\begin{array}{l}\text { - Difficult finding appropriate moment } \\
\text { to evaluate (I) }\end{array}$ & $\begin{array}{l}\text { - Starting evaluation based on signals from } \\
\text { other caregivers (F) }\end{array}$ \\
\hline & & - Not knowing when to evaluate (F) & $\begin{array}{l}\text { - Starting evaluation based on own experiences } \\
\text { as caregiver (F) }\end{array}$ \\
\hline & & & Desired gains \\
\hline & & & - Reminder of the next evaluation (F) \\
\hline & & & - Mandatory for each new client (F) \\
\hline & & & - Evaluate at set intervals (F) \\
\hline
\end{tabular}

Mentioned by $C=$ Clients, $I=$ Informal caregivers, $F=$ formal caregivers, $P=$ managers/policy officers

\section{Who should evaluate}

In determining who should conduct quality evaluations (see Table 4.4 for an overview), more flexibility for direct caregivers to formally evaluate experienced QoC was desired since this was currently not their role. However, taking into account the importance and fragility of care relationships while evaluating was brought forward. Appointing an external person to evaluate more sensitive topics was seen as a possible solution for this. Including the informal caregiver's perspective in evaluations is also needed. Furthermore, clearly indicating whom is appointed to evaluate experienced $\mathrm{QoC}$ is needed by informal caregivers. They also desired for evaluations to be conducted by the same evaluator(s).

A current pain was that direct caregivers do not have the formal role to formally evaluate experienced QoC. Currently, the district nurses have the formal responsibility to evaluate experienced quality of care every six months and not the nurses or nurse aids who provide everyday care. One formal caregiver mentioned, "Nurse aides have no formal role in evaluating; informal evaluations do take place... [I] experience a big difference between the two district nurses with regard to evaluating care, nurse aides should be more involved." The importance of care relationships between the client and formal caregiver was mentioned as well as the difficulties, due to a dependency in relationship, this poses in evaluating QoC. For instance, one policy officer stated, "You are still dependent within the care relationship...If I am your caregiver, then I should not ask you about it [experienced quality of care]." 
The size of care teams and the sufficient availability of caregivers was mentioned as a possible gain in evaluating QoC. The size of care teams provided informal caregivers the flexibility to choose whomever they would prefer to informally discuss care experiences. Involving family during evaluations was seen as important by formal caregivers, although whether to involve them should be decided by the client. Most clients and formal caregivers wished to evaluate QoC with direct caregivers. While informal caregivers and policy makers noted flexibility was viewed as a gain by some, formal caregivers mentioned it as a pain when sensitive topics had to be discussed in a formal evaluation. This is also related to the desire to involve an external person with care expertise when formally evaluating, facilitating a more open conversation. For instance, one informal caregiver mentioned that "If there are problems then you should be able to discuss these with whoever [formal caregiver] is coming to your home, but if there are difficulties with the whole [care process]....then you should be able to address them to someone else." The desire for more colleagues to conduct evaluations and provide possible insights to direct caregivers was seen as important. One informal caregiver elaborated on these insights and the potential dilemma of an evaluation by a direct caregiver or external person: "People who have the evaluation conversations themselves about their own clients can learn a lot immediately...how honest is that person to you when you hear the information from the client."

Table 4.4. Identified pains and (desired) gains for 'who should evaluate'.

\begin{tabular}{|c|c|c|}
\hline Category & Pains & Gains \\
\hline $\begin{array}{l}\text { Who should } \\
\text { evaluate }\end{array}$ & $\begin{array}{l}\text { - Direct caregiver lacks role to } \\
\text { formally evaluate (F,P) } \\
\text { - Experienced difficulties if } \\
\text { evaluation was conducted by } \\
\text { direct (influencing existing } \\
\text { relationship on responses) vs } \\
\text { indirect caregiver (difficulties } \\
\text { interpreting responses client) } \\
\text { (F,P) } \\
\text { - Missing perspective of informal } \\
\text { caregiver (F,P) } \\
\text { - Difficulties identifying evaluator } \\
\text { (I) }\end{array}$ & $\begin{array}{l}\text { - Sufficient availability of caregivers to } \\
\text { discuss care experiences (I) } \\
\text { - Client can decide if family is included (F) } \\
\text { Desired gains } \\
\text { - Direct caregiver instead of district nurse } \\
(C, F) \\
\text { - Someone with care expertise but not a } \\
\text { caregiver (I,P) } \\
\text { - Evaluation to be conducted by direct } \\
\text { caregiver so it is relevant to their own } \\
\text { experience, they can learn directly and } \\
\text { feel responsible for their own clients (F,P) } \\
\text { - More colleagues should have evaluation } \\
\text { discussions (F,P) } \\
\text { - Overarching contact beyond direct care (I) } \\
\text { - Same person (I) }\end{array}$ \\
\hline
\end{tabular}

Mentioned by $C=$ Clients, I=Informal caregivers, $F=$ formal caregivers, $P=$ managers/policy officers 


\section{How to evaluate}

Regarding how to evaluate QoC (see Table 4.5 for an overview), there is a need from participants for an evaluation method which requires minimal skills and time to analyze and document outcomes. Methods that are suitable to the ongoing care processes and existing care relationships were seen as important by most. In addition, participants preferred to be more aware of existing evaluation methods, favoring methods based on conversations (e.g. narratives) in which the experiences are evaluated.

Most participants mentioned pains in finding time to use, analyze, and document existing evaluation methods. They also worried that existing methods do not fit within the current care processes, possibly resulting in treating the client as a new and unknown individual. Other pains that were highlighted were the common physical properties of paper-based evaluations (e.g. possibility of becoming lost, damages easily), not evaluating QoC continuously, and asking questions during evaluation which leave too much room for interpretation errors.

The gains of the current methods to evaluate QoC were the access to existing patient files as a starting point for care evaluations. Humor during evaluations and flexibility in adjusting to the client's understanding were seen as important. Most clients and formal caregivers wished for care experiences to be shared more during conversations, looking beyond discussing standard quality indicators. Furthermore, participants mentioned that the evaluation tool should include sharing expectations of home care services, to prevent unrealistic expectations of evaluation outcomes by both clients and informal caregivers. Furthermore, the desired evaluation tool functionalities were cited such as sharing experiences anonymously by mail, obtaining visual supporting methods (e.g. a card containing images of relevant QoC topics), stimulating a more interactive evaluation by means of a digital application, and connecting to the existing organisational ICT platform (e.g. online care plan, OMAHA system, etc.). 
Table 4.5. Identified pains and (desired) gains for 'how to evaluate'.

\begin{tabular}{|c|c|c|}
\hline Category & Pains & Gains \\
\hline How to evaluate & $\begin{array}{l}\text { - Difficulties finding time to use, } \\
\text { analyze, and document existing } \\
\text { evaluation methods (I,F,P) } \\
\text { - Not suitable with ongoing care } \\
\text { process, creating worry that client } \\
\text { will be treated as new and unknown } \\
\text { (F,P) } \\
\text { - Missing supportive methods to } \\
\text { evaluate (F,P) } \\
\text { - Physical properties of evaluation on } \\
\text { paper (F) } \\
\text { - Provide only snapshot of client (P) } \\
\text { - Current questions asked are too } \\
\text { broad, leaves room for too many } \\
\text { interpretations (P) }\end{array}$ & $\begin{array}{l}\text { - Patient file as starting point evaluation (F) } \\
\text { - Room for humor during evaluation (F) } \\
\text { - Adjusting way of evaluating to understanding } \\
\text { client (F) } \\
\text { Desired gains } \\
\text { - Sharing experiences during conversation (C,F) } \\
\text { - Discussing multiple subjects and look beyond } \\
\text { standard quality indicators (F,P) } \\
\text { - Sharing expectations of care services (F) } \\
\text { - Ability to evaluate anonymously by mail (I) } \\
\text { - Visually supporting method to evaluate (F) } \\
\text { - Interactive application (F) } \\
\text { - Measurement should connect to existing ICT } \\
\text { platforms (P) }\end{array}$ \\
\hline
\end{tabular}

Mentioned by $C=$ Clients, $I=$ Informal caregivers, $F=$ formal caregivers, $P=$ managers/policy officers

\section{What motivates one to evaluate}

In determining what motivates one to evaluate (see Table 4.6 for an overview), it is desired that evaluations should be framed as a positive element in the care process. Allowing the possibility to evaluate anonymously was also mentioned by participants. It is believed that this would facilitate clients to honestly reflect on their care experiences and experienced QoC. In addition, participants mentioned the importance of motivating formal caregivers to incorporate evaluations in the daily care process, creating a shared feeling of ownership for the evaluation method and sharing experiences in care teams. Furthermore, participants noted that evaluations should be perceived as non-intrusive by clients and clients should feel more involved in the care process.

Some participants viewed evaluating as complaining, preventing them from initiating an evaluation and preventing clients from honestly sharing care experiences, often leading to socially desirable answers. Difficulties in motivating formal caregivers to incorporate evaluations in the daily care process were mentioned, as were feelings that most quality evaluations are done twice without a clear reason. This lack of motivation from formal caregivers was also related to being on their own in the home care setting. The communication and collaboration opportunities between formal caregivers is perceived as low, especially for formal caregivers coming from an institutional long-term care setting. For instance, one formal caregiver, in relation to evaluating experienced QoC, mentioned that "in home care, everyone is, yes you are alone [as a caregiver]. That is very different [than in a nursing home]. A lot relies on independence." 
Evaluating care is perceived as a positive aspect in the care process that involves clients in the care process. It is seen as a moment where understanding for others and wishes can be shared. Talking about experiences also helped participants to recall relevant care experiences and communicate unfulfilled care needs. Desired gains related to how to speak more openly such as evaluating anonymously. One manager indicated that evaluation should be made "anonymously, so you can get a lot more out of it than what clients might dare to say in person...I do not need to know which clients said that, because it will probably be something that several clients or informal caregivers have said."

Furthermore, care teams strive for shared ownership of an evaluation method in which mutual appreciation between caregivers is shared. For example, one district manager said that the measurement should be "about being part of the team...because it will be as if I am imposing something [as a manager] and they have to do something with it." Bringing relevant quality themes under the attention of caregivers while evaluating QoC is believed to motivate incorporating more evaluations in daily practice.

Table 4.6. Identified pains and (desired) gains 'what motivates to evaluate'

\begin{tabular}{|c|c|c|}
\hline Category & Pains & Gains \\
\hline $\begin{array}{l}\text { What motivates } \\
\text { one to evaluate }\end{array}$ & $\begin{array}{l}\text { - Evaluating is seen as complaining } \\
\text { (C,I,F) } \\
\text { - Experienced lack of motivation to } \\
\text { evaluate (F,P) } \\
\text { - Experienced duplications when } \\
\text { formally evaluating (F,P) } \\
\text { - Difficulties expressing experiences } \\
\text { and being sincere (I,F) } \\
\text { - Feel not being heard by caregiver (C) } \\
\text { - Feel burdened } \\
\text { organisational issues (I) } \\
\text { - Being on your own as caregiver in } \\
\text { home environment (F) } \\
\text { - Experienced having to be more } \\
\text { involved with their own clients in } \\
\text { sheltered housing vs. community (P) } \\
\text { - Not part of care process or } \\
\text { professional community (P) }\end{array}$ & $\begin{array}{l}\text { - Feels good to talk about care experience (C) } \\
\text { - Sharing care experiences is good for involving } \\
\text { client in care process (F) } \\
\text { - Show understanding and taking changes } \\
\text { seriously (F) } \\
\text { - Evaluate anonymously (I,F) } \\
\text { - Team ownership and bottom-up support for } \\
\text { tools (F,P) } \\
\text { - Build toward relationship with evaluator (I) } \\
\text { - Share mutual appreciation between } \\
\text { caregivers (I) } \\
\text { - Share responsibility to provide good care for } \\
\text { client (F) } \\
\text { - Bring relevant quality themes under attention } \\
\text { of caregivers (P) }\end{array}$ \\
\hline
\end{tabular}

Mentioned by $C=$ Clients, I=Informal caregivers, $F=$ formal caregivers, $P=$ managers/policy officers

\section{What to do with the outcomes}

When considering what to do with the outcomes while evaluating QoC (see Table 4.7 for an overview), there is a need to formulate concrete feedback and points of improvement, to avoid the use of difficult jargon while discussing evaluation outcomes, and to strive for outcomes that clearly reflect the evaluation content. Clear communication was also related to forming realistic expectations by clients based on the discussed content and evaluation 
outcomes. There was an effort to focus more on relevant themes that are within the scope of experienced quality of home care and to make room for discussing evaluation outcomes more extensively in care teams.

Participants mentioned pains with current evaluation methods were that they did not provide defined points of improvement and offered too little concrete feedback. An informal caregiver mentioned difficult jargon in discussing evaluation outcomes (e.g. care is being extended) and differences between evaluation content and what was written down afterwards, possibly contributing to undesired care outcomes. Forming unrealistic expectations for the client based on evaluation outcomes (e.g. adjust care planning) and discussing outcomes which are unrelated to nursing or personal care services (e.g. help with domestic chores) were highlighted by formal caregivers. Lastly, it was mentioned that only extreme outcomes are now being discussed in care teams and the rest is kept between the district nurse and direct caregiver.

Some informal caregivers mentioned that gains were that both verbal and written evaluation outcomes helped clients to gain insight in the care process and supported the discovery of specific points of attention. Formal caregivers mentioned that evaluation outcomes are currently being discussed with the district nurse; however, the aim is to discuss care difficulties but not solve them. Desired gains were that outcomes can help caregivers to reflect on their care provision and check for possible unrecognized assumptions or biases in the care process. It was mentioned that care teams should be the place where experiences are shared, outcomes evaluated, and together determine points of actions. 
Table 4.7. Identified pains and (desired) gains for 'what to do with outcomes'.

\begin{tabular}{|c|c|c|}
\hline Category & Pains & Gains \\
\hline $\begin{array}{l}\text { What to do with } \\
\text { outcomes }\end{array}$ & $\begin{array}{l}\text { - Little is done with outcomes, not } \\
\text { transparent (I,F,P) } \\
\text { - No concrete points of improvement } \\
\text { are being formed (I,F,P) } \\
\text { - Difficult jargon used in discussing } \\
\text { outcomes of measurement (I) } \\
\text { - Outcomes do not reflect content } \\
\text { evaluation (I) } \\
\text { - Outcomes only discussed by district } \\
\text { nurse with direct caregiver (F) } \\
\text { - Unrealistic expectations of outcomes } \\
\text { (F) } \\
\text { - Unrelated outcomes to nursing or } \\
\text { personal care services (F) } \\
\text { - Only extreme outcomes are } \\
\text { communicated in teams (P) }\end{array}$ & $\begin{array}{l}\text { - Provide client insight into evaluation with } \\
\text { - both verbal and written outcomes (I) } \\
\text { (I) } \\
\text { - Discuss outcomes of evaluation with district } \\
\text { nurses (F) } \\
\text { - Evaluation not aimed to solve all care } \\
\text { difficulties, but rather to discuss them (F) } \\
\text { - Hesired gains } \\
\text { provision (F,P) } \\
\text { - Discuss outcome evaluation in team and } \\
\text { decide what to feedback to client (I,P) } \\
\text { - Share outcomes in team to define points of } \\
\text { action together (F, P) } \\
\text { - Help caregiver to check for unrecognized } \\
\text { assumptions or biases in care process (F) } \\
\text { - Give daily update on positive and negative } \\
\text { experiences in team (F) } \\
\text { - Access client file and outcomes remotely (F) } \\
\text { - Create client awareness for organisational } \\
\text { restrictions on care services (F) } \\
\text { - Share outcomes evaluation in organisation in } \\
\text { multiple formats (e.g. figures and practical } \\
\text { solutions) (P) }\end{array}$ \\
\hline
\end{tabular}

Mentioned by $C=$ Clients, I=Informal caregivers, $F=$ formal caregivers, $P=$ managers/policy officers

\section{Prerequisites for evaluating}

A number of prerequisites for evaluating experienced QoC were discovered (see Table 4.8 for an overview). Current pains related to a lack of communication (skills) among caregivers and the omission of both space and culture to discuss experiences in care teams. Relating to the team's atmosphere, one formal caregiver mentioned that "currently, I do not experience safety to discuss client experiences within my care team." The low literacy rate and self-reflection skills of clients makes it difficult to use standard evaluation methods such as questionnaires. Lastly, the cost related to evaluating was highlighted by policy officers. The desired gains in prerequisites related to stimulating a supportive atmosphere in care teams that allows for evaluations. Furthermore, it was desired that formal caregivers gain support through individual coaching to foster professionalism and develop skills both in conducting conversations and writing effective reports based on evaluations outcomes. 
Table 4.8. Identified pains and desired gains for 'prerequisites for evaluating'.

\begin{tabular}{|c|c|c|}
\hline Category & Pains & Desired gains \\
\hline $\begin{array}{l}\text { Prerequisites for } \\
\text { evaluations }\end{array}$ & $\begin{array}{l}\text { - Bad communication between } \\
\text { caregivers in home care teams (F) } \\
\text { - No space and culture to discuss client } \\
\text { experiences in team (F) } \\
\text { - Low literacy and self-reflection skills of } \\
\text { clients (F) } \\
\text { - No evaluation moment because of } \\
\text { costs (P) } \\
\text { - Missing communication skills } \\
\text { evaluator (P) }\end{array}$ & $\begin{array}{l}\text { - Individual coaching and support in team to } \\
\text { conduct evaluations (I) } \\
\text { - Create supportive atmosphere in team (P) } \\
\text { - Foster professionalism and skills to conduct } \\
\text { conversations }(P) \\
\text { - Gain skills in writing outcomes evaluation } \\
\text { reports }(P)\end{array}$ \\
\hline
\end{tabular}

\section{DISCUSSION}

The study discovered needs in measuring experienced QoC that resulted in an overview of goals, pains, and gains from key-stakeholders regarding the current methods used to evaluate experienced quality of home care in the Netherlands. The different goals in measuring experienced QoC were recognized by most key-stakeholders, who primarily related the goals to understanding and improving the primary care process of individual clients and secondarily to learning and improving the performance of home care teams. Six categories throughout the process of evaluating experienced QoC emerged in this study, namely: when to evaluate, who should evaluate, how to evaluate, what motivates one to evaluate, and what to do with the outcomes. In addition, prerequisites for evaluations were identified such as the importance for home care teams to foster communication skills and individual coaching and to create a supportive atmosphere for evaluating experienced $\mathrm{QoC}$ and using the outcomes for quality improvements.

By reflecting on the discovered needs (goals, pains, and gains) in evaluating experienced QoC a number of dilemmas came to light. First, it was not clear when to evaluate. This varied from constant evaluations as part of the care process to being initiated as needed by the client or formal caregiver to once every pre-set period (e.g. once every six months). A second dilemma that emerged is not knowing who is best as an evaluator to speak openly about experienced QoC. This varied from a direct caregiver having a (longstanding) care relationship with the client and knowing how to interpret their response during evaluations to a coordinating person within care teams who can act based on the evaluation outcomes to an external evaluator with sufficient care expertise to even a non-personal digital format (e.g. mail, website) to address difficulties anonymously. A third dilemma related to the structure in discussing and acting on evaluation outcomes. This varied from implicitly using outcomes to reflect upon one's own 
care provision and individually checking for any unrecognized assumptions or biases in the care process to discussing evaluations outcomes within care teams to form concrete points of improvement to being explicit toward clients and informal caregivers about evaluation outcomes.

These dilemmas make it clear that it is important to define the QoC goal to be measured in home care before selecting and implementing a measure. It is known that different stakeholders in care organisations can have different (implicit) reasons for measuring experienced QoC. ${ }^{37}$ This is also stated in existing models for selecting and implementing new measures, like the PROM cycle, which starts by defining the goal of a measure in the implementation process. ${ }^{20}$ It is known that stating a clearly defined and achievable goal can help to feel motivated and committed in working toward that goal ${ }^{38}$. In determining when to evaluate, it is expected that experienced QoC should be measured more regularly when the goal is to gain insight and improve the primary care process, and less regularly when care teams and organisations are striving for an improvement on an overall level. A more continuous measurement of experienced QoC is also supported by the INDEXQUAL framework, defining it as a process before, during and after care is provided. ${ }^{15}$ Furthermore, when deciding who is best as an evaluator, it should be clear which aspect of the care process will be discussed. For instance, one can wonder how clients perceive their direct caregiver as an evaluator when care experiences are being discussed involving that same caregiver. It needs to be considered that clients and informal caregivers are, to some extent, dependent on formal care providers, which can contribute to a fear of possible consequences when being completely honest about their experienced QoC. ${ }^{39}$ However, care experiences on a team or organisational level, such as planning or access to care facilities, are some distance from the primary care process and can therefore be more easily discussed with direct caregivers. This highlights the importance of positioning the determined goal and individual needs within the different settings in home care before selecting a measure that is feasible for key-stakeholders, in line with the care process, as well as incorporating relevant experienced QoC attributes.

The results in this study underline the relevance of discussing care experiences during conversations imbedded in the care process above using questionnaires, which is in line with the trend of adopting more narrative evaluation methods. $16,40,41$ This also depicts the dichotomy with existing quantitative quality measures, such as the Consumer Quality Index (CQ-index) and Net Promotor Score (NPS). ${ }^{42}$ These measures often focus on satisfaction as the main outcome, which has been shown to be an incomplete measure for experienced $\mathrm{QoC}$ as it generates gratitude bias and interpretation difficulties for formal caregivers. ${ }^{16,42,43}$ In a previous study, attributes of experienced QoC were identified throughout the home care process. ${ }^{44}$ These attributes include the presence of more 'close' personal care relationships (relating to trust, openness, and empathy) and the importance 
of care routines that are consistent with the client's former way of living. Evaluating experienced QoC attributes during conversations provides valuable in-depth information on experienced QoC, for which standardized measures are insufficient. ${ }^{45,46}$ In order to select and implement a method to facilitate these conversations, a careful evaluation of suitable instruments and processes of how they will be used in organisations has to be designed in close collaboration with key-stakeholders. ${ }^{23,47,48}$ This is also supported by the VPC, in which a value-proposition is made to relieve the identified pains and enhance the discovered gains. ${ }^{27}$ One can determine which instrument's features and which subsequent instrument are of greatest value to achieve a problem-solution fit. By adopting a research method such as the Participatory Action Research (PAR), stakeholders can thoroughly be involved in the following phase by carefully planning actions, reflections, and revision in short iterative cycles. ${ }^{49}$ By doing so, the method that will best fit the needs for experienced QoC can be determined.

\section{Strengths and limitations}

A strength in this study is that triangulation was used by combining both individual and group interviews, involving multiple perspectives. This made it possible for stakeholders from all layers of the home care setting to reflect on the questions brought forward. In qualitative research, involving multiple perspectives from different stakeholders is likely to result in an increased understanding of complex phenomena such as experienced QoC. ${ }^{50}$ Individual interviews made it possible for clients and informal caregivers to receive extended information on examples for possible evaluation methods or visual stimuli to support them in formulating a response. For the individual interviews with clients and their informal caregivers, recruitment was done by their district nurses. This could have results in a selection bias such as only including clients with a less complex relationship or a specific client's residence (sheltered housing estate). To account for this, other district nurses were asked to recruit clients, striving a balance regarding less complex versus more complex relationships or situations, presence of an informal caregiver (spouse or other) and the client's residence (living in the community or sheltered housing estate). The focus group interviews allowed participants to respond to each other's responses, generating a more thorough discussion of the topics compared to individual interviews. A disadvantage of using different methods with different stakeholders is that it was more challenging to analyze and compare the collected qualitative data. To overcome this challenge, we used the principles of the VPC to identify, structure, and analyze the individual needs for each group of key-stakeholders. However, it was decided not the present the findings as individual customer profiles, since it is believed that all key-stakeholder needs should be taken into account when determining which solution has the most value for the direct care 
process and organisation. ${ }^{21,22}$ Furthermore, this research took place on a small scale in three care organisations focused on four key-stakeholders. It was therefore unclear whether data saturation was reached. Also, since clients included were aged above 75, it is unclear whether the findings in this study are applicable to clients populations below 75 or 65 years.

\section{Conclusions}

This study indicates that home care organisations should consider selecting methods that fit to clients and caregivers' needs and prevent dilemmas in evaluating experienced QoC. It is important to clearly define and communicate the goal of experienced QoC measures with all key-stakeholders and embed a feasible method in both the primary care process and care teams. Prerequisites for successfully assessing experienced QoC are that evaluators should have good communication skills, clients with low literacy and selfreflection skills should be able to sufficiently participate and feel heard during evaluations and a climate should be established in care teams to discuss evaluation outcomes. Formal caregivers in care teams should feel ownership over experienced QoC methods, so they are motivated to naturally incorporate it in the home care process. Clients and informal caregivers should feel supported to openly share care experiences with an evaluator, thereby being transparent about outcomes. Additionally, evaluations should lead to concrete points of improvement for the care process, avoid using difficult jargon while discussing evaluation outcomes, and strive for outcomes that clearly reflect the evaluation content. The findings of this study can serve as basis to develop or select methods, in cocreation with key-stakeholders, to assess the experienced quality in home care. 


\section{REFERENCES}

1. European Commission. The 2018 Ageing Report: Economic and Budgetary Projections for the EU Member States (2016-2070). 2018; https://ec.europa.eu/info/sites/info/files/economy-finance/ip079_en.pdf.

2. de São José J, Barros R, Samitca S, Teixeira A. Older persons' experiences and perspectives of receiving social care: a systematic review of the qualitative literature. Health \& Social Care in the Community. 2016;24(1):1-11.

3. Wiles JL, Leibing A, Guberman N, Reeve J, Allen RES. The Meaning of "Aging in Place" to Older People. The Gerontologist. 2012;52(3):357-366.

4. Centraal Bureau voor de Statistiek. Personen met indicatie naar gebruik Wlz-zorg. 2019;

https://opendata.cbs.nl/statline/\#/CBS/nl/dataset/84529NED/table?dl=2CAFA.

5. Institute of Medicine Committee on Quality of Health Care in America. In Crossing the Quality Chasm: A New Health System for the 21st Century. Washington (DC)2001.

6. Kroneman M, Boerma W, van den Berg M, Groenewegen P, de Jong J, vanGinneken E. The Netherlands: health system review. Health Systems in Transition. 18. 2016;2:1-239.

7. Halfens R, Meesterberends E, Neyens J, et al. Landelijke prevalentiemeting zorgproblemen rapportage resultaten 2015. Maastricht University: Maastricht, The Netherlands. 2016.

8. Luxford K, Safran DG, Delbanco T. Promoting patient-centered care: a qualitative study of facilitators and barriers in healthcare organizations with a reputation for improving the patient experience. International Journal for Quality in Health Care. 2011;23(5):510-515.

9. Ritchie CS, Leff B, Garrigues SK, Perissinotto C, Sheehan OC, Harrison KL. A Quality of Care Framework for Home-Based Medical Care. Journal of the American Medical Directors Association. 2018;19(10):818-823.

10. Koksma J-J, Kremer JA. Beyond the Quality Illusion: The Learning Era. Academic medicine: journal of the Association of American Medical Colleges. 2018;94(2):166-169.

11. Canadian Institute for Health Information. Profile of Clients in Home Care 20182019. 2019.

12. Guner $\mathrm{H}$, Acarturk $\mathrm{C}$. The use and acceptance of ICT by senior citizens: a comparison of technology acceptance model (TAM) for elderly and young adults. Universal Access in the Information Society. 2020;19(2):311-330.

13. Fine MD. A caring society?: care and the dilemmas of human service in the twentyfirst century. Houndmills, Basingstoke; New York: Macmillan International Higher Education; 2006.

14. Tronto JC. Moral boundaries: A political argument for an ethic of care. Psychology Press; 1993.

15. Sion K, Haex R, Verbeek H, et al. Experienced Quality of Post-Acute and Long-Term Care From the Care Recipient's Perspective-A Conceptual Framework. Journal of the American Medical Directors Association. 2019;20(11):1386-1390.

16. LaVela SL, Gallan A. Evaluation and measurement of patient experience. Patient Experience Journal. 2014;1(1):28-36.

17. Pascoe GC. Patient satisfaction in primary health care: A literature review and analysis. Evaluation and Program Planning. 1983;6(3-4):185-210.

18. Boer Dd, Bos N, Zuidgeest M, Beusmans P, Koopman L, Scheurs S. Ontwikkelingen in het meten en gebruiken van patiëntervaringen en patiëntgerapporteerde uitkomsten: van de huidige stand van zaken naar lessen voor de toekomst. 2018.

19. Stuurgroep Kwaliteitskader Wijkverpleging. Kwaliteitskader Wijkverpleging. 2018; https://www.zorginzicht.nl/kwaliteitsinstrumenten/wijkverpleging-kwaliteitskader. Accessed 15th Oktober, 2019. 
20. Verkerk E, Verbiest M, van Dulmen S, et al. The PROM toolbox: Tools for selecting and using Patient-Reported Outcome Measures (PROMs) in health care.[De PROM toolbox: Tools voor de selectie en toepassing van PROMs in de gezondheidszorg]. 2017.

21. Haywood KL, Wilson R, Staniszewska S, Salek S. Using PROMs in Healthcare: Who Should Be in the Driving Seat-Policy Makers, Health Professionals, Methodologists or Patients? The Patient - Patient-Centered Outcomes Research. 2016;9(6):495498.

22. de Wit M, Abma T, Koelewijn-van Loon M, Collins S, Kirwan J. Involving patient research partners has a significant impact on outcomes research: a responsive evaluation of the international OMERACT conferences. BMJ open. 2013;3(5):e002241.

23. Foster A, Croot L, Brazier J, Harris J, O'Cathain A. The facilitators and barriers to implementing patient reported outcome measures in organisations delivering health related services: a systematic review of reviews. Journal of patient-reported outcomes. 2018;2:46.

24. Bhattacharyya O, Blumenthal D, Stoddard R, Mansell L, Mossman K, Schneider EC. Redesigning care: adapting new improvement methods to achieve person-centred care. BMJ Qual Saf. 2019;28(3):242-248.

25. Epstein RM, Fiscella K, Lesser CS, Stange KC. Why the nation needs a policy push on patient-centered health care. Health affairs. 2010;29(8):1489-1495.

26. Clark T, Osterwalder A, Pigneur Y. Business model you: a one-page method for reinventing your career. Hoboken, New Jersey: John Wiley \& Sons; 2012.

27. Osterwalder A, Pigneur Y, Bernarda G, Smith A. alue proposition design: How to create products and services customers want. Hoboken, New Jersey: John Wiley \& Sons.; 2014.

28. Kitzinger J. Qualitative research: introducing focus groups. Bmj. 1995;311(7000):299-302.

29. Carey MA, Smith MW. Capturing the group effect in focus groups: A special concern in analysis. Qualitative health research. 1994;4(1):123-127.

30. Verbeek H, Zwakhalen SMG, Schols JMGA, Kempen GIJM, Hamers JPH. The Living Lab in Ageing and Long-Term Care: A Sustainable Model for Translational Research Improving Quality of Life, Quality of Care and Quality of Work. The journal of nutrition, health \& aging. 2019;24(1):43-47.

31. Thoma-Lürken T, Bleijlevens MH, Lexis MA, Hamers JP, de Witte LP. An overview of potential labor-saving and quality-improving innovations in long-term care for older people. Journal of the American Medical Directors Association. 2015;16(6):482-489.

32. Tausch AP, Menold N. Methodological aspects of focus groups in health research: results of qualitative interviews with focus group moderators. Global qualitative nursing research. 2016;3:2333393616630466.

33. Hsieh H-F, Shannon SE. Three approaches to qualitative content analysis. Qualitative health research. 2005;15(9):1277-1288.

34. Graneheim UH, Lundman B. Qualitative content analysis in nursing research: concepts, procedures and measures to achieve trustworthiness. Nurse education today. 2004;24(2):105-112.

35. Korstjens I, Moser A. Series: Practical guidance to qualitative research. Part 4: Trustworthiness and publishing. European Journal of General Practice. 2018;24(1):120-124.

36. Lincoln YS, Guba EG. Naturalistic inquiry. London: Sage; 1985.

37. OECD, European Union. A Good Life in Old Age? Monitoring and Improving Quality in Long-term Care. 2013; https://www.oecd.org/els/health-systems/a-good-lifein-old-age-9789264194564-en.htm.

38. Erez A, Judge TA. Relationship of core self-evaluations to goal setting, motivation, and performance. Journal of applied psychology. 2001;86(6):1270. 
39. Li Y, Li Q, Tang Y. Associations between family ratings on experience with care and clinical quality-of-care measures for nursing home residents. Medical Care Research and Review. 2016;73(1):62-84.

40. Wolf C, Jason A. Defining patient experience. Patient experience journal. 2014;1(1):7-19.

41. Duffy JR, Hoskins LM. The quality-caring model@: Blending dual paradigms. Advances in nursing science. 2003;26(1):77-88.

42. Reichheld FF. The one number you need to grow. Harvard business review. 2003;81(12):46-55.

43. Hamilton D, Lane JV, Gaston $P$, et al. Assessing treatment outcomes using a single question: the net promoter score. The bone \& joint journal. 2014;96(5):622-628.

44. Haex R, Thoma-Lürken T, Beurskens A, Zwakhalen S. How Do Clients and (In) Formal Caregivers Experience Quality of Home Care? A Qualitative Approach. Journal of Advanced Nursing. 2020;76(1):264-274.

45. Kingsley $C$, Patel S. Patient-reported outcome measures and patient-reported experience measures. BJA Education. 2017;17(4):137-144.

46. Martino SC, Shaller D, Schlesinger M, et al. CAHPS and comments: how closedended survey questions and narrative accounts interact in the assessment of patient experience. Journal of patient experience. 2017;4(1):37-45.

47. Damschroder LJ, Aron DC, Keith RE, Kirsh SR, Alexander JA, Lowery JC. Fostering implementation of health services research findings into practice: a consolidated framework for advancing implementation science. Implementation Science. $2009 ; 4(1): 50$.

48. Rycroft-Malone J, Harvey G, Seers K, Kitson A, McCormack B, Titchen A. An exploration of the factors that influence the implementation of evidence into practice. J Clin Nurs. 2004;13(8):913-924.

49. Koshy E, Koshy V, Waterman H. Action research in healthcare. London: Sage; 2010.

50. Malterud K. Qualitative research: standards, challenges, and guidelines. The lancet. 2001;358(9280):483-488. 

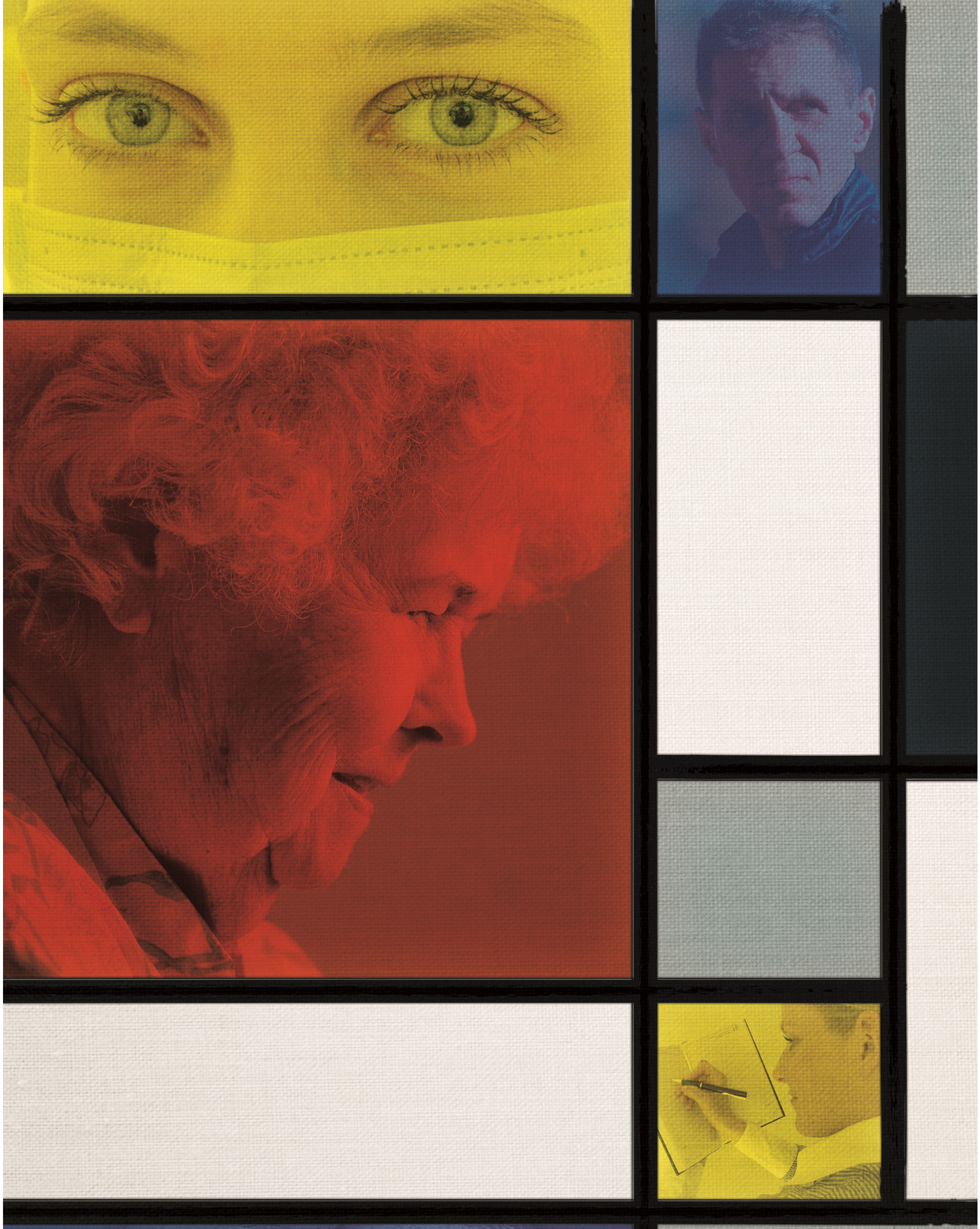


\section{CHAPTER 5}

How to select adequate experienced quality measures in long-term care: An exemplary case study in Dutch

home care

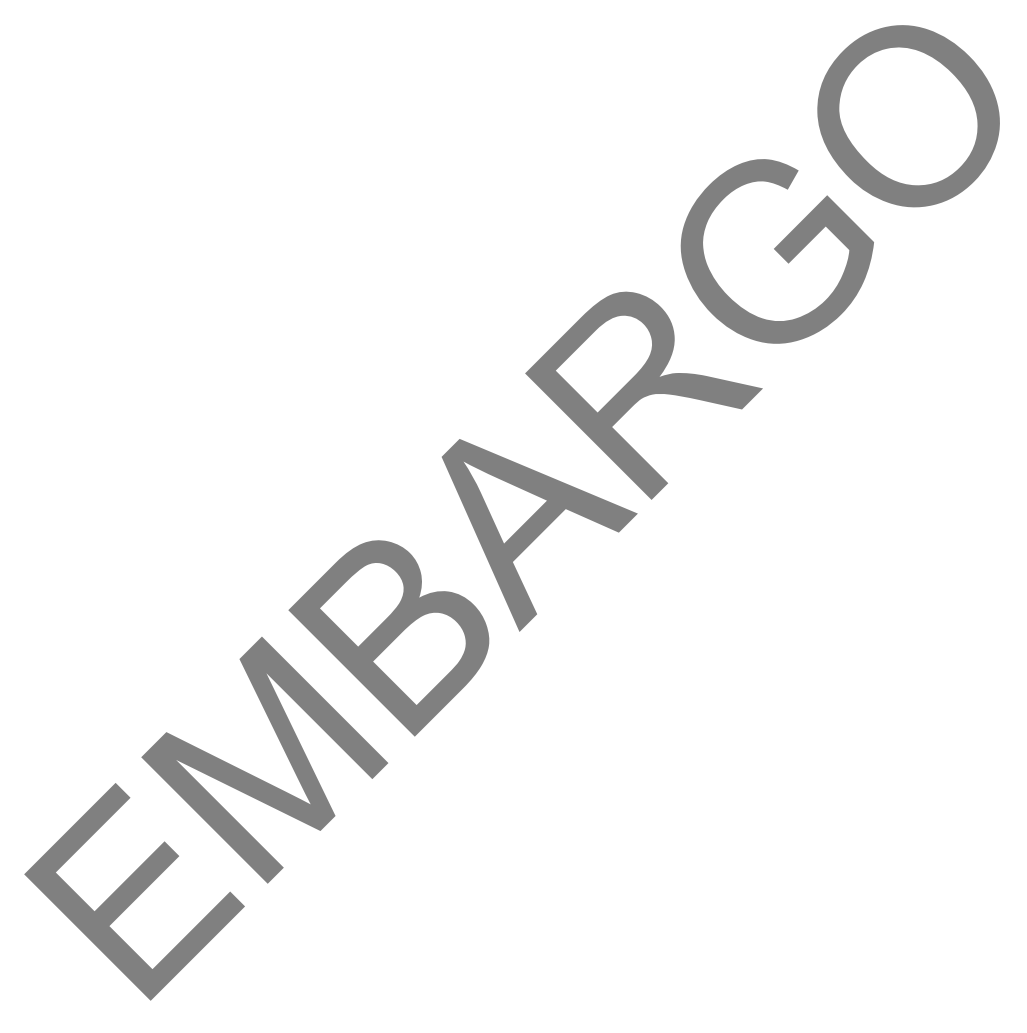

Haex R, Thoma-Lürken T, Beurskens AJHM \& Zwakhalen SMG. Submitted for publication 


\section{CHAPTER 6}

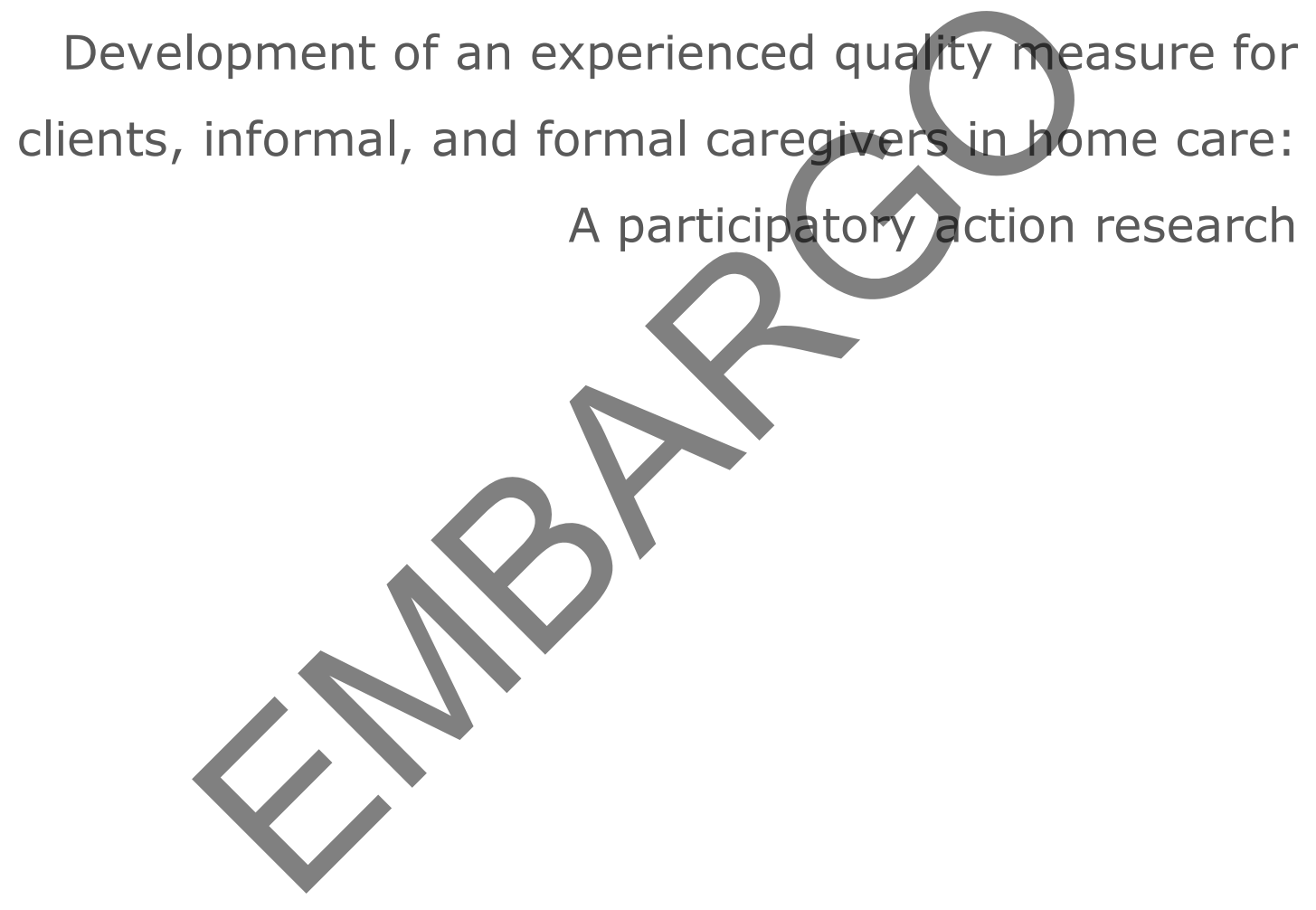

Haex R, Thoma-Lürken T, Beurskens AJHM \& Zwakhalen SMG. Submitted for publication 
CHAPTER 7

General discussion 


\section{GENERAL DISCUSSION}

This dissertation focuses on the process of determining stakeholders' needs as regards the development of a qualitative experienced quality measure from a client's perspective. By 'taking a look through my eyes', the dissertation focuses on clients' perceived care experiences from a relationship-centred care approach. The newly developed measure helps district nurses to look through the eyes of clients, informal caregivers and direct formal caregivers by having conversations about relevant topics of experienced quality. This could help to uncover new insights about ongoing care processes by involving clients, as well as informal and formal caregivers.

Three phases can be distinguished in this dissertation (see Figure 7.1): gaining an understanding of the concept of experienced quality for home care (Chapters 2 and 3); acquiring insight into the current practices and needs of measuring experienced quality of home care (Chapter 4); and developing a qualitative experienced quality measure for home care (Chapters 5 and 6 ). This final chapter addresses the main findings of the studies in this dissertation, reflects on both the methodological and the theoretical considerations, and provides recommendations for future research and practice. 
Figure 7.1 Dissertation outline

Phase 1 Understanding the concept of experienced quality of home care

Phase 2 Insight into current practices and needs of measuring experienced quality of home care

Phase 3 Development of qualitative experienced quality measure for home care
1. How can experienced quality in home care for older people, as perceived by the care recipients, be conceptualized?

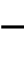

2. What are the views of clients, formal caregivers and informal caregivers about the experienced quality of home care for older people?

$-\left[\begin{array}{l}\text { 3. What are the needs of clients, formal and } \\ \text { informal caregivers, and managers/policy } \\ \text { officers as regards the feasibility and usability } \\ \text { aspects of measuring clients' experienced } \\ \text { quality of home care? }\end{array}\right.$

4. How can potentially adequate measures be selected for measuring the experienced quality of home care?

5. How can a usable and feasible measure of experienced quality be developed to improve clients' primary care processes in home care?

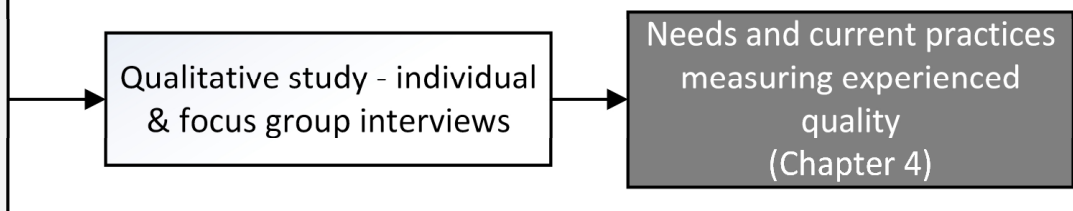

$\rightarrow \begin{gathered}\text { Review \& systematic } \\ \text { evaluation of existing } \\ \text { measures }\end{gathered}$
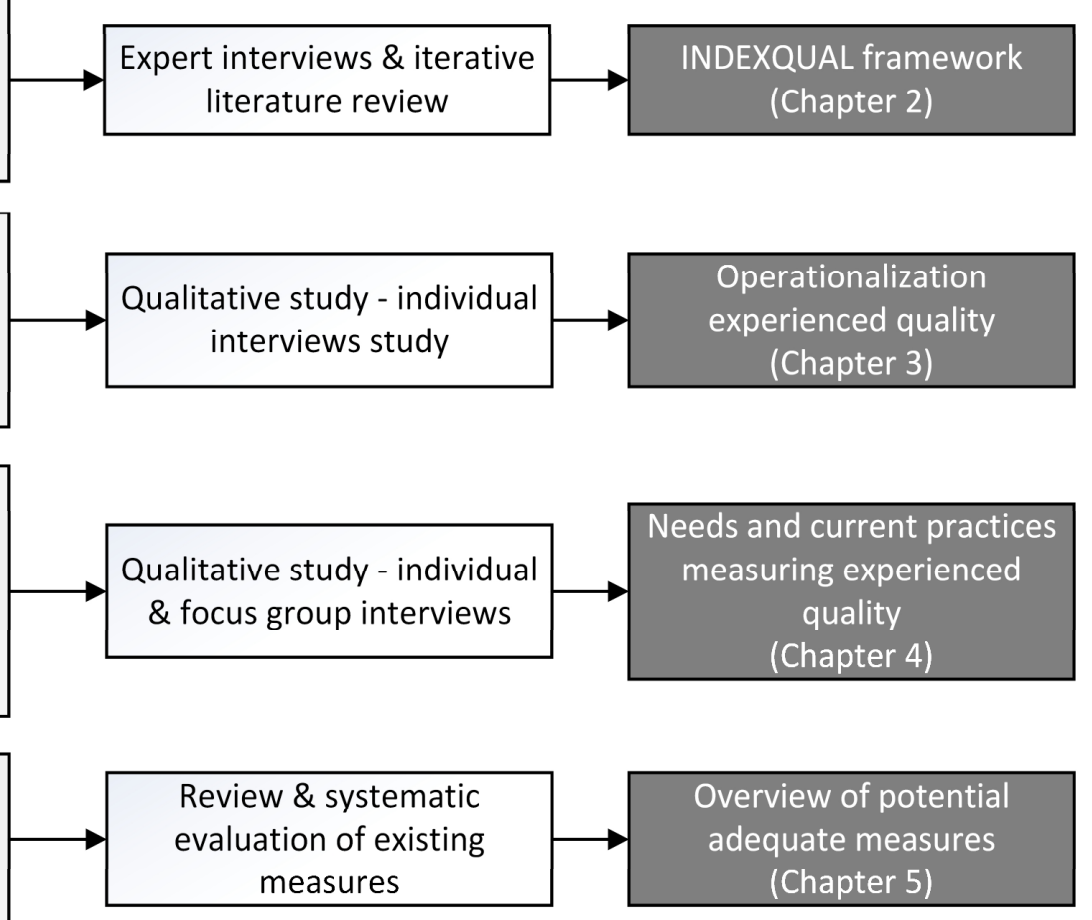

\section{(Chapter 3)}

Developed qualitative experienced quality

measure

(Chapter 6) 


\section{MAIN FINDINGS}

The main results of this dissertation can be related directly to the three phases. In the first phase, leading to an understanding of the concept of experienced quality, an innovative quality framework was constructed for long-term care (Chapter 2). The Individually Experienced Quality of Long-Term Care (INDEXQUAL) framework presents the process of individual care experiences consisting of expectations before care is provided, experiences taking place during care interactions, and an assessment afterwards. The assessment addresses what happened and how it happened (perceived care services), how the care influenced the client's health status (perceived care outcomes), and how the care made the client feel (satisfaction). The framework adopts a relationship-centred care approach by acknowledging the interactions between clients and their informal and formal caregivers (the care triad) as a central element during care experiences. When operationalizing experienced quality in the home care, on the basis of the INDEXQUAL framework, several important attributes came to light, such as the preferred number of caregivers, sufficient time for care provision and a caring atmosphere facilitating open communication and humour (Chapter $\mathbf{3}$ ). Clients and caregivers reported the importance of care routines that fit to a client's former way of living, and of communicating preferences about whether the care relationship should be more personal or more professional.

In the second phase, a thorough insight into the purpose, needs and current practices of assessing experienced quality was obtained by conducting a needs assessment with clients, informal and formal caregivers, and policy officers (Chapter 4). The purpose of measuring experienced quality of home care was seen to focus primarily on improve the primary care process for individual clients, with the desire that this would lead to learning and improvement in home care teams. The use of experienced quality measures for external accountability and transparency on an organisational or national level was considered by stakeholders to be less of a priority than doing so for the home care setting. In addition to the goal of assessing experienced quality, the participants provided insight into criteria for the feasibility of the measure in the setting and its usability, such as knowing when to evaluate, who should evaluate, how to evaluate, what motivates one to evaluate, and how to use the outcomes.

In the third of working towards a qualitative experienced quality measure, no existing qualitative measures were found applicable in Dutch long-term care that cover the relevant content, and are sufficiently feasible and usable for the home care sector (Chapter 5). For the feasibility, the stakeholders indicated, for example, that it is important that the questions and the images used are clearly framed and understandable, and that the measure can be administered within a limited timeframe of 10 minutes. For the usability, it was found that, for example, the measure must be administered at least 
twice a year, and must result in concrete outcomes reported in the care plan or communicated among the care team.

The INDEXQUAL framework, operationalization and needs assessment were the basis of a qualitative experienced quality measure, which was developed by a participatory action research with clients, their informal and direct care providers, and district nurses (Chapter 6). In a cyclic development process the measure was stepwise refined, with the aim of providing input to improve the primary care process. The key characteristics of the developed measure are the individual evaluations by the district nurse in a care triad consisting of a client, their informal caregiver and their direct formal caregivers from a relationship-centred care approach, and that it adopts the principles of an appreciative inquiry approach. In addition, the themes were illustrated with four cards (see Figure 7.2) so individual respondents could selecting and discuss the themes that was most relevant to the experienced quality. These cards aimed to support both assessors and respondents with a clear structure and content for discussing experienced quality from a client's perspective, as well as to provide example questions and visual support for communicating relevant topics. The developed measure was pilot tested by district nurses in existing care triads. Evaluation indicates that the measure can help in formulating concrete outcomes to improve the primary care process, and that it is generally seen as feasible in the home care setting; it can be administered within a limited time of 8 to 13 minutes, and questions were judged to be clear and sufficiently specific to their experienced quality. Furthermore, the measure was seen as being usable in an ongoing care process, in the sense that it could be conducted twice a year or more, it fitted with the role of district nurses as evaluators and the appreciative inquiry approach was appropriate in the setting while sufficient room was also allowed to discuss more negative care experiences. 
Figure 7.2 Cards developed to depict the experienced quality themes

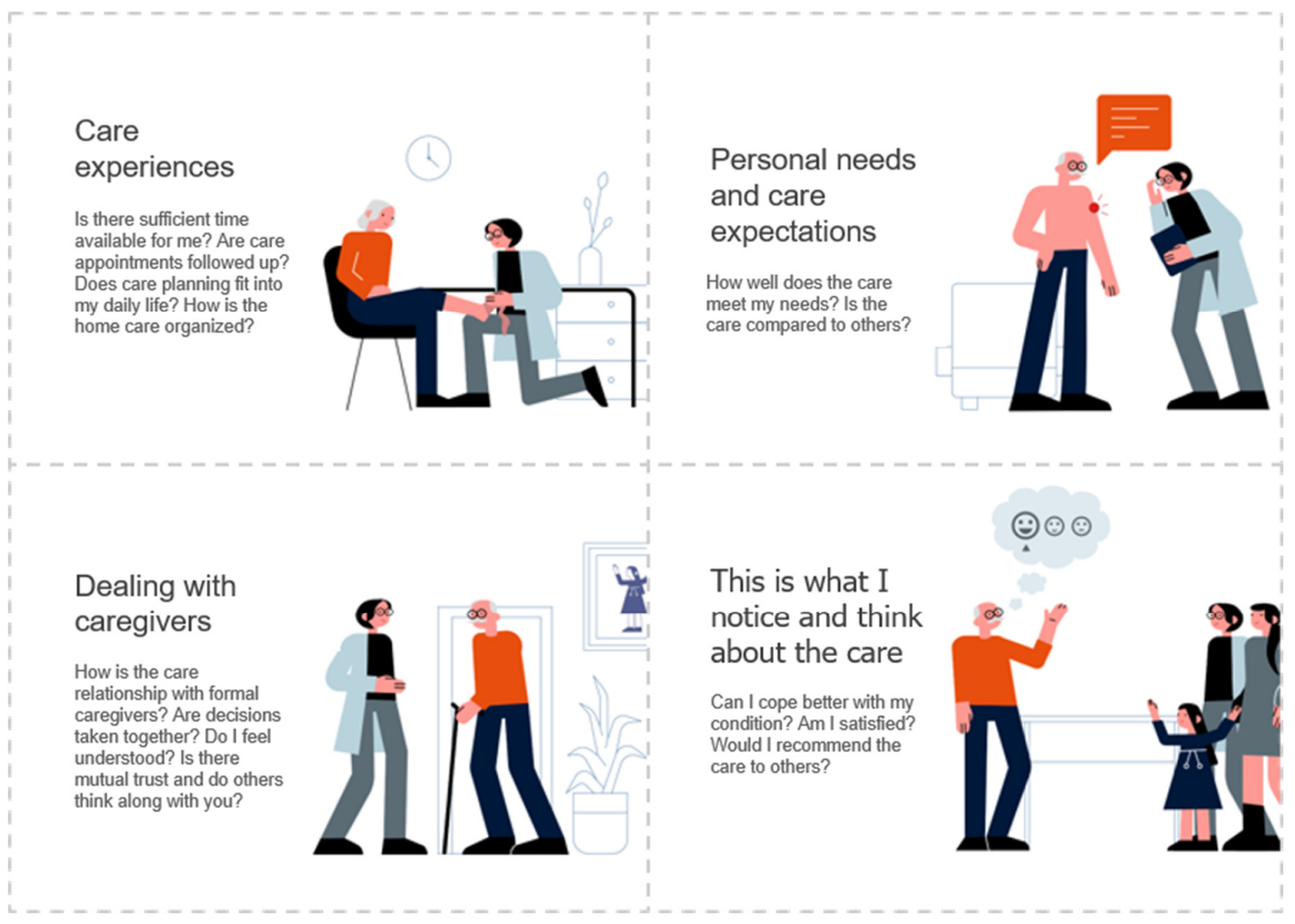

\section{METHODOLOGICAL CONSIDERATIONS}

In this section, some methodological considerations regarding the structured development approach, the study population and stakeholder participation, and the qualitative research within this dissertation will be discussed.

\section{Structured development approach}

The research in this dissertation followed a systematic and structured process leading to the development of an experienced quality measure. Important aspects of this process were the stakeholders' needs in determining the goal of the experienced quality measure, and the operationalization of experienced quality themes to specify the content of the measure, and the formulation of requirements concerning it's feasibility and usability. These aspects produced input for selecting the existing qualitative experienced quality measures and the iterative development of a novel experienced quality measure. The process was guided by existing methodologies, such as the PROM-cycle, whose steps seemed appropriate for this process because of their focus on determining the goal of the measure. ${ }^{1}$ In the second step of the cycle to 'determine het experiences', it was required to define the experienced quality attributes in home care. Existing experienced quality frameworks and definitions related to relationship-centred care were combined, resulting in the INDEXQUAL framework. This vital step during the development process was 
required, since the experienced quality concept is broad and addresses both physical as well as social and emotional care aspects. The concept of experienced quality can be addressed as being more task-centred, person-centred or relationship-centred. In chapter 3 a further identification of attributes related to experienced quality of care from the perspectives of clients, formal caregivers, and informal caregivers in home care took place. The selected relationship-centred approach based on the INDEXQUAL framework (Chapter 2) and its operationalization to home care (Chapter 3), has similarities to other operationalizations of experienced care quality, such as the Senses framework. The INDEXQUAL framework would benefit from more validation in practice. ${ }^{2}$ Therefore, it is vital to explore if the elements of experienced quality as defined in INDEXQUAL are applicable to home care services and in agreement with national quality frameworks in other countries.

Existing client experienced quality measures from the nursing home and disability care setting were identified and assessed to determine how well they fitted the home care setting. Criteria were defined for the measure's goal, content validity, feasibility in setting and usability in the care process. Since elaborate information on the development process of the existing measures was not always available for all measures at the point of the study, it was difficult to compare all of the criteria for all existing measures. Therefore, first the best fitting measures were selected based on their goal and content validity (experienced quality dimensions: multiple perspectives, care relationship and whether the measure was concerned solely with outcomes/satisfaction). Although the identified measures did not entail the discovered attributes on experienced quality for home care, the measures did provide valuable insight into relevant aspects for feasibility (e.g. visual design) and usability (e.g. how the measure is conducted). Stakeholders discussed these aspects of the measures in term of must haves and nice to haves (Chapter 4) for measuring experienced quality for home care and these were implemented in the developed measure. The lack of total availability of information on existing measures, hinders identification of appropriate ways to measure experience quality of care. Because of this information gap, it cannot be certain that the developed measure in this dissertation does not overlap with existing measures. This shows the importance of transparent reporting for applicability and availability of these measures and progress in this research field.

Study population and stakeholder participation

Clients, informal and formal caregivers in existing care triads were explicitly involved in developing a qualitative experienced quality measure not only for keystakeholders in home care, but with them as active partners in the journey. These keystakeholders and the subsequent interactions between in existing care triads were key in 
defining experienced quality from a relationship-centred care approach. The district nurse was seen as the person best able to judge which clients would be eligible to participate, based on his or her expert opinion of the mental and physical ability needed to participate. As a result, in the studies concerning the operationalization, need assessment and the evaluation of the developed measure participants were recruited by their district nurse. However, this could have resulted in selection bias of clients with a more positive care relationship with the district nurse or direct formal caregiver. To account for this, district nurses were asked to also include clients with more challenging care relationships. In addition, the studies presented in this dissertation may overrepresent clients with an above average cognitive and/or physical ability living at home. A significant population of home care clients cope with cognitive impairments or the onset of dementia, the results have to be checked for robustness within a more diverse sample. ${ }^{3}$ The visual stimuli and structure of the conversations offered by the cards that were developed need to be elaborated, which will possibly assist clients coping with a mild cognitive impairment to disclose narratives related to their care experiences. ${ }^{4,5}$ It is worth exploring whether this is indeed possible, and to do this the content of the measure in terms of experienced quality themes included and the trustworthiness of the requirements for its feasibility and usability, has to be tested within a more heterogenous client population.

Another means by which the study strove for stakeholder participation was by following a participatory action research (PAR) during the development of the measure. ${ }^{6}$ Key principles of PAR were adopted when involving the key-stakeholders (clients, informal caregivers and formal caregivers) throughout the process. ${ }^{7}$ PAR is often seen as a continuous learning process in which the researcher learns but also shares newly generated knowledge with those who may benefit from it. This became challenging during the COVID-19 pandemic since most research activities had to be conducted remotely and decreased the availability as well as involvement of participants. Meetings had to be conducted online and relatively more caregivers than clients were involved during the first development cycle. Also, participants were not optimally involved in the informal evaluations and adjustments during the refinement of the developed measure. The difficulty in this project of both accessing and involving stakeholders was a letdown since PAR draws its strength from empowering both caregivers and clients to engage in research and development activities. ${ }^{8}$ When possible, a move from a unilateral 'information' or 'consultation' level to a more bilateral 'advice' level with participants ideally results to a more direct influence of participants on the decision-making process. ${ }^{9,10}$ The use of existing promising qualitative participatory methods, such as the Photovoice method, could have facilitated a more in-depth and creative involvement of clients, both those with and those without cognitive impairments. ${ }^{11}$ In future research, it is worth exploring 
whether these methods can support a more inclusive participation with more diverse client sample in the development process.

Qualitative research in home care

Qualitative research in mixed groups with (older) clients receiving home care, informal caregivers and formal caregivers can be challenging. This was apparent during the mixed focus group interviews with clients, informal caregivers, and formal caregivers (Chapter 2). Our experiences showed it was challenging to achieve an in-depth understanding of experienced care quality from the perspective of clients due to the complexity of the concept itself and a lack of previous experience in evaluating experienced quality of home care. During evaluations, clients expressed that the questions asked during the mixed focus group interview were not specific and clear enough and the mixed setting made it difficult for them to elaborate on their own personal care experiences. In addition, the mixed setup of clients with direct caregivers prevented them from speaking openly about their personal care experiences and situations. Therefore, it may be possible that the outcomes of the focus group interviews have overrepresented the needs of formal caregivers, compared to the needs of clients and informal caregiver. During the second focus group of the needs assessment, clients and informal caregivers participated in smaller sub-groups, thereby providing them with more clear information and space to elaborate on questions and achieving more in-depth insight into their personal experiences and needs. In addition, individual interviews were conducted to allow clients and informal caregivers to share more details about their needs, facilitating a more open discussion and allowing for an equal comparison between perspectives. It is known that a combination of qualitative methods, for instance by discussing preferences for measuring experienced quality in focus groups and interviews, allows for a more detailed understanding of a concept than a single qualitative method can achieve. ${ }^{12}$

Qualitative study designs and methods were used to understand the concept of experienced quality and explore stakeholders' needs. ${ }^{13}$ In this dissertation different qualitative research methods and designs were selected. The themes of INDEXQUAL served both as the framework in the development of the topic list for data collection and as the thematic coding framework for the direct content analysis (Chapter 3), possibly limiting the input from participants beyond these discussed themes. For the operationalization of experienced quality, it was uncertain if the resulting quality attributes derived from the INDEXQUAL framework fully reflected an in-depth analyses of individual experiences in home care as sorting of data can be expected. Moreover, it can be questioned whether participants felt sufficiently supported and encouraged in discussing experienced quality topics beyond the questions asked, as the involved researchers were unknown to the participants and the research setup could be perceived as unnatural. To 
allow for a somewhat broader elaboration, cards of the MyHomeLife visual inquiry tool were used as a tool to help participants provide a more in-depth exploration on topics asked. ${ }^{14}$ In the next phase of the study, the Value Proposition Canvas was used as a thematic framework (Chapter 4 ) to get insight in the needs regarding the feasibility and usability. During the deductive analysis the framework was used to categorize stakeholder's needs. ${ }^{15}$ New categories and sub-categories were identified based the current drawbacks and (desired) benefits of existing measures by means of inductive analyses. In doing so, the input from various stakeholders was categorized and compared using a piori themes, while allowing for the inductive formulation of needs.

Quality criteria and corresponding techniques for qualitative research were applied to achieve a certain degree of trustworthiness for the studies in this dissertation. ${ }^{16}$ Although, transferability is not a main goal in qualitative research, the setting as well as participants were described thoroughly to allow readers to evaluate if and how the results apply in other contexts or settings. As the research was conducted in two home care organizations in the Southern part of the Netherlands, it would be beneficial to perform further research in home care organizations in other (more rural) regions. Concerning the credibility of the research conducted, the question arises as to whether the data in this dissertation represent the view of the participants comprehensively. Although the diversity of stakeholders reflected multiple layers in the home care organizations, the small sample size and composition of the groups are challenging to the credibility of the results. During the operationalization of the attributes (Chapter 3) and needs (chapter 4) data completeness was strived for by checking for data saturation until no new information emerged related to experienced quality themes and needs. ${ }^{17}$ Techniques, such as member checks during group meetings, were applied to verify that interpretations were correct and that the discovered experienced quality attributes and assessed needs were complete. Although no missing or incomplete data came out of this, it was unclear whether the clients and informal caregivers sufficiently recognized their own personal circumstances in the presented with experienced quality attributes and identified needs. Ideally, this process would have benefitted from conducting individualized member checks (e.g. by communicating summaries of transcripts to the participants) to identify missing attributes and needs. During the development process (Chapter 6) the COVID-19 pandemic influenced the methods used for data collection and the sampling procedure of participants. It was not possible to observe how district nurses applied the measure and therefore the research team had to rely on audio-recordings. This made it challenging to gain insight into the practical application of the developed measure and identify possibilities to embed the measure in existing evaluation processes. To achieve dependability, it is important to evaluate whether the process is logical, traceable and clearly documented. During the individual studies as part of the final development of the 
measure, the researchers strove to provide a detailed description of the process and provided argumentations for decisions and steps that were taken. To achieve transparency for participating organisations and as a future reference, this process could have benefitted from a clear and more easily accessible overview. In addition, transparency on both the development process and the outcomes can also help in engaging and convincing care providers and organizations to use new quality measures. ${ }^{18}$ This can assist home care organizations, policy makers and formal caregivers with, for example, selecting or recommending appropriate measures given the goal that has been set, the stakeholders that have been involved and the national requirements for the setting to measure experienced quality. Lastly, for reliability of findings, techniques were used such as independent coding by multiple researchers, joint reflection on the data, and the facilitation of detailed discussions between researchers on the (possible) discovery of, for example, experienced quality themes were used. There might have been a benefit to this process by additionally involving a larger number and more diverse clients and informal caregivers as active partners during the process of analysing the data and formulating quality themes. ${ }^{19}$

\section{THEORETICAL CONSIDERATIONS}

Next, a reflection is given on some theoretical considerations of this dissertation regarding the experienced quality of care, the perspectives involved in care triads, and the assessment of experienced quality using qualitative measures.

\section{Experienced quality of home care}

This dissertation identified relevant attributes related to experienced quality, categorized by the INDEXQUAL themes that were defined. The INDEXQUAL framework served as the theoretical foundation in this dissertation, thereby combining existing theories from both health sciences and service sciences literature. Existing quality framework, such as Donabedian's Quality of Care Framework or SERVQUAL, did not cover the complexity of long-term care provision throughout the client's journey and the involvement of multiple stakeholders in home care. ${ }^{20-24}$ The unique setting and the complexity of care relationships bring forth the need for a more holistic quality definition throughout the care process. ${ }^{25,26}$ INDEXQUAL was developed in following the principles of relationship-centred care and an elaboration of standard quality indicators by including interactions between multiple actors in the care environment and addresses the continuity in individualized care processes. The INDEXQUAL framework was developed and operationalized from the necessity to obtain a clear understanding of the meaning of experienced quality in both long-term care and home care in specific, for which a thorough quality framework was needed. ${ }^{27}$ The operationalization of INDEXQUAL in home care resulted in a wide variety of attributes and 
sub-attributes related to personal needs, word-of-mouth, past experiences, expectations of care services, relationship-centred care attributes, experiences with care services and the context. This foundation for the experienced quality concept was needed before stepping towards measuring and eventually improving it in practice. Since INDEXQUAL presents and overarching representation on experienced quality from a relationship perspective, the framework builds upon existing theories by allowing flexibility in adapting to specific long-term care settings, timings and populations.

Perspectives involved in care triads

Throughout this dissertation, experienced quality has been approached by considering interactions between individuals in existing care triads consisting of clients, informal and formal caregivers. Both informal and formal caregivers were involved as proxies in understanding and evaluating the client's experienced quality. This is in line with the ongoing developments in Dutch home care, which focus not only on meeting the client's needs but also on recognizing the value of (informal) caregivers and the existing care relationships within the client's home care environment. ${ }^{28}$ An example comes from an interview with a client who mentioned the importance of having a close, personal care relationship with caregivers as a precondition for home care provision. However, in this case the formal caregiver indicated that she did not feel the desire to act 'like being her best friend', and that preferred a more distant, professional care relationship with this client. The goal of the dissertation of gaining insight into experienced quality in home care from a client's perspective, a distinction has to be made between asking informal and formal caregivers to respond to the experienced quality (as proxies) from a client's perspective and asking them to respond from their own perspective and point of view. The perspectives of different stakeholders can overlap, but during the interviews with existing care triads it became apparent that these views can differ in meeting a client's versus adhering to one's own principles, needs or desired experience throughout the care process. For informal caregivers, providing home care could conflict with their own needs, ranging from maintaining their social contacts and being able to combine care provision with family responsibilities, to having access to adequate transportation and finding information on access to supportive services. ${ }^{29,30}$ In addition, previous studies have discovered needs of formal caregivers that could conflict with satisfying the client's desired experienced care quality, such as the importance of doing both dignifying and satisfying labour, providing continuity of care, and establishing positive relationships with both home care clients and supervisors (e.g. district nurse, manager). ${ }^{31,32}$ Being aware of these different points of view to a specific situation is called 'insiderness' by Todres, Galvin and Holloway, who state that every person has their own frame of reference through which he/she perceives the world. ${ }^{33}$ This frame of reference is shaped by the person's background and mood but also 
by previous experiences, which influence what particular experiences are like for someone. It is expected that openly communicating and disclosing each other's insiderness (to a certain extent) can help to create an understanding of what matters for the experience of the other. In doing so, care can be provided in a way that one perceives will be good experienced care, but one can also act according to the other's perspective. ${ }^{34}$

An awareness of the different perspectives, as well as being a means to facilitate the disclosures of the stakeholders' insiderness in home care, can shed additional light on the measurement of experienced quality of care. Therefore, the developed measure can be used to explore how to facilitate both informal and formal caregivers in sharing their own perspectives more, while adhering to feasibility and usability requirements in home care. More insight in the added value of including all perspectives when wanting to improve the primary care process is needed. This could justify the expected time investment of including all these perspectives when measuring experienced quality.

\section{Assessing experienced quality with a qualitative approach}

The developed measure assists with eliciting in-depth qualitative information related to the client's experienced care quality, with a goal being to formulate concrete points of improvement for the primary care process. Qualitative measures should be seen as complementary to quantitative measures to allow more insight into care experiences. ${ }^{35-37}$ This is also emphasized by the national quality framework for home care in the Netherlands, which states that good quality care should be provided if better insight is gained into the experienced quality for individual clients. ${ }^{28,38}$ Resulting from the national quality framework, the 'PREM home care' was proposed for Dutch home care as a mandatory standardized questionnaire. ${ }^{39}$ The PREM home care measures experienced quality mainly in a quantitative way (e.g. 'Do you feel at ease with your caregivers?' on a 10-item Likert scale), at the group (district) or organizational level. ${ }^{40,41}$ The new quality measure developed in this dissertation fills the gap between existing measures (e.g. PREM home care) and measures that gain more in depth insight into experienced quality at the individual level, due to the qualitative nature of the instrument. In doing this, it can facilitate work towards a total quality system for home care when used alongside existing measures. ${ }^{42}$

Although the developed measure allows for in-depth qualitative information to be obtained, questions remain on how data can be optimally used for the home care process. The developed measure strives to offer respondents space to share their care experiences, resembling a more narrative approach in measuring experienced quality. In doing so, it is important to ask the right questions in a more open conversation than in semi-structured interviews. ${ }^{43,44}$ In other words, broad questions are needed, such as 'what happened?', or similar more probing questions if the respondent has difficulty in starting, such as 'can you 
tell me a little more?'. In the qualitative measure that was developed in this dissertation, the conversation between respondent and assessor is structured using four main themes, followed by a number of main and in-depth questions. Principles adopted from appreciated inquiry focused on sharing what is already going well and what could be improved to make respondents feel motivated and encouraged to perceive the evaluation as beneficial for the future care process. ${ }^{45}$ Although assessors are advised to ask follow-up questions and to give respondents the room to share their care experiences, it is unsure to what extend the setting enables extended conversations beyond the main themes of the measure. The developed measure is thereby funnelled from broad themes of experienced quality to more specific in-depth questions addressing attributes, possibly leading in formulating concrete points of improvement for the primary care process, all within a limited time frame. A reporting sheet was developed for assessors in which outcomes could be reported, yet a more flexibel approach of reporting was preferred by formal caregivers for reporting and following up on outcomes. More insight is thus needed how the developed measure could be embedded optimally in Dutch home care in, for example, in regular evaluation conversations between clients and district nurses. There are indications that these regular evaluation conversations last around an hour, and focus on evaluating outcome indicators and goals in the client's care plan, which would allow to incorporate the current developed measure. This still leaves the question of how to analyze and act upon the resulting outcomes that are left unanswered.

\section{RECOMMENDATINOS AND IMPLICATIONS}

Based on the findings of this dissertation, this section summarizes both the recommendations and the implications for practice and future research.

Implications for practice

First, this dissertation adds to the understanding of experienced quality in home care, for which a qualitative experienced quality measure was developed. This measure assists with eliciting qualitative information related to the experienced quality from the client's perspective, aimed to formulate concrete points of improvement for the primary care process. In Dutch home care, patient-reported outcomes measures (PROMs) are currently being developed such as the 'PROM quality of life', while care experiences are yearly measured by the PREM home care at group-level and evaluated more unstructured at an individual-level. ${ }^{46-49}$ The newly developed measure measures experienced quality of care at the individual level more structured and in-depth, thereby facilitating towards a total quality system in home care when used alongside existing mainly quantitative quality

measures. ${ }^{42}$ By doing so, a more continuous measurement for (experienced) quality can be realized. Ideally, the new measure leads to concrete points of improvement of quality 
of care. Although it is advisable to administrate the measure at least twice-a-year, some flexibility is needed towards evaluating more frequently for clients with complex or declining care status. In addition, the importance of care relationships needs to be acknowledged between stakeholders receiving or providing long-term care. Involving clients, informal and formal caregivers is crucial in gaining insight into experienced quality from a client's perspective, an additional need seems to exists that informal caregivers and formal caregivers also want to share their own point-of-view then just reporting about the client's perspective.

Second, the experienced quality measure that has been developed seems to meet to stakeholders' needs in home care. For this reason, it is expected that stakeholders will feel motivated to apply it as a potentially useful tool in practice. An important precondition for good implementation in practice is the allocated time for discussing relevant experienced quality themes. District nurses need to be facilitated to spent sufficient time to use the new measure and to plan discussions with clients, informal caregivers and formal caregivers. However, home care providers are dealing with a dramatic increase of staff-shortages and workload over the past decades. ${ }^{50}$ This calls for a more structured approach as proposed by the new measure which could result in a more efficient way of discussing experienced quality as compared to unstructured approaches more communally applied in home care. The results show that applying the measure takes around 10 minutes by selecting one experienced quality theme for discussion. However, it should be borne in mind that additional time has to be allocated to have separate conversations with informal caregivers as well as formal caregivers, which potentially takes time to become accustomed to. It is vital for stakeholders to perceive these conversations as likely to lead to improvements in the care process and to experience an open, positive and nonjudgmental atmosphere when conducting the measure. Measuring experienced quality has obvious benefits for clients with pressing matters concerning a negative care experience, but it also offers a structured approach for the discovery of new insights for clients when everything is fine. Besides the role of district nurses in evaluating care plans and utilizing quality measurements, it is worth exploring whether other caregivers, such as registered nurses or nurse assistants, could fill a role during the assessment of experienced quality. If this is done, sufficient communication skills need to be fostered within care teams for conducting conversations within care triads. This includes maintaining a balance between open versus closed questions, insight into applying the appreciative inquiry approach and thereby focusing on what is going well and what can be done more frequently, and an understanding of how silence can facilitate a more in-depth discussion of the individual quality themes. ${ }^{51}$ These communication skills are expected from assessors to successfully apply the measure and could be facilitated as part of a more elaborate training when needed. 


\section{FUTURE RESEARCH}

This dissertation indicates several suggestions for future research.

First, the developed measure would benefit from evaluating its usability with a more diverse sample and explore its potential worth for clients coping with cognitive deficits, dementia or functional illiteracy. Although clients with an above average cognitive and/or physical ability were overrepresented in the studies in this dissertation, the potential use of the measure for clients with cognitive deficits or communication difficulties was mentioned multiple times by formal caregivers. Arguments for this were the clear structure of the measure and the visual aids used in presented the quality themes, the discussion of main and in-depth questions, and the involvement of key-stakeholders in care triads. However, more research is needed into whether the operationalizing of experienced quality still holds from this more diverse sample and whether care triads need to be extended by, for example, introducing dementia case managers. As for the developed measure, it is possible that the pictograms for the individual themes are considered too abstract or that the questions need to be adapted to fit this group of home care clients.

Second, the individual studies show that, whereas it is important to follow a structured approach in developing experienced quality measures, there is a need for additional tools and methods to allow for more elaborate stakeholder participation. Although existing methods and principles adapted from the user-centred design approach were applied, it would be worth to apply other methods such as heuristic evaluations, wireframing or cognitive walkthrough during future research. ${ }^{52}$ In doing so, it might help both researchers and developers to allow stakeholders a more prominent role during the development process.

Third, more insight is needed into how to use the perspectives of informal and formal caregivers in measuring experienced quality. Although the limited duration for conducting the measure was a clear requirement, it would be worth exploring whether, in addition, sharing their own point of view is beneficial for the primary care process of individual home care clients.

Fourth, more research into the developed measure is needed to understand if and how the measure's outcomes are used for learning and improving the care quality in home care. A first evaluation indicated that the measure is beneficial for discovering concrete points of improvement for the primary care process. Also, it would be valuable to gain insight into how outcomes of the measure are ideally communicated and followed-up in practice. Although the formal caregivers and district nurses preferred a more liberal approach towards reporting the outcomes, it is recommended that feasible methods for analysing the collected qualitative data in relation to the determined goal are explored. However, it might be necessary to modify existing, or develop new ICT infrastructures 
(e.g. in existing digital client files) in order for these outcomes to be systematically reported and made accessible for stakeholders in the care triad, without increasing administrative workloads. Outcomes should be compared with existing quality measures used in the primary care process, such as the PREM home care, to prevent the redundant measurement of similar quality themes. Conditions and strategies for implementing the developed measure should be explored in home care practice, ultimatly leading to the purposeful use of both the measure and its outcomes for the improvement of care quality in home care.

\section{CONCLUSION}

In conclusion, both the presented process and the developed qualitative experienced quality measure seem to facilitate discussing relevant experienced quality topics in care triads from a client's perspective, aimed at improving primary care process in home care. To what extend the outcomes are used and how the measure should be implemented in the care process has yet to be further explored. Throughout the development process, stakeholders in home care were involved in operationalizing experienced quality as defined by the INDEXQUAL framework, discovering their needs for selecting existing measures and developing a novel measure in iterative steps. The developed measure shows potential for formulating concrete points of improvement for the primary care process and has been seen to be as feasible measurement for the setting and an usable measure to implement in the in the regular care process. 


\section{REFERENCES}

1. van der Wees PJ, Verkerk EW, Verbiest ME, et al. Development of a framework with tools to support the selection and implementation of patient-reported outcome measures. Journal of patient-reported outcomes. 2019;3(1):1-10.

2. Nolan M, Brown J, Davies S, Nolan J, Keady J. The Senses Framework: improving care for older people through a relationship-centred approach. Getting Research into Practice (GRiP) Report No 2. 2006.

3. OECD. Health at a Glance 2019. 2019.

4. Drummond C, Coutinho G, Fonseca RP, et al. Deficits in narrative discourse elicited by visual stimuli are already present in patients with mild cognitive impairment. Frontiers in Aging Neuroscience. 2015;7:96.

5. Shell L. Photo-Elicitation with Autodriving in research with individuals with mild to moderate Alzheimer's disease: advantages and challenges. International Journal of Qualitative Methods. 2014;13(1):170-184.

6. Koshy E, Koshy V, Waterman H. Action research in healthcare. London: Sage; 2010.

7. Parkin P. Managing change in healthcare: Using action research. London: Sage; 2009.

8. Meyer J. Using qualitative methods in health related action research. Bmj. 2000;320(7228):178-181.

9. Arnstein SR. A ladder of citizen participation. Journal of the American Institute of planners. 1969;35(4):216-224.

10. Binkhorst $T$, Weerts $M$, Schipaanboord $A$. Patiënten betrekken bij de zorg in het ziekenhuis. Een handboek. Utrecht: CBO in samenwerking met NPCF. 2009.

11. Wiersma EC. Using photovoice with people with early-stage Alzheimer's disease: A discussion of methodology. Dementia. 2011;10(2):203-216.

12. Kuper $A$, Reeves $S$, Levinson $W$. An introduction to reading and appraising qualitative research. Bmj. 2008;337.

13. Creswell JW, Poth CN. Qualitative inquiry and research design: Choosing among five approaches. London: Sage publications; 2016.

14. Dewar B. Using creative methods in practice development to understand and develop compassionate care. International Practice Development Journal. 2012;2(1).

15. Osterwalder A, Pigneur Y, Bernarda G, Smith A. Value proposition design: How to create products and services customers want. John Wiley \& Sons; 2014.

16. Lincoln YS, Guba EG. Naturalistic inquiry. London: Sage; 1985.

17. Guest G, Bunce A, Johnson L. How many interviews are enough? An experiment with data saturation and variability. Field methods. 2006;18(1):59-82.

18. Foster A, Croot L, Brazier J, Harris J, O'Cathain A. The facilitators and barriers to implementing patient reported outcome measures in organisations delivering health related services: a systematic review of reviews. Journal of patient-reported outcomes. 2018;2:46.

19. Vennik F. Interacting patients: the construction of active patientship in quality improvement initiatives. Rotterdam, Erasmus University Rotterdam; 2016.

20. Donabedian A. The definition of quality and approaches to its assessment: explorations in quality: explorations in quality assessment and monitoring. In: Chicago: Health Administration Press; 1980.

21. Duffy JR, Hoskins LM. The quality-caring model(C): Blending dual paradigms. Advances in nursing science. 2003;26(1):77-88.

22. McCormack B, van Dulmen S, Eide H, Skovdahl K, Eide T. Person-centred healthcare research. John Wiley \& Sons; 2017.

23. Parasuraman A, Zeithaml VA, Berry LL. Servqual: A multiple-item scale for measuring consumer perc. Journal of retailing. 1988;64(1):12.

24. Sandager M, Freil M, Knudsen JL. Please tick the appropriate box: Perspectives on patient reported experience. Patient Experience Journal. 2016;3(1):63-79. 
25. Kromhout M, Kornalijnslijper N, de Klerk M. Veranderde zorg en ondersteuning voor mensen met een beperking. Landelijke evaluatie van de Hervorming Langdurige Zorg. 2018.

26. Francke AL, Rijken PM, Groot Kd, de Veer A, Verkleij KA, Boeije HR. Evaluatie van de wijkverpleging: ervaringen van cliënten, mantelzorgers en zorgprofessionals. 2017.

27. Sion $\mathrm{KYJ}$, Verbeek $\mathrm{H}$, de Boer $\mathrm{B}$, et al. How to assess experienced quality of care in nursing homes from the client's perspective: results of a qualitative study. BMC Geriatrics. 2020;20(1):67.

28. Stuurgroep Kwaliteitskader Wijkverpleging. Kwaliteitskader Wijkverpleging. 2018; https://www.zorginzicht.nl/kwaliteitsinstrumenten/wijkverpleging-kwaliteitskader. Accessed 15th Oktober, 2019.

29. Criel B, Vanlerberghe V, De Koker B, Decraene B, Engels E, Waltens R. Informal home care for elderly in Belgium: a study on the features and challenges of informal care at local level. Community mental health journal. 2014;50(7):848-853.

30. Lamura G, Mnich E, Nolan M, et al. Family Carers' Experiences Using Support Services in Europe: Empirical Evidence From the EUROFAMCARE Study. The Gerontologist. 2008;48(6):752-771.

31. Delp L, Wallace SP, Geiger-Brown J, Muntaner C. Job stress and job satisfaction: Home Care Workers in a consumer-directed model of care. Health services research. 2010;45(4):922-940.

32. Tourangeau AE, Patterson E, Saari M, Thomson H, Cranley L. Work-related factors influencing home care nurse intent to remain employed. Health Care Management Review. 2017;42(1):87-97.

33. Todres L, Galvin KT, Holloway I. The humanization of healthcare: A value framework for qualitative research. International Journal of Qualitative Studies on Health and Well-being. 2009;4(2):68-77.

34. Goossensen A. Schetsen van mismatch. Een zorgethische visie op Evaluatieonderzoek Utrecht. 2014.

35. Kingsley C, Patel S. Patient-reported outcome measures and patient-reported experience measures. BJA Education. 2017;17(4):137-144.

36. Coulter A, Fitzpatrick R, Cornwell J. Measures of patients' experience in hospital: purpose, methods and uses. London: King's Fund London; 2009.

37. Locock L, Robert G, Boaz A, et al. Testing accelerated experience-based co-design: a qualitative study of using a national archive of patient experience narrative interviews to promote rapid patient-centred service improvement. Health Services and Delivery Research. 2014;2(4).

38. Zorginstituut Nederland. Zorgpartijen krijgen ruimte om meetinstrumenten te ontwikkelen.

2015; https://www.zorginstituutnederland.nl/actueel/nieuws/2015/12/08/zorgpartijenkrijgen-ruimte-om-meetinstrumenten-te-ontwikkelen.

39. Zorginstituut Nederland. Wijkverpleging indicatoren: meetinstrumenten langdurige zorg. 2021; https://www.zorginzicht.nl/kwaliteitsinstrumenten/wijkverplegingindicatoren. Accessed 5th of January, 2021.

40. Handboek voor zorgaanbieders van wijkverpleging: Toelichting op de kwaliteitsindicatoren en meetinstructies meetjaar 2019. 2019. https://www.patientervaringsmetingen.nl/wpcontent/uploads/2019/04/Handboek-en-vragenlijst-voor-zorgaanbieders-vanwijkverpleging_def_1-april.pdf. Accessed 25 February 2021.

41. Heath I. Arm in arm with righteousness. Philosophy, Ethics, and Humanities in Medicine. 2015;10(1):1-4.

42. Chadborn NH, Devi R, Hinsliff-Smith K, Banerjee J, Gordon AL. Quality improvement in long-term care settings: a scoping review of effective strategies used in care homes. European Geriatric Medicine. 2020.

43. Mishler EG. Models of narrative analysis: A typology. Journal of narrative and life history. 1995;5(2):87-123.

44. Riessman CK. Narrative analysis. London: Sage; 1993. 
45. Cooperrider D, Whitney D, Stavros J. Appreciative inquiry handbook: lakeshore communications. Inc, Bedford Heights. 2003.

46. Withers KL, Puntoni S, O'Connell S, Palmer RI, Carolan-Rees G. Standardising the collection of patient-reported experience measures to facilitate benchmarking and drive service improvement. Patient Experience Journal. 2018;5(3):16-24.

47. Smith A, Hex N, Taylor M. Patient-Reported Experience Measures (PREMS). A Scoping Document to Inform the Evaluation of the NHS Vanguard sites. In. Wakefield: York Health Economic Consortium; 2015.

48. Kroneman M, Boerma W, van den Berg M, Groenewegen P, de Jong J, vanGinneken E. The Netherlands: health system review. Health Systems in Transition. 18. $2016 ; 2: 1-239$.

49. Tzelepis F, Rose SK, Sanson-Fisher RW, Clinton-McHarg T, Carey ML, Paul CL. Are we missing the Institute of Medicine's mark? A systematic review of patientreported outcome measures assessing quality of patient-centred cancer care. BMC cancer. 2014;14(1):1-32.

50. OECD. Who Cares? Attracting and Retaining Care Workers for the Elderly. 2020.

51. Cooperrider D, Srivasta S. Appreciative Inquiry in organizational life. Research in Organizational Change and Development, 1, 129-169. In:1987.

52. Jaspers MW. A comparison of usability methods for testing interactive health technologies: methodological aspects and empirical evidence. International journal of medical informatics. 2009;78(5):340-353. 


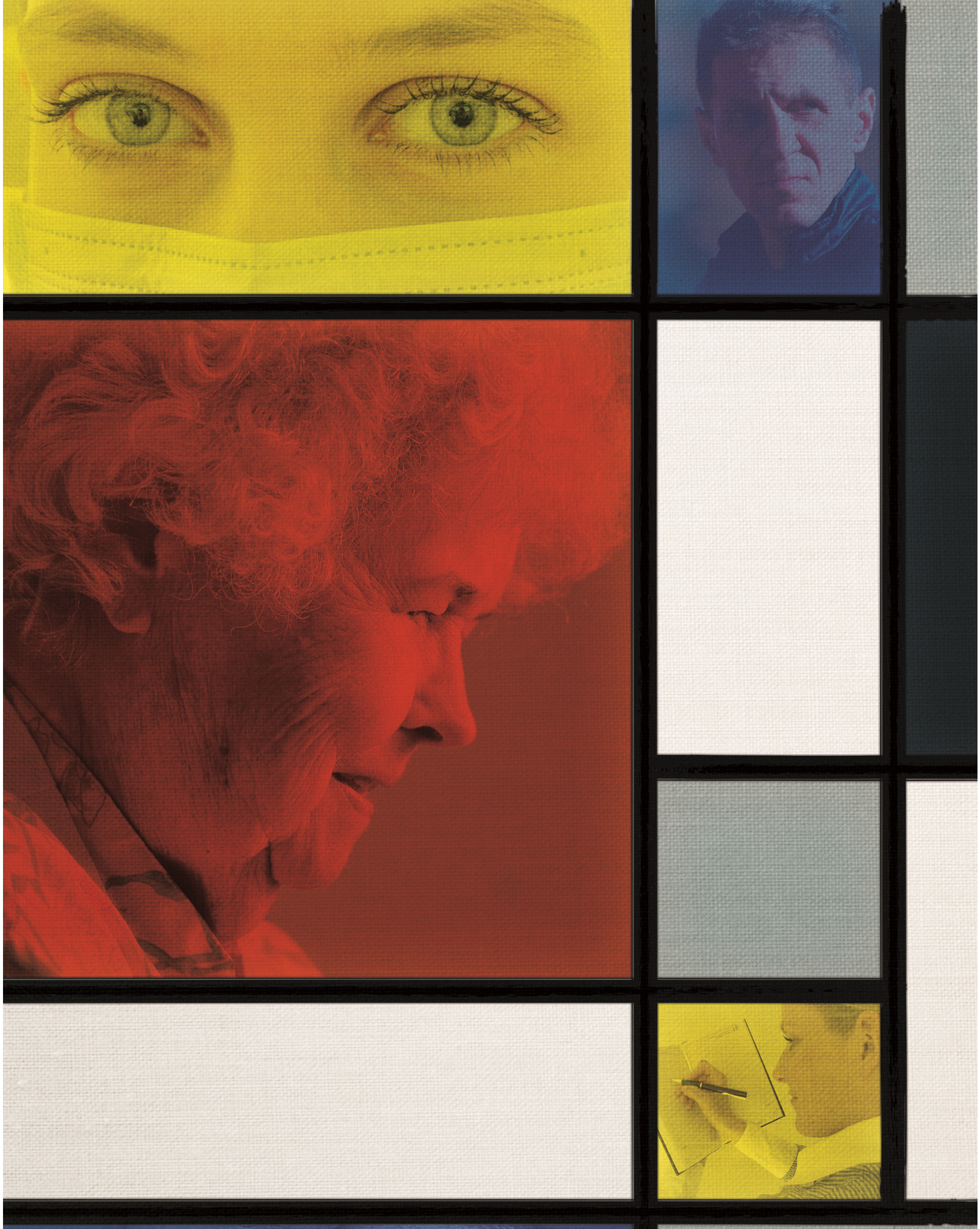


\title{
Addendum
}

\author{
English summary
}

Samenvatting

Impact

Living lab in ageing and long-term care Dankwoord About the author 


\section{Summary}

There is an increasing focus on delivering high-quality care services tailored to the individual needs and care experiences of home care clients. To improve the primary care process in home care, it is important to gain insight into experienced quality from the perspective of clients within existing care triads. It is necessary to include qualitative measures in the home care process, in addition to their quantitative counterparts, to facilitate the sharing of the client's care experiences and to obtain rich quality information. However, at the start of this dissertation no existing qualitative measures were identified in Dutch home care, measuring relevant content for the home care setting as well as being both feasible in the settings and usable in care processes. This dissertation, therefore, focused on the process of determining stakeholders' needs when developing a qualitative experienced quality measure from a client's perspective specifically for the home care setting. This dissertation focuses on home care clients receiving long-term care.

Chapter 1 provides a general introduction, describing the home care setting for clients receiving long-term home care in the Netherlands who are suffering from one or more chronic conditions. Next, a conceptual understanding of care quality is given, together with information on the way in which quality of care is measured in home care. This chapter ends with a presentation of the overall aim and outline of this dissertation.

Chapter 2 presents the Individually Experienced Quality of Long-Term Care (INDEXQUAL) framework to conceptualize the experienced quality of care for long-term care as perceived by clients. The framework is constructed based on an iterative review of the existing models and frameworks defining care quality from a client's perspective, as well as consultations with a panel of experts in long-term care (e.g. representatives from the Ministry of Health and the National Health Care Institute) to obtain feedback on the findings. INDEXQUAL presents the process of individual care experiences consisting of expectations before care is provided, experiences taking place during care interactions, and an assessment afterwards. The INDEXQUAL framework differs from existing frameworks and models by incorporating knowledge from the healthcare and service sciences literature, thus offering a more holistic view on how care is experienced from a client's perspective.

Chapter 3 focuses on exploring and understanding the views of clients, formal caregivers, and informal caregivers on the experienced quality of home care for older people. A descriptive qualitative study was conducted using individual interviews, with the aim of operationalizing the INDEXQUAL quality themes for the home care setting (e.g. personal needs, care expectations and past experiences). Six care triads, consisting of clients, formal caregivers and informal caregivers, participated. The study identified a wide range of attributes related to the experienced quality of home care, such as the preferred number of caregivers, a perception of sufficient time being given for care provision and a 
caring atmosphere facilitating open communication and humour. Different perspectives from the care environment highlighted the importance in fitting care routines to a client's former way of living and communicating preferences, for more personal versus professional care relationships. The results underline the importance of incorporating care preferences and experiences throughout the care process, and taking a relationshipcentred care approach in determining relevant care measures and outcomes.

Chapter 4 aims to understand the needs of clients, formal/informal caregivers, and managers/policy officers as stakeholders in measuring a client's experienced quality in home care. Both focus group interviews and semi-structured interviews with stakeholders were conducted, with the Value Proposition Canvas used as a thematic structure during the content analysis. The purpose of measuring experienced quality of home care was found to focus primarily on improving the primary care process of individual clients. In addition to the goal of assessing experienced quality, both insight and agreement are needed on when to evaluate, who should evaluate, how to evaluate, what motivates one to evaluate, and what to do with the outcomes. Among other things, stakeholders described how they do not currently have enough time or a clear existing procedure for evaluating experienced quality. Furthermore, desired needs emerged, such as a more informal evaluation of experienced quality and a more open discussion of negative experiences with a familiar caregiver. The results underline the relevance of adopting, in addition to quantitative evaluations like the PREM home care, more qualitative evaluation methods to support open communication about care experiences, leading to concrete points of improvement for the primary care process for individual clients.

Chapter 5 describes an exemplary case study with an in-depth description of the first three steps of the patient-reported outcomes measure (PROM) cycle framework is provided in relation to the measurement selection. First, the goal of the measurement, the key stakeholders and the setting were determined, following national guidelines, stakeholder analysis, and a prior needs assessment with clients, informal and formal caregivers, and managers/policy makers as the key stakeholders. Second, patientreported experiences were studied following the INDEXQUAL framework and its operationalization for home care. Third, to select and assess experienced quality measures, existing inventories were consulted and assessed using defined criteria for the goal of the measure, content validity, feasibility in a care setting and usability in the care process. Home care associations and organisations should consider following a structured process when selecting measures for experience quality by including the needs of key stakeholders, as well as adhering to the goal that has been determined, the underlying theoretical constructs and the selection criteria on content, feasibility and usability. The resulting, potentially adequate, measures should be extensively tested and evaluated to determine their value for practice. 
Chapter 6 presents the development process for a qualitative experienced quality measure to facilitate conversations by district nurses with clients, informal caregivers, and informal caregivers to generate useful outcomes for the primary care process. By means of participatory action research, the developed measure followed three iterative cycles in which various data sources were used to evaluate the requirements related to its goal, its feasibility in the care setting, and its usability in the care process. The final design comprises an instruction meeting for district nurses as assessors and a structured approach to evaluate experienced quality with clients, informal caregivers, and formal caregivers. In addition, cards and corresponding exemplary questions were developed for the experienced quality themes (e.g. personal needs and expectations) and sub-themes (e.g. preferred way of communicating care needs). District nurses, who conducted conversations in existing care triads during a limited evaluation study, applied the method that had been developed in existing care practice. The measure was seen as a structured approach towards discovering concrete points of improvement for a client's primary care process. As regards feasibility, the measure appears to have a helpful structure, with the visual communication of experienced quality themes on the cards that were developed; the measurement can be conducted in around 10 minutes, and includes clear and appropriate questions. However, it was necessary to reformulate the questions on the basis of the respondent's communication skills and background. As for usability, a biannual administration of the measure was seen as a strived average, although flexibility is needed to allow it to be applied more frequently for clients with complex care situations. The measure seem to fit the current care relationships between respondents and district nurses, although follow-up questions are required for an in-depth discussion and to formulate the concrete points of improvement. The outcomes were mostly reported within existing care plans, although more insight is needed into how the developed measure can be further embedded with existing care processes.

Chapter $\mathbf{7}$ includes a general discussion of the main findings of this dissertation, and includes a methodological and theoretical reflection on the findings. Lastly, implications and recommendations for future practice and research are provided. 


\section{Samenvatting}

$\mathrm{Er}$ is in toenemende mate aandacht voor het verlenen van kwalitatief hoogwaardige zorg die is afgestemd op de individuele behoeften en zorgervaringen van cliënten in de thuiszorg. Hierbij is het van belang inzicht te krijgen over de ervaren kwaliteit vanuit het cliëntperspectief in bestaande zorgnetwerken, om zo het primaire zorgproces te verbeteren. Om deze zorgervaringen in kaart te brengen en te benutten als rijke bron voor kwaliteitsinformatie zijn kwalitatieve methodieken nodig als aanvulling op bestaande kwantitatieve instrumenten. Desondanks waren er bij aanvang van dit proefschrift geen bestaande kwalitatieve methodieken binnen de Nederlandse thuiszorg die relevante inhoud meten en zowel uitvoerbaar zijn in de setting als bruikbaar in het zorgproces. Dit proefschrift richt zich daarom op het proces om behoeften van belanghebbenden te bepalen in het ontwikkelen van een kwalitatieve ervaren kwaliteitsmeting vanuit cliëntperspectief voor cliënten die gebruik maken van langdurige zorg thuis.

Hoofdstuk 1 geeft een algemene inleiding. In dit hoofdstuk wordt de thuiszorgsetting in Nederland beschreven van cliënten die langdurige thuiszorg ontvangen. Vervolgens wordt een conceptueel inzicht gegeven over de kwaliteit van zorg en wordt toegelicht op welke wijze zorgkwaliteit in de thuiszorg wordt gemeten. Het hoofdstuk eindigt met het algemene doel en de opzet van dit proefschrift.

Hoofdstuk 2 presenteert het Individually Experienced Quality of Long-Term Care (INDEXQUAL) raamwerk om de ervaren kwaliteit binnen de langdurige zorg te conceptualiseren vanuit het cliëntperspectief. Het raamwerk is ontwikkeld op basis van een review naar bestaande modellen en raamwerken die zorgkwaliteit definiëren vanuit het cliëntperspectief. Verder zijn hierbij een groep experts geraadpleegd (o.a. vertegenwoordigers van het Ministerie van Volksgezondheid, Nationale Zorginstituut) in de langdurige zorg om feedback te verkrijgen op de bevindingen. INDEXQUAL stelt het proces van individuele zorgervaringen voor, bestaande uit verwachtingen vóór de zorgverlening, ervaringen die plaatsvinden tijdens zorginteracties, en een evaluatie achteraf. Het INDEXQUAL raamwerk is gebaseerd op bestaande raamwerken en modellen waarbij kennis uit de literatuur in de gezondheidszorg en dienstverlening is gecombineerd, het geeft hierbij een holistische kijk op hoe zorg wordt ervaren vanuit cliëntperspectief. Het raamwerk diende als basis binnen het project om ervaren kwaliteit in de thuiszorg te operationaliseren.

Hoofdstuk 3 richt zich op het verkennen van de opvattingen over de ervaren kwaliteit van thuiszorg van cliënten, formele zorgverleners en informele zorgverleners. Een beschrijvende kwalitatieve studie werd uitgevoerd met behulp van individuele interviews, gericht op het operationaliseren van de INDEXQUAL kwaliteitsthema's in de thuiszorg (bijv. persoonlijke behoeften, zorgverwachtingen en eerdere ervaringen). Zes zorgdriehoeken bestaande uit cliënten, formele en informele zorgverleners namen hierin 
deel. Een breed overzicht van aspecten gerelateerd aan ervaren kwaliteit van de thuiszorg werd geïdentificeerd zoals het gewenste aantal zorgverleners, ervaren tijdsdruk tijdens de zorgverlening en een atmosfeer met ruimte voor open communicatie en humor. Verschillende perspectieven in de zorgomgeving benadrukten het belang van het afstemmen van zorgroutines op de eerdere manier van leven van een cliënt en het communiceren van voorkeuren in het soort zorgrelatie als zijnde meer persoonlijk of professioneel. De resultaten onderstrepen het belang van het opnemen van persoonlijke zorgbehoeften en ervaringen gedurende het zorgproces vanuit een meer relatiegerichte benadering in het bepalen van relevante zorgindicatoren en -uitkomstmaten.

Hoofdstuk 4 heeft als doel om inzicht te krijgen in de behoeften van cliënten, formele/informele zorgverleners, en managers/beleidsmedewerkers als stakeholders in het meten van de ervaren kwaliteit van cliënten in de thuiszorg. Zowel focusgroepen als semigestructureerde interviews werden afgenomen met stakeholders, waarbij de waarde propositie canvas werd gebruikt als thematische structuur tijdens de inhoudsanalyse. Het gewenst doel bij het meten van ervaren kwaliteit bleek hoofdzakelijk gericht op het verbeteren van het primaire zorgproces van individuele cliënten. Naast het doel in het evalueren van ervaren kwaliteit, was inzicht nodig over wanneer te evalueren, wie te evalueren, hoe te evalueren, wat motiveert iemand om te evalueren, en wat te doen met de uitkomsten. De stakeholders benoemde voldoende tijd is en de aanwezigheid van duidelijke bestaande structuren als noodzakelijk voor het evalueren van ervaren kwaliteit. Verder kwamen gewenste behoeften naar voren zoals informeel evalueren en meer openlijk bespreken van negatieve ervaringen met een vertrouwde zorgverlener. De resultaten benadrukken de relevantie in het toepassen van meer kwalitatieve evaluatiemethoden naast kwantitatieve evaluaties zoals de PREM thuiszorg. Op deze manier wordt een open communicatie over zorgervaringen ondersteund, wat kan leiden tot concrete verbeterpunten voor het primaire zorgproces van individuele cliënten.

Hoofdstuk 5 beschrijft een exemplarische case studie met een uitvoerige beschrijving werd gegeven in het toepassen de eerste drie stappen van het patientreported outcomes measure (PROM)-cyclus raamwerk, gericht op het selecteren van bestaande methodieken. Eerst werden het doel van de meting, de belangrijkste belanghebbenden en de setting bepaald aan de hand van nationale richtlijnen, stakeholder analyse en behoeften studie met cliënten, informele en formele zorgverleners, en managers/beleidsmakers als belangrijkste belanghebbenden. Ten tweede werden de door ervaren kwaliteit attributen vastgesteld volgens het INDEXQUAL raamwerk en de operationalisering hierin in de thuiszorg. Ten derde, om ervaren kwaliteitsmethodieken te selecteren en te beoordelen, werden bestaande waaiers van instrumenten geraadpleegd en beoordeeld aan de hand van gedefinieerde criteria voor het doel, inhoudsvaliditeit, haalbaarheid in de zorgsetting en bruikbaarheid in het zorgproces. Resultaten 
benadrukken dat zorgorganisaties zouden moeten overwegen om een gestructureerd proces te volgen bij het selecteren van ervaren kwaliteit methodieken, waarbij rekening wordt gehouden met zowel de behoeften van de belangrijkste stakeholders en het vastgestelde doel, als zowel het onderliggende theoretische construct en selectiecriteria voor inhoud, haalbaarheid en bruikbaarheid.

Hoofdstuk 6 presenteert het ontwikkelproces van een kwalitatief ervaren kwaliteitsmethodiek voor het faciliteren van gesprekken tussen cliënten en zorgverleners. Deze methodiek is gericht op het vinden van bruikbare uitkomsten voor het primaire zorgproces. Door middel van participatief actieonderzoek doorliep de iteratieve ontwikkeling drie cycli, waarin vereisten zijn geëvalueerd naar het beoogd doel, haalbaarheid in de zorgsetting en bruikbaarheid in het zorgproces. Het uiteindelijke ontwerp omvat een instructiebijeenkomst voor wijkverpleegkundigen als beoordelaars en een gestructureerde aanpak om ervaren kwaliteit te evalueren met cliënten, informele zorgverleners, en formele zorgverleners. Daarnaast werden ondersteunende kaarten en bijbehorende voorbeeldvragen ontwikkeld voor het bespreken van kwaliteitsthema's (bijv. persoonlijke behoeften en verwachtingen) en subthema's (bijv. voorkeursmanier van communiceren over zorgbehoeften). Als onderdeel van een beperkte evaluatiestudie voerden wijkverpleegkundigen gesprekken in bestaande zorgdriehoeken waarin de ontwikkelde methode werd toegepast in de bestaande zorgpraktijk. De methodiek werd als een gestructureerde benadering gezien in het formuleren van concrete verbeterpunten voor het primaire zorgproces van cliënten. Voor de uitvoerbaarheid biedt het een structuur in het visueel communiceren van ervaren kwaliteitsthema's, is het toepasbaar in ongeveer 10 minuten en bevat het heldere en passende vragen. In enkele gevallen was het herformuleren van de vragen op basis van de communicatieve vaardigheden van respondenten echter nodig. Wat betreft de bruikbaarheid wordt een tweejaarlijkse afname als een goed gemiddelde gezien, hoewel flexibiliteit nodig is om deze frequenter toe te passen voor cliënten met een complexe zorgsituatie. De methodiek sluit aan bij de huidige zorgrelaties tussen respondenten en wijkverpleegkundige, hoewel vervolgvragen nodig zijn voor een diepgaande discussie in het formuleren van concrete verbeterpunten. Voor het rapporteren van de uitkomsten van de gesprekken werden de bestaande zorgplannen gebruikt. Meer inzicht is nodig over de wijze waarop de ontwikkelde methodiek verder kan worden ingebed binnen bestaande zorgprocessen.

Hoofdstuk 7 bevat de algemene discussie waarin de belangrijkste bevindingen van dit proefschrift worden besproken, inclusief een methodologische en theoretische reflectie op de bevindingen. Tenslotte worden implicaties en aanbevelingen gedaan voor zowel praktijk en onderzoek. 


\section{Impact}

"As a district nurse, I've found the experienced quality measure as very pleasant because conversations took place with clients, informal caregivers, and formal caregivers. Through this measure, we were able to elaborate about the care in an accessible way from the client's perspective. By using the cards, topics come up that would not normally come up during an evaluation conversation."

The aim of this dissertation was to 1) gain an understanding of the experienced quality in the home care setting, 2) acquire insight into current practices and needs of measuring experienced quality of home care, and 3) develop a novel qualitative experienced quality measure from a client's perspective for home care. This was done in collaboration with clients, informal caregivers, and formal caregivers from a relationship-centred care approach and focused on discovering improvements for the client's primary care process in home care. This chapter addresses the societal and scientific impact of this dissertation, thereby elaborating on both efforts made and those still needed to disseminate the findings.

\section{Societal impact}

The results of this dissertation provide new insights into the client's experienced quality in home care; the needs of clients, informal caregivers, formal caregivers, and policy officers regarding current practices and desires with regard to experienced quality measures; and the development of a qualitative experienced quality measure from a client's perspective in Dutch home care. The relationships among clients, their informal caregivers, and their formal caregivers are important and should be included in measuring experienced quality from a client's perspective. Personal care experiences are shaped by dynamic interactions among clients, informal caregivers, and formal caregivers, requiring a different way of assessing these experiences. This can be achieved by using a more qualitative approach in measuring experienced quality in addition to quantitative measures. These types of measures are seen as fitting to care provided in the home care setting, since receiving care for extended periods allows for a more continuous evaluation in which multiple stakeholders can aid to understand and improve the experienced care quality. Using cards with pictograms can structure the evaluation and help in communicating the client's experiences compared to utilising standardised questionnaires. However, a qualitative measures approach requires a different way of analysing and interpreting the results. Compared to quantitative measurements and outcomes, this is seen as time-consuming 
and labour-intensive in the long run and can have implications for use in the home care setting. ${ }^{1}$ The use of qualitative measures such as the developed qualitative experienced quality measure should thus be seen as complementary to existing mandatory measures in Dutch home care, such as the PREM home care. ${ }^{2} \mathrm{~A}$ reason for this is that the goal (micro-level) as well as the type of measure (qualitative, in-depth) and perspectives involved differ (clients, as well as informal caregivers and formal caregivers from a relationship-centred care perspective).

The developed measure was based on analyses of stakeholders' views on its feasibility in the home care setting (e.g., are the questions understandable and clearly framed) and usability in the existing care process (e.g., does it result in a sufficiently indepth discussion of care experiences). Also, for the implementation of quality measures, it is important to attend to its robustness, as well as the fit with feasibility and usability criteria. Underlying motivational and other personal factors can be met by involving the key stakeholders from the start, since it is believed they are important to address when selecting suitable implementation strategies. ${ }^{3,4}$ The goal, feasibility, and usability criteria served as a red line throughout the individual studies and were thus (to some degree) taken into account as must haves during the development of the measure. However, more work is needed in evaluating the developed experienced quality measure in a larger practice setting before it can be implemented in practice.

This dissertation and the studies conducted fit within a broader framework to develop an experienced quality measure in long-term care as supported in the Province of Limburg by the Limburg Meet knowledge programme and national advances in the Netherlands within various long-term care settings, such as nursing home care and disability care. ${ }^{5}$ For the nursing home setting, a narrative method was developed in collecting and connecting residents' stories to provide information about the experienced quality of a care organisation. ${ }^{6}$ For the disability care setting, several implementation strategies are being developed and evaluated for an existing narrative PREM. ${ }^{7}$ The quality measure developed as a results of this dissertation is aimed at discovering concrete points of improvement to enhance the primary care process of individual home care clients. A first application of the developed measures shows that in most cases this was the result, although more insight is needed on outcomes if individual perspectives are analysed, communicated, and applied in practice. Team care meetings are often mentioned as a suitable place for discussing these outcomes with and among formal caregivers, although currently these meetings seem to focus mostly on discussing urgent matters. Activities undertaken to generate societal impact are listed under the dissemination of findings. 


\section{Scientific impact}

In addition to the societal impact, the studies in this dissertation have scientific impact for several reasons. First, this dissertation contributes to the scientific literature on the systematic approach towards the iterative development of a quality measure for home care. To our knowledge, this is the first attempt to apply the first three steps of the PROM cycle for the iterative development of a qualitative measure. ${ }^{8}$ In the first step, the measurement's goal, key stakeholders, and setting were determined. Second, experienced quality was conceptualised by a theoretical framework and operationalised for the home care setting. Third, existing measures were selected and assessed using defined criteria for their goal, content validity, feasibility in setting, and usability in the care process. By following this approach, the goal in measuring experienced quality is placed above the actual measurement. During this process, attention was given to the measurement's content validity by determining which experienced quality domains to include. Moreover, a less conventional step is the application of requirements concerning the measurement's feasibility and usability during the development process. Although the developed measure adheres to the feasibility criteria, more insight is needed on its usability to integrate it within existing (evaluation) processes in home care.

Second, this dissertation contributes to a new view on experienced quality of longterm care as presented by the INDEXQUAL framework. INDEXQUAL presents the process of individual care experiences consisting of expectations before, interactions during, and an assessment of experiences afterwards. It adopts a relationship-centred care approach by acknowledging care relationships and following interactions among clients, informal caregivers, and formal caregivers as key-stakeholders in the caring context. Proposing quality as a dynamic process throughout the care process and acknowledging care relationships provide an additional layer to the previously dominant person-centred care approach in home care.

Third, existing methods from the user-centred design approach were adopted to allow for stakeholder participation as a central element throughout this dissertation for implementation in practice. An example was the Value Proposition Canvas, which served as a robust thematic framework during the analyses of stakeholders' needs. ${ }^{9}$ Identifying and differentiating between key-stakeholders allowed to approach a single concept from multiple perspectives. However, during the study, this also brought dilemmas to light when individual perspectives did not align or even contradicted each other. An example was the dilemma of what needed to be done with the outcomes following the developed measure. In this case, managers and policy officers strived for a more systematic reporting, while formal caregivers stressed the importance of having no obligations in discussing or reporting outcomes in a given format within the care team. It is therefore important to 
acknowledge the existence of these (sometimes conflicting) needs and be transparent about possible consequences on the following steps taken in the development of the measure. By doing so, both the scientific community and home care organisations can judge the trustworthiness of the developed qualitative experienced quality measure. There is a need for a more structured and transparent development process, since a number of qualitative measures in Dutch nursing care are not developed upon theoretical foundations nor provide available information regarding their (content) validity or usability for both clients and formal caregivers. ${ }^{10}$ Although existing inventories are a first step towards making information on existing measures more easily accessible, progress is ongoing for the development of online databases providing a wide and more up-to-date overview of existing measures for multiple care settings. ${ }^{11,12}$

\section{Dissemination of findings}

Throughout this project, various channels were used to disseminate the findings. This study was founded within the Brightlands Innovation Programme LIME (Limburg Measures), a programme that facilitates smarter measurement methods and more efficient data collection for better care and health. The programme strived in making connections between individual research projects and its outcomes with the needs of small business owners and governmental institutes such as municipalities and the Province of Limburg. The outcomes of individual studies were presented yearly in various settings, such as locally during the LIME symposia and internationally during the International Society of Quality of Life Research (ISOQOL) conference, the European Doctorate Conference of Nursing Sciences (EDCNS) conference to young academia, and an online Measuring Differently symposium with similar projects in both disability care and nursing home care. Local activities in participating home care organisations were organised, such as an online webinar during the Kennispreuvenement at Envida, where experiences with the developed experienced quality measure were shared with formal caregivers, managers, and policy officers. Although dissemination during additional symposia was planned, such as during the 2nd International Conference of the German Society of Nursing Science 2020 in Berlin, it was cancelled as a result of the COVID-19 pandemic.

All studies in this thesis were submitted to and/or published in international peerreview journals. Findings presented in this dissertation were integrated in existing education programmes. Lectures on care quality use the INDEXQUAL quality framework, and the developed experienced quality measure served as an example during interactive lectures for students in the health sciences bachelor's programme at Maastricht University. In addition, both bachelor's and master's students conducted literature reviews on factors related to experienced quality in long-term care and explored how the implementation of 
the developed measure could be facilitated in home care for writing theses on these subjects.

The studies in this dissertation were imbedded in the research line of the Living Lab in Ageing and Long-Term Care, which disseminated findings widely through its network. ${ }^{13}$ Additionally, individual care organisations shared items about both the project and the developed measure using their channels, such as an internal magazine distributed to employees, clients, and partners. A facts sheet and animation video was made to elaborate on the project and outcomes. Both a client council and a think tank of leading district nurses from the participating organisations were consulted during the individual studies. In addition, the outcomes of individual studies and research activities were presented to participating clients, informal caregivers, formal caregivers, and managers/policy officers during various group meetings throughout this dissertation. Various care organisations planned to continue in the further refinement and implementation of the developed measure within their home care teams. 


\section{REFERENCES}

1. Steckler A, McLeroy KR, Goodman RM, Bird ST, McCormick L. Toward integrating qualitative and quantitative methods: an introduction. In: Sage Publications Sage CA: Thousand Oaks, CA; 1992.

2. Zorginstituut Nederland. Wijkverpleging indicatoren: meetinstrumenten langdurige zorg. 2021; https://www.zorginzicht.nl/kwaliteitsinstrumenten/wijkverplegingindicatoren. Accessed 5th of January, 2021.

3. Damschroder LJ, Aron DC, Keith RE, Kirsh SR, Alexander JA, Lowery JC. Fostering implementation of health services research findings into practice: a consolidated framework for advancing implementation science. Implementation Science. 2009;4(1):50.

4. Rycroft-Malone J, Harvey G, Seers K, Kitson A, McCormack B, Titchen A. An exploration of the factors that influence the implementation of evidence into practice. J Clin Nurs. 2004;13(8):913-924.

5. LIME Limburg Meet. https://www.limeconnect.nl/en/about-lime/.

6. Sion K, Verbeek H, Aarts S, et al. The Validity of Connecting Conversations: A Narrative Method to Assess Experienced Quality of Care in Nursing Homes from the Resident's Perspective. International Journal of Environmental Research and Public Health. 2020;17(14):5100.

7. van Rooijen M, Lenzen S, Dalemans R, Moser A, Beurskens A. Implementation of a Patient Reported Experience Measure in a Dutch disability care organisation: a qualitative study. Journal of patient-reported outcomes. 2020;4(1):1-10.

8. van der Wees PJ, Verkerk EW, Verbiest ME, et al. Development of a framework with tools to support the selection and implementation of patient-reported outcome measures. Journal of patient-reported outcomes. 2019;3(1):1-10.

9. Osterwalder A, Pigneur Y, Bernarda G, Smith A. alue proposition design: How to create products and services customers want. Hoboken, New Jersey: John Wiley \& Sons.; 2014.

10. Triemstra M, Francke A. Kwaliteit van leven en zorg: Van meten naar verbeteren. In. Utrecht: Waardigheid en trots; 2017.

11. Movisie. Eerste hulp bij keuze meetinstrumenten sociaal domein: Aan de slag met de Instrumentenwijzer. 2016; https://www.movisie.nl/artikel/eerste-hulp-keuzemeetinstrumenten-sociaal-domein. Accessed 29th of June, 2021.

12. Zuyd University of Applied Sciences. Meetinstrumenten in de zorg: de vindplaats voor Nederlandstalige meetinstrumenten. 2020; https://meetinstrumentenzorg.nl/. Accessed 29th of June, 2021.

13. Verbeek H, Zwakhalen S, Schols J, Kempen G, Hamers J. The Living Lab in Ageing and Long-Term Care: A Sustainable Model for Translational Research Improving Quality of Life, Quality of Care and Quality of Work. The journal of nutrition, health \& aging. 2020;24(1):43-47. 


\section{Living Lab in Ageing and Long-Term Care}

This thesis is part of the Living Lab in Ageing and Long-Term Care, a formal and structural multidisciplinary network consisting of Maastricht University, nine long-term care organizations (MeanderGroep Zuid-Limburg, Sevagram, Envida, Cicero Zorggroep, Zuyderland, Vivantes, De Zorggroep, Land van Horne \& Proteion), Intermediate Vocational Training Institutes Gilde and VISTA college and Zuyd University of Applied Sciences, all located in the southern part of the Netherlands. In the Living Lab we aim to improve quality of care and life for older people and quality of work for staff employed in long-term care via a structural multidisciplinary collaboration between research, policy, education and practice. Practitioners (such as nurses, physicians, psychologists, physio- and occupational therapists), work together with managers, researchers, students, teachers and older people themselves to develop and test innovations in long-term care.

\section{ACADEMISCHE WERKPLAATS OUDERENZORG ZUID-LIMBURG}

Dit proefschrift is onderdeel van de Academische Werkplaats Ouderenzorg Limburg, een structureel, multidisciplinair samenwerkingsverband tussen de Universiteit Maastricht, negen zorgorganisaties (MeanderGroep Zuid-Limburg, Sevagram, Envida, Cicero Zorggroep, Zuyderland, Vivantes, De Zorggroep, Land van Horne \& Proteion), Gilde Zorgcollege, VISTA college en Zuyd Hogeschool. In de werkplaats draait het om het verbeteren van de kwaliteit van leven en zorg voor ouderen en de kwaliteit van werk voor iedereen die in de ouderenzorg werkt. Zorgverleners (zoals verpleegkundigen, verzorgenden, artsen, psychologen, fysio- en ergotherapeuten), beleidsmakers, onderzoekers, studenten en ouderen zelf wisselen kennis en ervaring uit. Daarnaast evalueren we vernieuwingen in de dagelijkse zorg. Praktijk, beleid, onderzoek en onderwijs gaan hierbij hand in hand.

\section{PHD-THESES LIVING LAB IN AGEING AND LONG-TERM CARE / PROEFSCHRIFTEN ACADEMISCHE WERKPLAATS OUDERENZORG LIMBURG}

Roy Haex. Take a look through my eyes: The development of an experienced quality measure with clients, informal, and formal caregivers in Dutch home care. 2021

Fabian Groven. The bed bath with or without water? It's a wash! Experiences with the washing without water intervention used for the bed bath. 2021

Sascha Bolt. The fundamentals of a DEDICATED palliative approach to care for people with dementia. 2021

Angela Mengelers. To risk or to restrain? Involuntary treatment use in people with dementia living at home. 2021

Katya Sion. Connecting Conversations. Experienced quality of care from the resident's perspective: a narrative method for nursing homes. 2021 
Linda Hoek. Change begins with choice. Supporting the autonomy of nursing home residents with dementia through partnership. 2020

Mirre den Ouden. Every step counts. Daily activities of nursing home residents and the role of nursing staff. 2018

Theresa Thoma-Lürken. Innovating long-term care for older people. Development and evaluation of a decision support app for formal caregivers in community-based dementia care. 2018

Eveline van Velthuijsen. Delirium in older hospitalised patients: diagnosis and management in daily practice. 2018

Bram de Boer. Living at a green care farm. An innovative alternative for regular care in nursing homes for people with dementia. 2017

Nienke Kuk. Moving forward in nursing home practice. Supporting nursing staff in implementing innovations. 2017

Irma Everink. Geriatric rehabilitation. Development, implementation and evaluation of an integrated care pathway for older patients with complex health problems. 2017

Ramona Backhaus. Thinking beyond numbers. Nursing staff and quality of care in nursing homes. 2017

Martin Van Leen. Prevention of pressure ulcers in nursing homes, a big challenge. 2017

Mariëlle Daamen-Van der Velden. Heart failure in nursing home residents. Prevalence, diagnosis and treatment. 2016

Armand Rondas. Prevalence and assessment of (infected) chronic wounds. 2016

Hanneke Beerens. Adding life to years. Quality of life of people with dementia receiving long-term care. 2016 (Cum Laude)

Donja Mijnarends. Sarcopenia: a rising geriatric giant. Health and economic outcomes of community-dwelling older adults with sarcopenia. 2016

Tanja Dorresteijn. A home-based program to manage concerns about falls. Feasibility, effects and costs of a cognitive behavioral approach in community-dwelling, frail older people. 2016

Basema Afram. From home towards the nursing home in dementia. Informal caregivers' perspectives on why admission happens and what they need. 2015

Noemi Van Nie-Visser. Malnutrition in nursing home residents in the Netherlands, Germany and Austria. Exploring and comparing influencing factors. 2014

Esther Meesterberends. Pressure ulcer care in the Netherlands versus Germany 0-1. What makes the difference? 2013

Math Gulpers. EXBELT: expelling belt restraints from psychogeriatric nursing homes. 2013

Hilde Verbeek. Redesigning dementia care. An evaluation of small-scale homelike care environments. 2011

Judith Meijers. Awareness of malnutrition in health care, the Dutch perspective. 2009

Ans Bouman. A home visiting program for older people with poor health. 2009

Monique Du Moulin. Urinary incontinence in primary care, diagnosis and interventions. 2008

Anna Huizing. Towards restraint free care for psychogeriatric nursing home residents. 2008

Pascalle Van Bilsen. Care for the elderly, an exploration of perceived needs, demands and service use. 2008

Rixt Zijlstra. Managing concerns about falls. Fear of falling and avoidance of activity in older people. 2007

Sandra Zwakhalen. Pain assessment in nursing home residents with dementia. 2007 


\section{Dankwoord}

$\mathrm{Na}$ vier bewogen en intensieve jaren is het dan zo ver en komt ook mijn proefschrift tot een einde. In een wereld die er voor mij, net zoals voor velen, heel anders uitziet dan enkele jaren geleden. Waarin onderzoek een belangrijk onderdeel speelde, maar nog zo veel andere uitdagingen op mijn pad voorbijkwamen. Gedurende deze reis zijn er velen die moeten worden bedankt voor hun bijdrage aan dit avontuur. Voordat het boek sluit, wil ik jullie bij deze alvast bedanken!

Ten eerste iedereen die vanuit de praktijk heeft bijgedragen aan het onderzoek. In het bijzonder alle deelnemende medewerkers van Envida, Zuyderland en MeanderGroep Zuid-Limburg. Welke vaak bovenop hun dagelijkse werkzaamheden tijd vrijmaakten om mee te doen met het onderzoek. Voor de inspirerende meeloopdagen in de thuiszorg, tot de vele ontroerende gesprekken met cliënten en naasten. Voor de motivatie die ik in veel ogen van zorgverleners heb gezien om kwaliteit anders te gaan meten, tot de tranen tijdens het bespreken van persoonlijke ervaringen in de zorg. Van Zuyderland wil ik Renee Henssen, Ellen Kusters en Ine Aussems bedanken voor hun deelname en gesprekken gedurende het project. Van Envida wil ik Lisette Ars en Mariska de Bont bedanken voor hun deskundige en enthousiaste bijdrage aan het project en het meedenken. In het bijzonder wil ik Margo van Haeringen bedanken voor haar inzet, ik hoop dat je de komende jaren veel inspiratie opdoet om de lekkerste baksels te maken van alle appels die Arnold mee naar huis neemt! Tot slot natuurlijk alle andere cliënten, naasten, zorg- en beleidsmedewerkers, zonder jullie kon deze studie niet plaatsvinden. Bedankt voor jullie tijd, openhartigheid en vertrouwen!

Mijn promotieteam, prof. dr. Sandra Beurskens, dr. Theresa Thoma-Lürken en natuurlijk prof. dr. Sandra Zwakhalen, wil ik bedanken voor de begeleiding in de aflopen jaren. Sandra B., jouw energieke manier van begeleiden heb ik als prettig en verfrissend ervaren tijdens de afgelopen jaren. Ondanks de beperkte tijd die je had voor de begeleiding van je promovendi na je vertrek bij Hogeschool Zuyd, was je altijd even goed bereikbaar en betrokken. Theresa, toen Sandra Z. vroeg wie er geschikt zou zijn als copromoter hadden we allebei jou voor ogen als geschikte kandidaat. Dit heb je zeker waargemaakt en ik heb de tijd in 'het veld' met jou als kwalitatief onderzoeker als heel prettig ervaren. Wat hebben we vaak gelachen, maar er was ook tijd voor een goed gesprek wanneer er persoonlijke dingen werden besproken met deelnemers. Ik wens je alle succes in je nieuwe functie bij Cicero. Sandra Z., ik heb je vanuit verschillende rollen mee mogen maken binnen het project als dagelijks begeleider en co-promoter vanuit je eerdere UHD functie, naar promoter als professor zijnde en later weer als dagelijks begeleider toen Theresa met zwangerschapsverlof was. Ik heb respect hoe je je verschillende taken vanuit je leerstoel combineert met de begeleiding van je verschillende 
promovendi. Dat je toekomstig werk nog moge bijdragen aan de inspiratie van vele andere (toekomstige) wetenschappers en een verdere verbetering van de langdurige zorg in Nederland en daarbuiten. Verder wil ik ook prof. dr. Jan Hamers bedanken voor zijn begeleiding in het eerste jaar van de promotie waarin het INDEXQUAL model tot stand is gekomen.

Natuurlijk wil ik ook de leden van de beoordelingscommissie van dit proefschrift bedanken voor zowel het lezen als het beoordelen ervan: prof. dr. Silvia Evers, prof. dr. Katrien Luijkx, dr. Erik van Rossum en dr. Nienke Bleijenberg, onder voorzitterschap van prof. dr. Trudy van der Weijden. De corona bedank ik voor hun aanwezigheid en het lezen van mijn proefschrift.

Beste collega's van de vakgroep Health Services Research, bedankt voor jullie belangstelling in mijn onderzoek, de leuke en constructieve gesprekken tijdens verschillende bijeenkomsten. De sfeer tijdens de lunchpauzes was een goede reden om naar kantoor te komen en te ontladen van alle frustraties. Vanaf het begin heb ik geluk gehad om in kamer 0.050 terecht te komen. Wat was dat een geweldige kamer! Angela, wat hebben wij vaak gelachen (en wij hebben als Jut en Jul hopelijk ook anderen een beetje kunnen laten lachen). Voor mij was je een rots in de branding in Maastricht en samen hebben we elkaar er toch mooi doorheen gesleept. Ik weet zeker dat we elkaar blijven spreken, maar ik wil je toch het allerbeste wensen samen met Jack en met je werk aan de Open Universiteit. Katya, jammer dat we 'maar' een klein jaar intensief samen hebben mogen werken. Ik heb je als een super integer en kundig persoon ervaren, iemand die echt voor een verdere academische carrière is gemaakt. Ik weet zeker dat je voor een hele prettige en frisse wind gaat zorgen op de afdeling. Ruth, wat ben jij een doorzetter zeg. Twee jaar lang non-stop schrijven, ik doe het je niet na, chapeau! Verder wil ik het zonnetje in huis Luca bedanken voor de leuke gesprekken. I would like to wish Irina all the best of luck with her new position in the UK. Natuurlijk de geweldige humor en natuurlijk de wort-das-tages oefeningen van Lena. Tot slot Mirre niet te vergeten, die ons in het begin ontzettend heeft geholpen en op de hoogte bracht van alle gebruiken van zowel de afdeling als kamer 0.050. Tot slot wil ik nog Anne, Svenja, Erica, Rachelle, Marlot, Bram, Ramona, Annick en Ines bedanken als de echte stemmingsmakers tijdens de lunch en op de afdeling, keep up the spirit!

Verder wil ik ook (deels vanuit Zuyd Hogeschool) dr. Albine Moser, dr. Anita Stevens, dr. Ruth Dalemans en dr. Anneke van Dijk bedanken voor het meedenken en coachen bij al mijn vragen rondom kwalitatief onderzoek en expertise vanuit LIME met alles rondom co-creatie. Vanuit Hogeschool Utrecht wil ik Jessica Veldhuizen bedanken voor haar interesse in het project en onze gesprekken die we vanaf het begin hebben gehad over de raakvlakken tussen onze projecten. 
Mijn dank gaat ook uit naar Limburg Meet (LIME), CAPHRI Care and Public Health Research Institute, Hogeschool Zuyd, de Provincie Limburg, Brightlands en Zuyd Hogeschool voor zowel het financieren van deze studie, maar ook de totstandkoming van inspirerende bijeenkomsten en workshops.

Uiteraard wil ik mijn ouders en mijn broer Wesley bedanken voor hun steun. Mam, bedankt voor het meedenken vanuit je ervaring in de thuiszorg. Ik ben blij voor je dat je nieuwe werk bij Zuyderland je nu zoveel beter bevalt. Pap, bedankt voor hulp bij het opzetten van mijn onderneming en de goede gesprekken samen met opa. Opa, ik ben blij dat ik zowel jou als oma een plek heb kunnen geven op de kaft van mijn proefschrift. Ook al kan oma dit moment dan niet meer onder ons meemaken, ik weet zeker dat ze trots zou zijn net zoals ze trots was op al haar klein- en achterkleinkinderen. Wesley en Judith, bedankt voor de gezellige spellen avonden. Gelukkig hebben jullie samen een eigen huis gevonden en ik weet zeker dat jullie van je nieuwe huis een gezellig thuis gaan maken. Voor alle vragen rondom (duurzaam) verbouwen weten jullie me te vinden ;)

Mijn schoonouders wil ik bedanken voor de goede gesprekken, hulp bij de verbouwingen en natuurlijk alle opvang van Lucas en Merijn. Zonder jullie hulp was het niet gelukt om alles thuis draaiende te houden tijdens de afgelopen drukke jaren. Natuurlijk wil ik ook Lotte en Damiano bedanken voor de gezelligheid en BBQs in de afgelopen jaren. Verder wil ik Britt en JP nog bedanken voor de keren dat we bij jullie hebben gegeten terwijl we thuis nog volop aan het verbouwen waren. Dat heeft het combineren van verbouwen, hebben van jonge kinderen en onderzoek doen toch net even iets prettiger gemaakt! Verder wil ik ook de geweldige buurtjes in Elsloo bedanken voor hun interesse en het creëren van een super omgeving om zowel te wonen en te werken. In het bijzonder wil ik René en Marina bedanken voor al hun tips over de tuin en de kippen, Mariëlle en Roger voor hun eerste hulp wanneer Lucas weer eens gevallen was, Debbie en Dion voor de leuke spellenavonden en wil ik Robert en Sonja veel sterkte wensen samen. Samen sta je sterk en een hechte woonomgeving maakt het leven zo veel prettiger of net even iets dragelijker tijdens moeilijke tijden.

Tot slot wil me richten tot het thuisfront met Brenda, Lucas en Merijn als belangrijkste reden om te kunnen relativeren tot wat er echt toe doet. Brenda, wat fijn dat ik met jou al bijna 17 jaar mijn lief en leed mag delen. Naast je werk als universitair docent aan de Universiteit Maastricht wist je toch altijd tijd vrij te maken om mijn frustraties aan te horen of stukken door te lezen. Maar vooral het vertrouwen uit te spreken om na mijn promotie een pad te kiezen waar mijn hart ligt. Ik weet zeker dat je met jouw passie en inzet voor de bewegingswetenschappen een mooie wetenschappelijke carrière in het verschiet hebt liggen. Lucas, ik ben ontzettend trots hoe jij de afgelopen jaren bent gegroeid op school. Ik weet zeker dat je de beste Lego-bouwer van Elsloo bent met al je fantastische bouwwerken. Jij bent een super lieve grote broer en hebt altijd 
goede ideeën voor papa om nieuwe dingen te bouwen van hout, maar vooral ook te testen met je kleine broertje. En tot slot Merijn, het mooiste wat tijdens mijn promotie is ontstaan. Je hebt al zo veel grote stappen gezet de afgelopen tijd waar ik, dankzij het vele thuiswerken, erg van heb kunnen genieten. Met jou is thuiswerken elke dag weer een (soms iets te gezellig) feestje. Bedankt! 


\section{About the author}

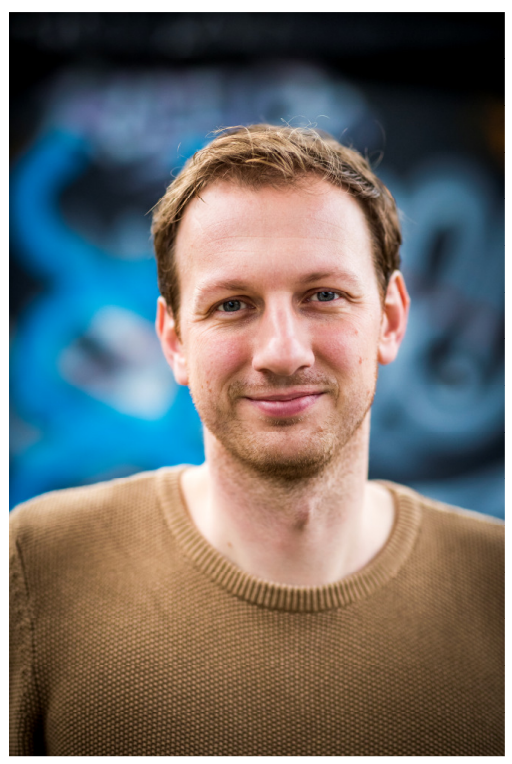

Roy Haex was born in Geleen, January 3th in 1987. He grew up in Geleen and attended secondary school at Graaf Huyn College where he graduated in 2004 (HAVO) and 2006 (VWO). From 2006 till 2007 he studied Architecture at Hogeschool Zuyd. From 2007 till 2011 he studied Psychology at Maastricht University where he obtained his Master of Science in Work and Organisational Psychology.

After graduating, Roy worked from 2011 at the Technical University of Eindhoven in the field of User-System Interaction. Here he obtained his Professional Doctorate in Engineering from the Stan Ackermans Institute for his work at Philips Research into fundamental lighting research.

From 2014 till 2016 Roy worked as a usability researcher and project leader for European projects and local care organisations. Here he co-developed domotica solutions and designed interfaces to enable patients and elderly home care clients to communicate online with caregivers such as general practitioners. In May 2017 he started his PhD trajectory at Maastricht University focused on the development of an experienced quality measurement from a client's perspective in the home care setting. His research has led to several scientific publications in international peer-reviewed journals and presentations at both national and international conferences.

Roy currently lives in Elsloo with his family where he just started his own company to support customers in developing sustainable projects for their home environment. His goal is to build bridges between the academic field, industrial engineering and traditional craftsmanship in moving towards a more smart, healthy and sustainable environment to both work and live in. In his spare time, Roy passionately restores architectural antiquities and designs custom made furniture. 